\title{
Abandoned chip: Investigating abandonment of commercial wearables
}

\author{
by
}

\author{
Simon Eden-Walker
}

A thesis submitted to the Faculty of Graduate and Postdoctoral Affairs in partial fulfillment of the requirements for the degree of

Master of Information Technology: Digital Media

School of Information Technology

Carleton University

Ottawa, Ontario

(C) 2020, Simon Eden-Walker 


\begin{abstract}
Abandonment of wearable fitness trackers continues to be an ongoing issue. Literature has compiled many reasons; however, the roles of data literacy and data visualization literacy have been underexplored. Two qualitative studies, an online survey and in depth semi-structured interviews investigated whether insufficient data interpretation is a barrier to sustained tracker use. Results found that users may overestimate their literacy levels potentially leading them to misinterpret health data, and better support from designers and professionals is warranted. In particular, mandatory tutorials and assessments unlocking data are explored. Interaction with smart shorts, smart insoles, and accompanying data provided insight on who might adopt newer wearables, who could benefit, and how to design a better onboarding user experience. Recommendations for better use of wearable technology to address physical inactivity and obesity, as well as suggestions to support literacies are presented that the HCI community can use to move the field forward.
\end{abstract}




\section{Acknowledgements}

As the adage goes 'It takes a village to raise a child' and I could not have completed this thesis without the support from so many people. Thank you to my supervisor, Audrey Girouard, who had the patience to see me through and provided the knowledge and feedback to guide my writing. Thank you to Ali Arya and the fortuitous meeting at Sunnyside Library where his presentation introduced me to the program and convinced me to apply. Thank you to the survey respondents and interviewees in this thesis who enabled me to learn from their experiences and stimulate my thinking. Thank you to my family, Mom, Nick, Fiona, and Alexandra for encouraging me to hone my skills and challenge myself to achieve more. To my lab mates in the Creative Interactions Lab who provided countless insights on how to proceed, step by step, through this journey. A special thank you to my girlfriend, Gitashu Jain, who listened patiently to my fountain of thoughts and helped channel them when I struggled to make sense. An especial thank you to my late father who was the inspiration for this thesis, Dr. Michael Eden-Walker. You helped me and showed me the door to my future. I only wish you had been here to see me walk through.

Terar Dum Prosim 


\section{Table of Contents}

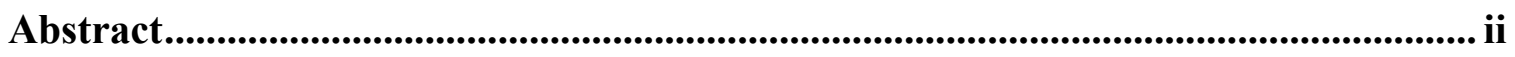

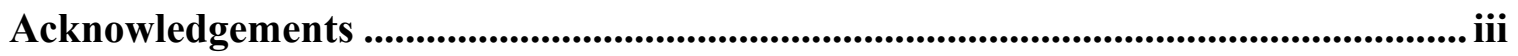

Table of Contents ....................................................................................................................... iv

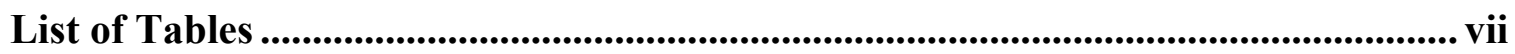

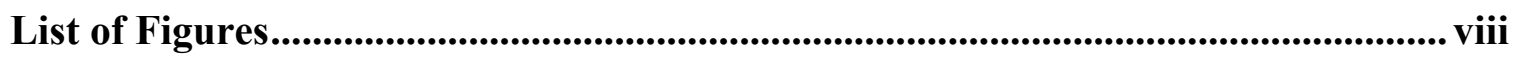

List of Appendices ......................................................................................................... $\mathrm{x}$

List of Abbreviations ............................................................................................................ xi

Chapter 1: Introduction ........................................................................................................ 1

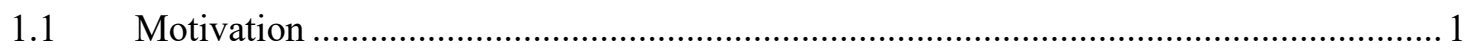

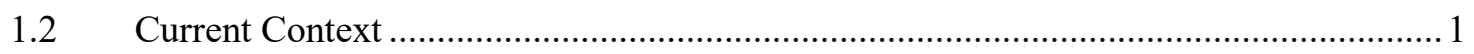

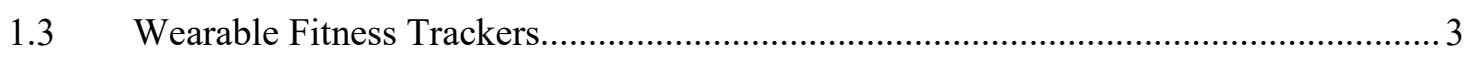

$1.4 \quad$ Tracking: We Have a Problem ............................................................................ 4

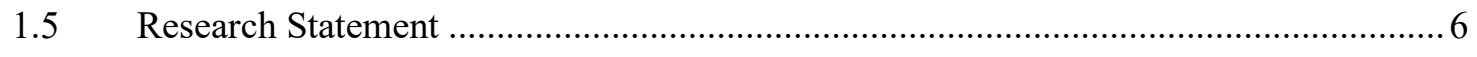

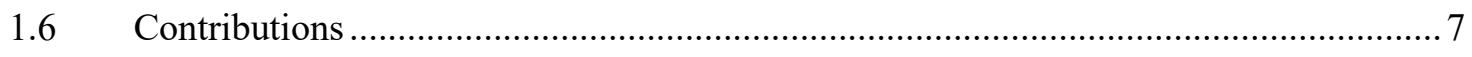

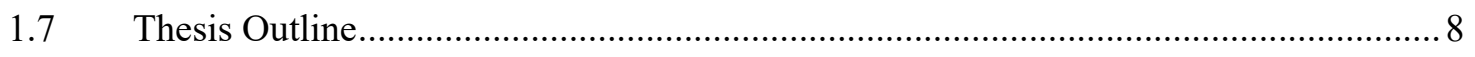

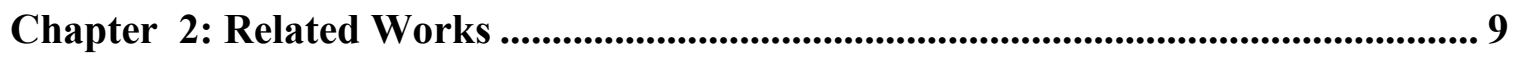

2.1 Adoption of Wearable Fitness Trackers: ............................................................. 9

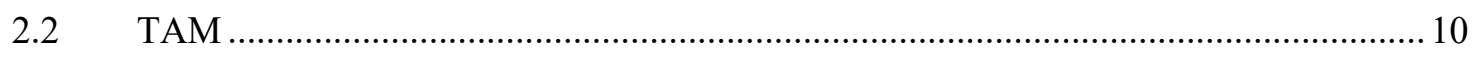

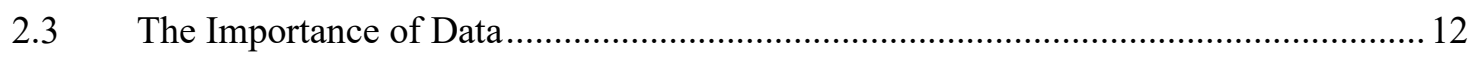

2.4 Quantified Self and Personal Informatics.......................................................... 17

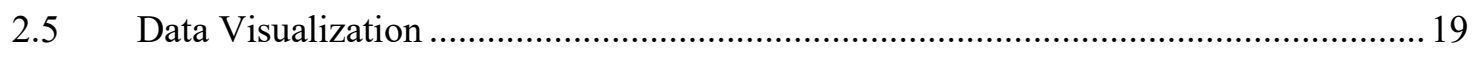

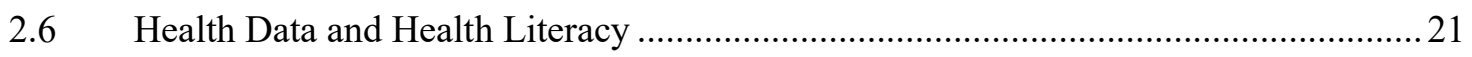




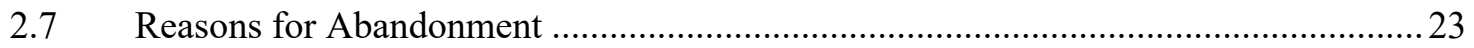

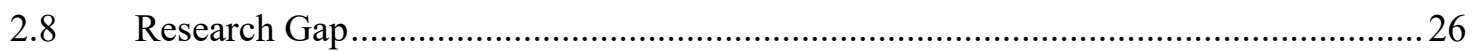

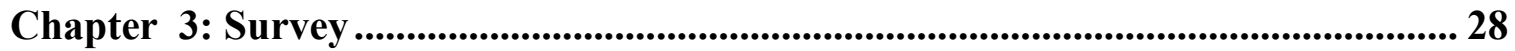

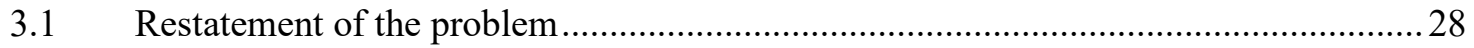

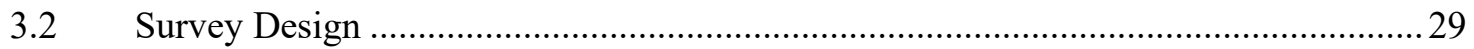

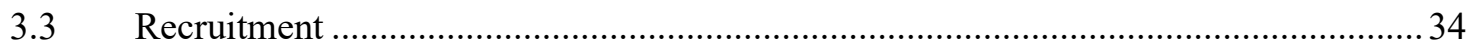

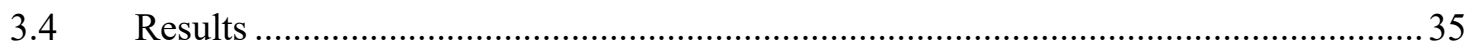

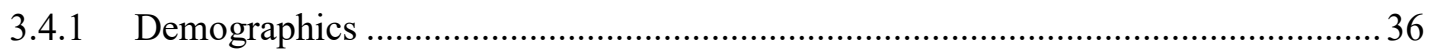

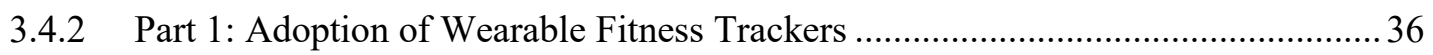

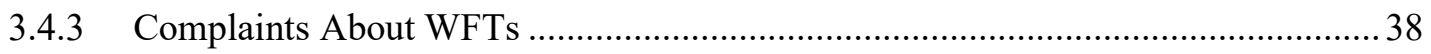

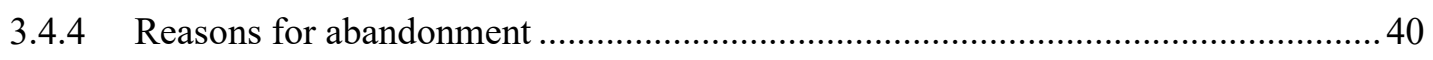

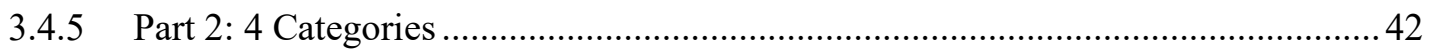

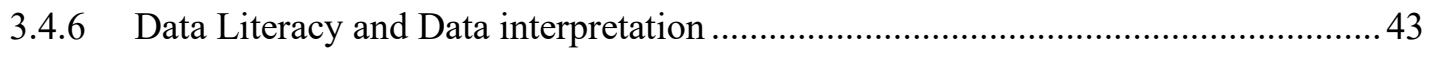

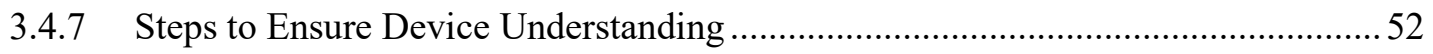

3.4.8 Tracking for increasing bodily awareness ......................................................... 54

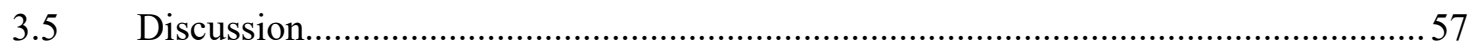

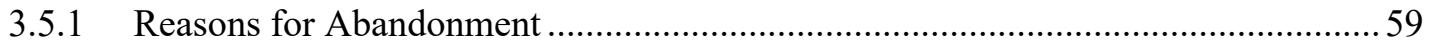

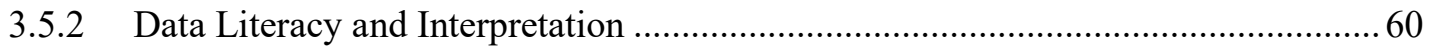

Chapter 4: Study 2: Semi-Structured Interviews ...................................................6 65

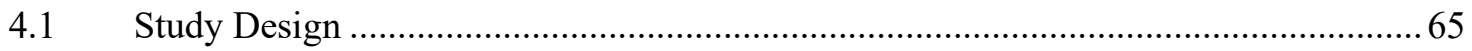

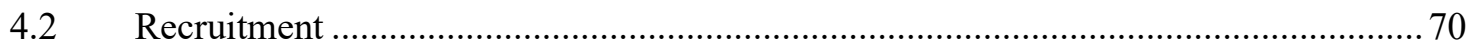

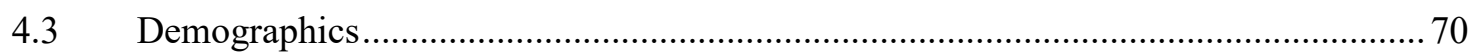

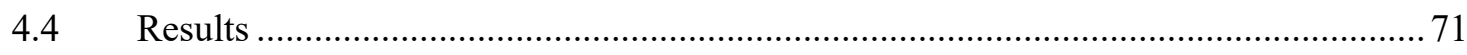

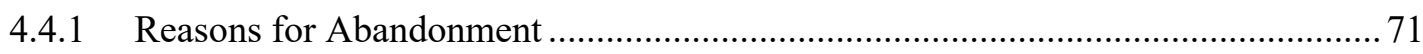

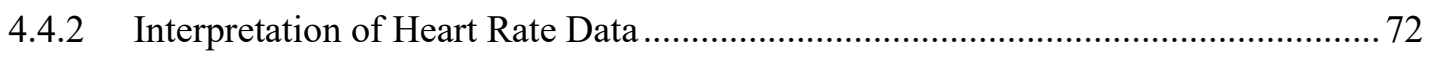

4.4.3 Interpretation of Visualizations Generated by Other Fitness Trackers ................... 73 


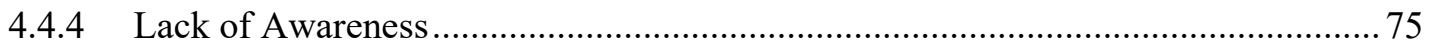

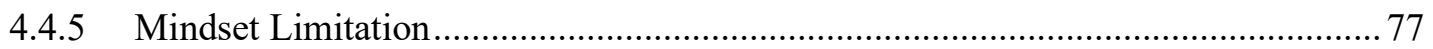

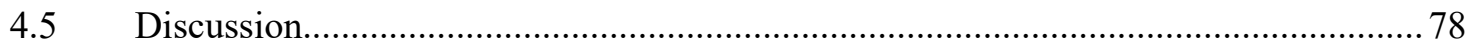

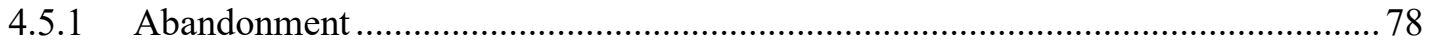

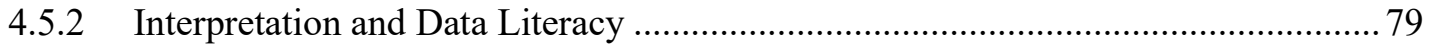

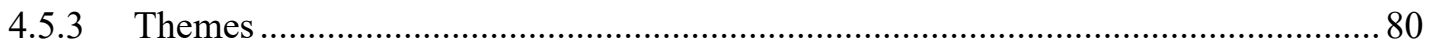

Chapter 5: Discussion .............................................................................................................. 82

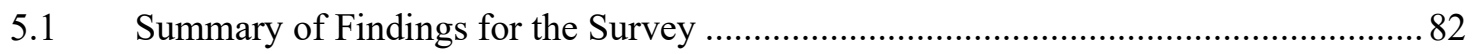

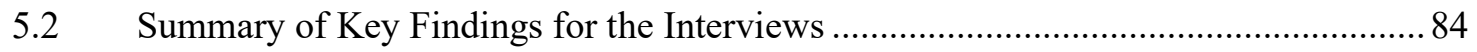

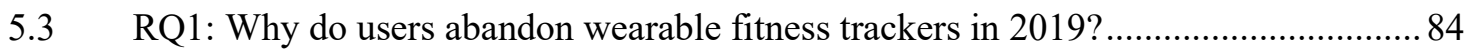

5.4 RQ2: Do people have trouble interpreting the data generated by their wearable fitness

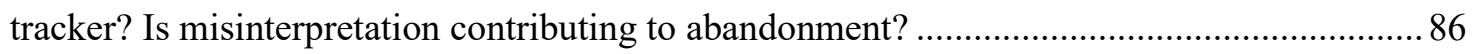

5.5 RQ3: Are there any identifying features about former users that is different from

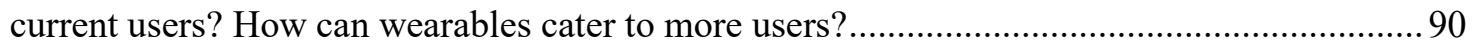

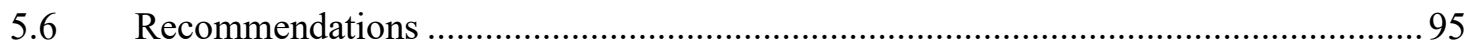

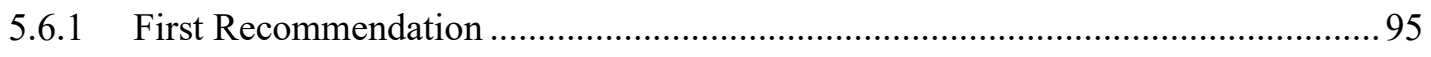

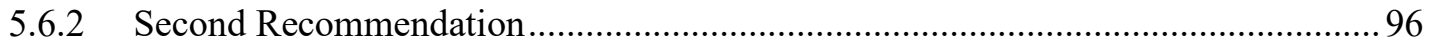

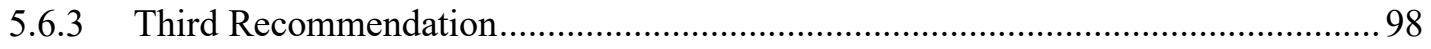

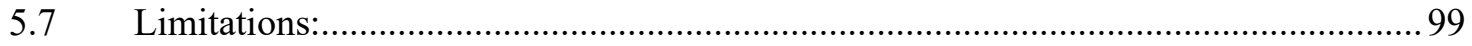

Chapter 6: Conclusion ....................................................................................................... 102

Bibliography ................................................................................................................. 104

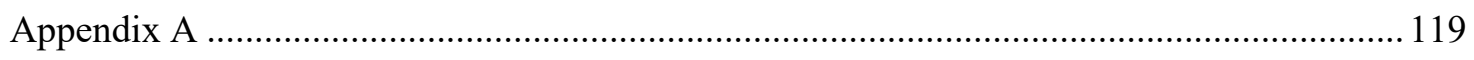

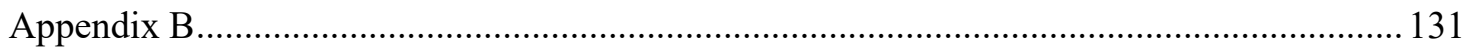




\section{List of Tables}

Table 1. List of questions asked during the survey ........................................................ 31

Table 2. Maher et al. showing primary motivation for adopting a tracker ....................... 37

Table 3. Eden-Walker - All motivations for adopting a wearable..................................... 37

Table 4. Comparison of complaints with Eden-Walker and Maher et al. with raw numbers

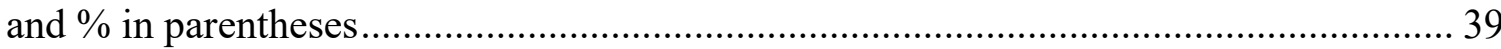

Table 5. Comparison of reasons for abandonment between the two studies. Respondents

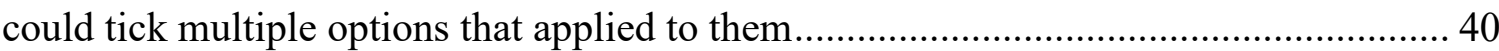

Table 6. Number of respondents broken down by fitness level........................................ 43

Table 7. If you had trouble understanding or interpreting data, what did you have trouble

with?

Table 8 Categories of responses to the heart rate graph …………................................ 49

Table 9. LFFUs interpretation of the heart rate graph (\% in parentheses) …................... 49

Table 10. HFFUs interpretation of heart rate graph (\% in parentheses) .......................... 49

Table 11. LFCUs interpretation of heart rate graph (\% in parentheses) ........................... 50

Table 12. HFCUs interpretation of heart rate graph (\% in parentheses) ......................... 50

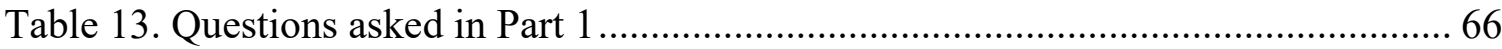

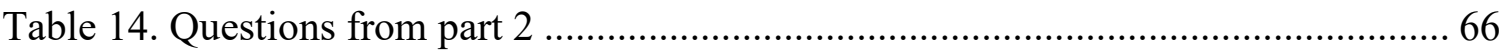


List of FiguresFigure 1. Apple Watch (Left) and Fitbit (right) .................................. 4

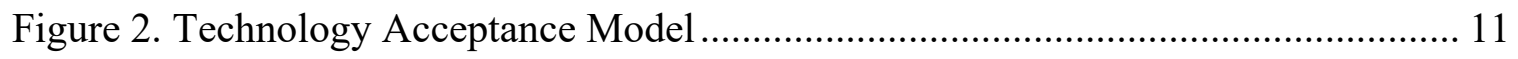

Figure 3. Smart insole that generates data using embedded sensors. ............................ 13

Figure 4. VO2 Max metric displayed on a Garmin wearable indicating fitness level...... 15

Figure 5. Motus wearable sleeve and data visualization......................................... 16

Figure 6. Ambiguous visualization suggesting the same visualization could lead to two

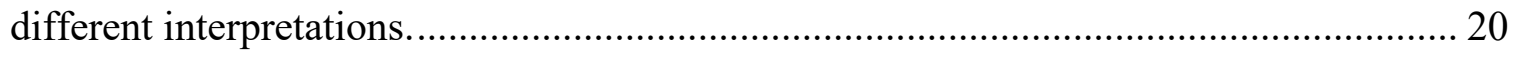

Figure 7. Illustration of how people may focus their attention on different aspects of the graph and draw 2 completely different conclusions (Xiong, 2019)............................. 20

Figure 8. Illustrates overlap of various literacies and their interconnectedness (Bhargava

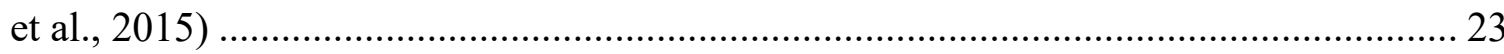

Figure 9. Table from Attig et al. outlining reasons why users abandon trackers. ........... 25

Figure 10. Heart Rate data for a man while he is sleeping. His Apple Watch woke him up after reading 121, which is dangerous for resting heart rate ...................................... 34

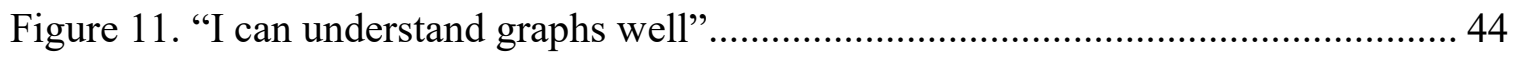

Figure 12. "I can plan a course of action based on the results" ................................. 45

Figure 13. "I have had trouble interpreting the data generated by a fitness tracker"....... 46

Figure 14. " I have had trouble deciding what to do with the data generated" ................ 46

Figure 15. "I find the following measure on my wearable helpful...heart rate." ............ 48

Figure 16. Before using the WFT did you read the manual? ..................................... 52

Figure 17. Before using the WFT did someone show you how to use it? ...................... 53

Figure 18. Before using the WFT did you watch a tutorial? ....................................... 54 
Figure 19. My experience with my wearable made me feel more knowledgeable about my body....... 55

Figure 20. "My experience with the wearable made me feel more aware of my form while I perform movements." 56

Figure 21. Since using my wearable, I now spend more time learning about my body... 57 Figure 22. Stridalyzer smart insoles and app interface with heat map on the right ......... 68 Figure 23. Data visualization of feedback from Stridalyzer insole 68 Figure 24. Athos smart shorts and app interface showing a heat map of muscles being used. Yellow indicates less effort, while orange equals more intense effort. 69 


\section{List of Appendices}

Appendix A - Ethics Forms............................................ 119

Appendix B - Online Survey ....................................... 131 


\section{List of Abbreviations}

Quantified Self $=$ QS

Personal Informatics $=$ PI

Human Computer Interaction $=\mathrm{HCI}$

High Fitness Current User $=$ HFCU

Low Fitness Current User $=$ LFCU

High Fitness Former User $=$ HFFU

Low Fitness Former User $=$ LFFU 


\section{Chapter 1: Introduction}

\subsection{Motivation}

The motivation for this thesis is two-fold. One, it is our belief that wearable fitness trackers present an opportunity to address the health and obesity crisis in Canada and throughout the world, and abandonment may waste this opportunity. Two, wearable fitness trackers like the Apple Watch, may contribute to saving lives of those who suffer medical conditions like cardiac arrest, so abandonment presents another barrier to health. By researching abandonment in the fields of Human Computer Interaction and Digital Media, we can learn to design a better user experience and usability of devices to support health and well-being.

\subsection{Current Context}

According to Statistics Canada, 61\% of Canadians are overweight or obese (Vogel, 2017) and this rate doubled between 1978 and 2014 due in large part to diet and a lack of exercise (Young, 2018). While the relationships between food, exercise, weight, and fitness are complex, recent research suggests a positive relationship between physical activity and healthier food choices which cyclically foster increased physical activity (Lounassalo et al., 2019). Furthermore, weight alone does not imply fitness and health. The key piece missing from health is sufficient physical activity.

Research shows that physical activity is crucial for healthy development of the human body, including healthier brain development (Raichlen \& Alexander, 2020; Wittfeld et al., 2020). Additionally, physical activity "not only reduces early deaths but 
decreases the risk of 35 chronic health conditions and ...there is 'conclusive and overwhelming' scientific evidence that physical inactivity is the primary cause" (Getamoveon, 2019). Physical activity is therefore essential, yet in a pooled analysis of school-aged children from 146 countries, 81\% were not sufficiently active (Guthold, Stevens, Riley, \& Bull, 2019). In fact, Americans received a D- for overall physical activity for youth from one of their not-for-profits, National Physical Activity Plan (Pancrazi, Corbin, \& Welk, 2018). For adults, the reports are equally grim with Canadian adults receiving a D for overall physical activity and an F for Moderate to Vigourous Physical Activity (ParticipACTION, 2018) which is activity that elevates heart rate. The American Heart Association recommends adults get 150 minutes per week of MVPA to ensure health (Foundation, 2018), yet neither Canadians nor Americans, youth or adults are sufficiently achieving this goal.

The consequences of living such an unhealthy lifestyle not only affects individuals but is costing all citizens. In 2018 , Canadians spent $\$ 253.5$ billion, or $\$ 6,839$ per person on health care ("Health Spending," 2018). Much of this money is spent on preventable diseases, as the UK also notes in their struggles to rein in health care spending (Getamoveon, 2019).

How is this an issue for Human Computer Interaction and Digital Media? Increasingly technology use is being linked with increased sedentary behavior (Rosen et al., 2014) and video game, use as well as computers and iPhones, are targets for blame. Yet, technology can also be part of the solution. One current example that is being leveraged to help address the crisis are known as Wearable Activity Trackers, or Wearable Fitness trackers (WFTs) which help individuals monitor and improve their health through 
feedback in the form of data. For many people they are a successful way of raising awareness around health and performance (Choe, Lee, Lee, Pratt, \& Kientz, 2014). The problem, which is the crux of this thesis, is that while these trackers are becoming more popular to acquire, they have high abandonment rates as Endeavor Partners first found in their oft-cited white paper in 2014 (Ledger \& Partners, 2014). Since then, researchers have verified that abandonment can be as swift, with $50 \%$ abandonment within 2 weeks in one study, and 34\% at 9 weeks in a second study (H. Lee \& Lee, 2017).

In this thesis I will explore the reasons why this is happening and why abandonment is a problem, and opportunity worth caring about.

\subsection{Wearable Fitness Trackers}

First of all, we need to understand what we mean by a WFT and what benefits users get from using them. Fitbit and Apple Watches are two common devices that are worn on the wrist and give users data to help them keep track of their workouts, as well as sleep, and heart rate and other metrics (See Figure 1). These WFT's are electronic devices that are equipped with sensors to provide users with feedback on basic metrics like calories burned, steps taken, and total distance. 

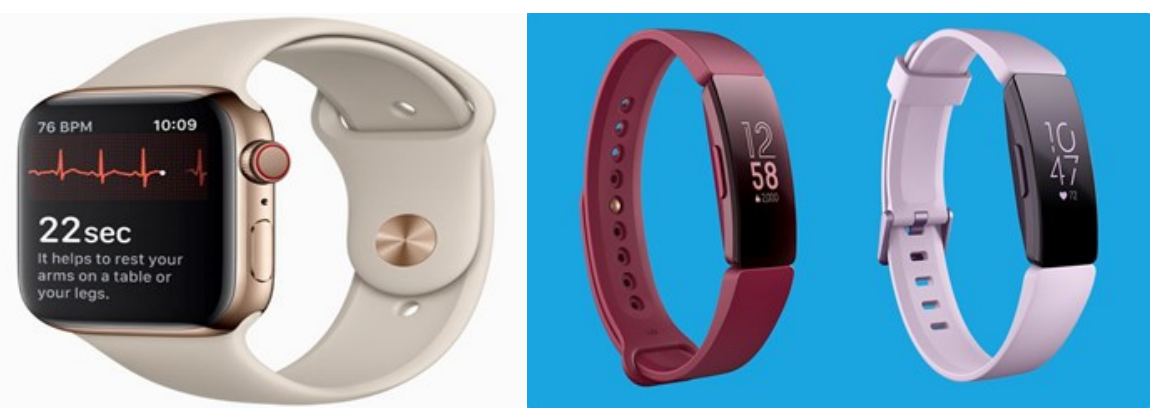

Figure 1. Apple Watch (Left) and Fitbit (right) ${ }^{1}$

In the past, the medical profession was the gatekeeper to health information, yet users of devices such as trackers are being empowered to look at their own data, often in real time (Maher, Ryan, Ambrosi, \& Edney, 2017). This desire for health data, that was not so easily available until recently, is fueling a growing \$26 billion USD industry (Lamkin, 2018). Additionally, a worldwide survey of fitness trends for 2020 has wearable technology listed as number one (Thompson, 2019). Researchers are likewise interested in studying trackers as the number of studies published per year on them increased from 8 in 2013 to 199 in 2017 (Shin et al., 2019). Wearables are emerging as a viable solution to sedentary behavior.

\subsection{Tracking: We Have a Problem}

The user experience (UX) of wearable fitness trackers continues to be both positive and negative. While there are positive reports such as the of ease of use in self-monitoring activity levels (Attig \& Franke, 2020; Ridgers et al., 2018), there still exists negative reports such as poor battery life and issues syncing devices (Michaelis et al., 2016). While sales continue to increase as awareness around fitness tracking increases, so does

\footnotetext{
${ }^{1}$ https://www.forbes.com/sites/davidphelan/2020/03/14/apple-watch-series-6-everything-we-know-so-far/\#794a6de32281
} 
abandonment as research suggests a third of users of wearable fitness trackers abandoned them within six months (Ledger \& Partners, 2014). For some researchers, the abandonment rate is much sooner and higher. For Lazar et al. almost $80 \%$ of participants abandoned their device within the first 2 months (Lazar, Tanenbaum, Koehler, \& Nguyen, 2015) citing, amongst other reasons, the data collected was not useful or required too much work. Maher et al. surveyed over 200 users and former users and found people complained the trackers were uncomfortable, or the battery life was too low (Maher et al., 2017). However, newer and updated devices continue to address the technical limitations, yet other UX issues continue, such as devices that continue to be uncomfortable (Michaelis et al., 2016). We wanted to verify if the complaints and issues users face are the same in 2019 , and if there are new ones. So, we decided to conduct a similar survey study to Maher et al. and generate a dataset for 2019 which informed our first research question: Why do users abandon wearable fitness trackers in 2019 ?

As we continued to delve into the reasons people abandoned, one reason did not stand out at first, but became noticeable as more and more studies revealed similar problems. Lazar et al. found that some participants reported not knowing what to do with the data, and how to analyze the data (Lazar et al., 2015). Yang et al. conducted semistructured interviews and found that some users wanted more detailed and clearer explanations about what the data meant (Yang, Shin, Newman, \& Ackerman, 2016). Maher also found that $8.1 \%$ of former users reported having problems interpreting the data (Maher et al., 2017). Additionally, researchers are finding that some people struggle to understand simple bar charts and data visualizations (Bertini, 2016; Kehaulani Goo, 2015). Are users 
of WFTs struggling to make sense of and understand their data? Thus, our second research question is: do users struggle to understand data and what kind of data? Is this 'illiteracy' contributing to abandonment?

Lastly, current research only reports on abandonment rates, and not on who are the users that are abandoning. The third research question therefore is to investigate if there are any features about former users that are distinguishable from current users so that we can understand further why users abandon.

\subsection{Research Statement}

The goal of this research is to gain further insight into why users abandon wearable fitness trackers and what role understanding the data plays in this abandonment. Also, are lesser physically literate users more likely than physically literate users to abandon? From these insights better design criteria may be outlined to help improve retention rates as well as inform future iterations of more advanced wearable technologies, such as smart garments, glasses, earphones, necklaces and other gear.

We focus on the following research questions:

1. Why do users abandon wearable fitness trackers in 2019 ?

2. Do people have trouble interpreting the data generated by their wearable fitness tracker? Is misinterpretation contributing to abandonment?

3. Are there any identifying features about former users that is different from current users? How can wearables cater to more users? 
To answer these research questions, we designed two studies to further investigate from a qualitative and quantitative point of view. First, we built on a previous survey on the reasons why people reported abandoning their wearable fitness tracker. We wanted to compare 2019 data with the data generated in 2016 to see if the same issues are affecting and/or if new issues are presenting themselves. In particular, we wanted to delve deeper into whether understanding the data generated has an impact on user experience. Secondly, we investigated abandonment more deeply by conducting semi-structured interviews with former users and asked them to explain their reasoning as well as show them other examples of emerging technology to see if they would provoke interest and seek their opinions on user experience and user interface.

\subsection{Contributions}

This thesis contributes an analysis of international current users and former users of wearable fitness trackers. The analysis and recommendations from the surveys and interviews contributes to the field of Human Computer Interaction by building on the evidence of abandonment and user experience principles to support better devices that help a greater number of people.

This analysis adds a layer of previously understudied research into data interpretation and data literacy with wearable technology. Our contribution that users may need data literacy and data visualization literacy is novel. That companies may need to design a better onboarding process scaffolding literacy is also novel. We also confirm that users, and especially former users, continue to complain that trackers are uncomfortable, and the straps are not durable. Lastly, the discussion and recommendations provide 
solutions to ongoing problems in HCI, as well as offering ideas to industry, and especially the educational realm.

\subsection{Thesis Outline}

In chapter 2, we establish theory and perspective of HCI, in particular, Technology Acceptance Model (TAM) and review research into wearable fitness adoption, in particular the Quantified Self movement. We then outline the reasons for abandonment and, investigate complaints of experiencing trouble with making sense of data, or 'data literacy' and how it factors into ease of use and usability of trackers. We also provide an analysis of the study by Maher et al. that formed the basis for our study.

In chapter 3, we report on the online survey of 233 current and former users and present findings on the role of data literacy and other findings surrounding the current situation with trackers. In chapter 4 , we use some of the results from chapter 3 to inform study 2 which is in-depth interviews with 16 former users, and report on their experiences with a fitness tracker. Specifically, we investigate the issue of interpreting data and provide them with opportunities to engage with data generated with different wearable technology in the form of a pair of smart shorts and a smart insole.

In chapter 5 we combine insights gained from the two studies and discuss how to reduce abandonment and improve the user experience based on the findings and look at possible implications of the research as well as limitations. In Chapter 6 we identify future work on wearable technology abandonment. We also provide ideas on how the wearable industry may improve in their future designs and how users of all kinds may better be served. 


\section{Chapter 2: Related Works}

Before we investigate why users abandon their fitness trackers, we first need to see why users adopt them in the first place. Wearable Fitness Trackers are electronic devices that are equipped with sensors to provide users with feedback on basic metrics. Their core features include the ability to track steps taken, distance covered, calories burned, and heart rate. Newer models include the ability to track oxygen in the blood as well as VO2 maximum (Stables, 2020). Using the Technology Acceptance Model and adapted models (Wolf, Menzel, \& Rennhak, 2018), we will look at the reasons for why people decide to adopt a tracker, including the Quantified Self movement and Personal Informatics, which are ways users of trackers are using the data to improve their self-awareness (Choe, Lee, Zhu, \& Riche, 2017; Rapp \& Tirassa, 2017). We then look at the reasons why users report abandoning their trackers and look at the complaints they report. We specifically investigate how they use and (mis) understand the data generated. This leads into a look at how literacies play a role in being able to make sense of data, in particular, data literacy and visualization literacy and what it means to be literate. This will provide context for the purpose of the study.

\subsection{Adoption of Wearable Fitness Trackers:}

One of the first reasons to adopt a tracker can be traced to pedometers that count the steps one takes. Worn on the hip, this device began to become popular in the 1960s through a Japanese physician's attempt to ward off growing obesity in his country (TudorLocke, Hatano, Pangrazi, \& Kang, 2008). Doctors and researchers continue to recommend exercise and are now prescribing it for all kinds of ailments, including obesity and 
diabetes(Chan, Ryan, \& Tudor-Locke, 2004; Roan, 2019). In this case, adopters are patients being prescribed exercise and measured through a wearable. While pedometers are still used, step counting is now a component of modern WFTs, such as the Apple Watch via accelerometers and are worn on the wrist like most trackers today.

On the other hand, Piwek et al. note that wearables are more likely to be bought by individuals who already lead a healthy lifestyle but are looking to track their progress (Piwek, Ellis, Andrews, \& Joinson, 2016). Additionally, Lee and Lee found that being interested in innovative technological products indicated intention to adopt (S. Y. Lee \& Lee, 2018). This suggests that even those who are not exactly health conscious can choose to adopt if the technology is sufficiently interesting to them. In fact, style and staying up to date with technology is another driving factor in adopting a wearable (Chatterjee \& Gupta, 2018). Thus, tech savvy, the health conscious, and medical patients are more likely to adopt. These findings are further supported from a theoretical point of view called the Technology Acceptance Model (TAM).

\subsection{TAM}

From a theoretical point of view the Technology Acceptance Model (TAM) is a common place to start when looking at theories to explain why users adopt wearable technology, such as fitness trackers and smart watches (Lunney, Cunningham, \& Eastin, 2016)(Joon \& Dong-Hee, 2015). TAM is a framework for understanding how likely individuals are to adopt a new technology (Davis, 1989) (See Figure 2). Two key features predict acceptance which are "perceived usefulness" and "perceived ease-of-use" and is based on how well an individual believes the two features will influence their performance 
(Davis, 1989). The combination of features leads to develop behavioral intentions, which leads to adoption.

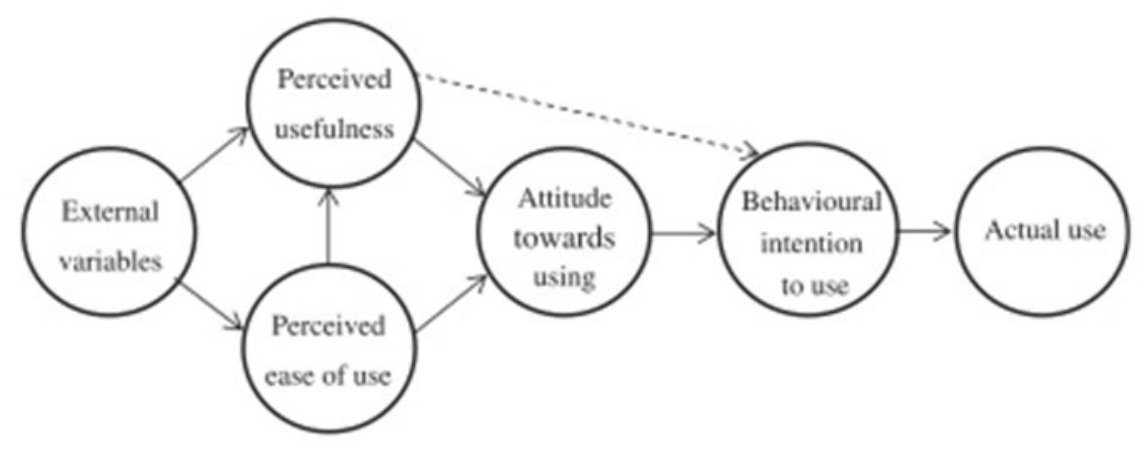

Figure 2. Technology Acceptance Model

Extending the model is an area of active research, and that includes wearable technology (Wolf et al., 2018), including smart watches (Joon \& Dong-Hee, 2015). These models include adding psychological determinants such as affective domain and relative advantage (Joon \& Dong-Hee, 2015) In addition, perceived health benefits is also associated with intention to adopt (Lunney et al., 2016). These health benefits are also explored in a study involving construction workers and their willingness to adopt a smart vest with GPS location to provide occupational safety (B. Choi, Hwang, \& Lee, 2017). Aesthetic evaluations, like simplicity also function as an antecedent variable for perceived ease-of-use meaning that clear, simple interactions suggest technology acceptance (Lazard et al., 2016)

For older adults, having access to health information is another avenue being explored. Older adults are interested in using patient portals to access their data, but the user experience is often a barrier (Portz et al., 2019). Portz et al. found that the older adults 
had a lack of awareness around functions available, but ultimately found the system easy to use and intended to adopt. Thus, older adults, and the workforce, such as construction workers who see perceived health benefits, also show an intention to adopt.

Furthermore, functional usefulness is not the only predictor of adoption as fashion is also being explored as a possible avenue for adoption. Choi and Kim found that not only perceived capability, but the watch as a luxury fashion product and statement of uniqueness predicted intention (J. Choi \& Kim, 2016).

Another element of adoption and motivation is what is known as gamification. Gamification is "usage of game design elements to motivate user behaviour in non-game contexts"(Browne \& Anand, 2013; Zhao, Ali Etemad, \& Arya, 2016). Apps like Zombies, Run! which motivate users to be active by telling a story that unfolds as the user runs are other ways that users are adopting technology to address physical inactivity (Zhao, Arya, Whitehead, Chan, \& Etemad, 2017). Challenges with friends, and badges earned for achievements like being active for many days in a row also contributes to adoption (Asimakopoulos, Asimakopoulos, \& Spillers, 2017).

\subsection{The Importance of Data}

The data generated by devices such as the Apple Watch or Fitbit provide a new form of feedback to the user. For the ones wearing a device, there is now new data that can lead to knowledge, and hopefully insight. Coaches, teachers, physiotherapists and doctors can also use the data to inform their analysis. As new devices develop and new iterations are released, newer metrics become available, such as being able to monitor 'gait' which 
is the manner in which a person walks. Smart insoles, such as one created by the company Retisense (see Figure 3) provide data generated by sensors embedded in the insole.

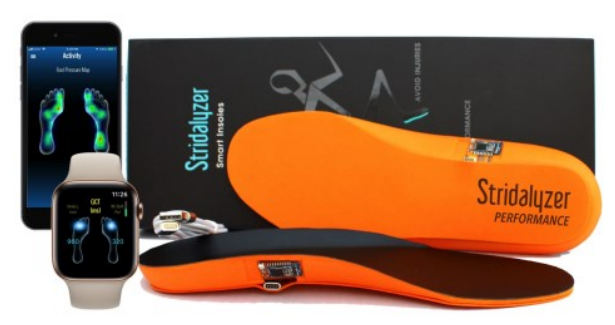

Figure 3. Smart insole that generates data using embedded sensors. ${ }^{2}$

In the big picture, data from wearable fitness trackers is providing multiple avenues for users to explore. Fitbits and Apple Watches, for example are now able to track sleep metrics that give feedback on how well users are sleeping. This can be used to improve conditions for sleeping. The whoop wearable allows users to track how well they are recovering from the previous day, and users are changing their drinking habits due to the new data (Ahmed, 2019). Step Counts tracked by Apple Watch and presented over time, allow users to track their activity day by day, and see if some days are more active than others, and make plans to add or reduce activity accordingly. This new data, however is not able to enact change by itself.

Wolff states that data, by itself, has little value (Wolff \& Montaner, 2016). From Latin origin it means literally "something given", or "a piece of information" or "facts and statistics collected together for reference or analysis"3. At first, pedometers provided users

\footnotetext{
${ }^{2}$ http://retisense.com/)

${ }^{3}$ Dictionary.com/data
} 
with data in the form of step counts, represented by a simple number. This step count measurement is still used to this day to help measure physical activity. Other simple statistics like calories burned or distance run are also important metrics that inform health. For some people the data is for merely monitoring, while others are seeking to change their behavior by having data to ground their interventions (Maher et al., 2017). One advantage of wearable fitness trackers is that they are generating new data that were previously unavailable to the user, such as $\mathrm{VO} 2$ max provided by some Fitbit and Garmin devices (See Figure 4). VO2 Max is a measurement of oxygen consumption important to athlete's endurance.

However, as Wolff highlights the data itself is not the crucial element. What's more important is what we learn from it, what awareness we gain, and what we do with that knowledge that is. It is important that we acknowledge that data, information, knowledge, and wisdom are not the same thing as has been discussed in the literature (Nürnberger, Seising, \& Wenzel, 2009; Stafford, 2009). Data are defined as simple facts, either quantitative or qualitative, while information is organized data. Knowledge is the ability to understand the meaning of information, while wisdom is the ability to act appropriately on knowledge (Stafford, 2009). In this case, data acts as a form of feedback provided, yet as one researcher explained "Measurements don't mean anything without telling us what to make of the measurements" (Schüll, 2016) which illustrates the interconnection between data, information, knowledge and wisdom. 


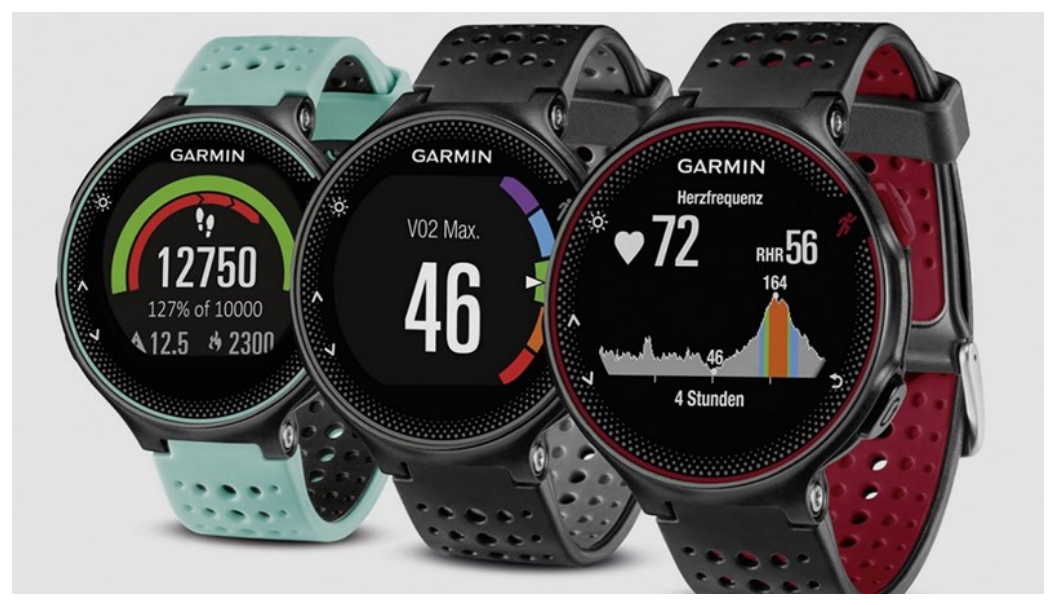

Figure 4. VO2 Max metric displayed on a Garmin wearable indicating fitness level ${ }^{4}$

To improve performance, traditionally coaches of athletes provided expertise feedback orally or visually. Wearable fitness trackers provide feedback in the form of data that can lead to knowledge and awareness. An example is a wearable sleeve created by Motus that is being used for conducting analysis on a baseball pitcher's throwing in order to measure the user's effort and power (See Figure 5). Throwing too hard or poor throwing technique can lead to a serious injury of the Ulnar Collateral Ligament, which stabilizes the elbow during the throwing motion (John Hopkins Medicine, n.d.). Researchers investigated perceived effort vs. real effort while wearing the Motus sleeve and showed that for every $25 \%$ decrease in perceived effort while throwing, there was only a $7 \%$ decrease in torque and $11 \%$ for velocity (Melugin et al., 2019). This means that the feedback provided by the wearable was able to help the athletes understand that their perception of effort did not match the reality. One professional pitcher used the sleeve

\footnotetext{
${ }^{4}$ https://www.wearable-technologies.com/2018/06/whats-vo2-max-and-why-is-it-essential-for-fitnessfreaks/
} 
during the season in order to establish a baseline of maximum effort and then monitor the strain on his elbow to prevent a serious injury (Lemire, 2019).

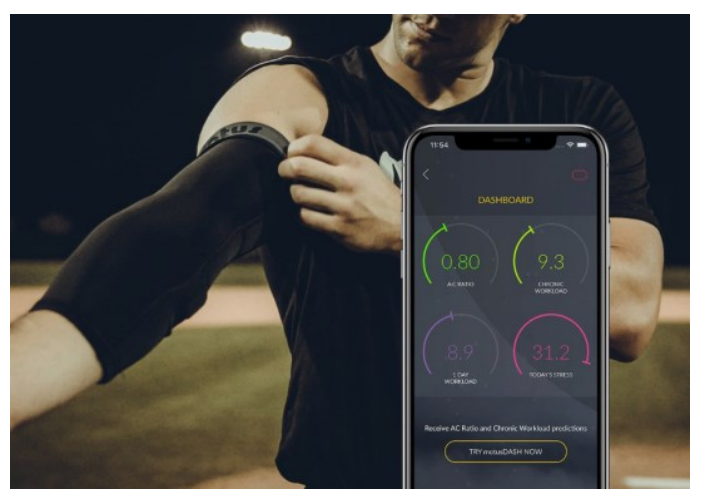

Figure 5. Motus wearable sleeve and data visualization ${ }^{5}$

This data is therefore helpful for elite performance but is also being used to manage health. Singh et al. created a prototype that gave sonification feedback to help patients manage their chronic pain. Participants reported an increase in body awareness that enhanced their quality of life (Singh, Bianchi-Berthouze, \& Williams, 2017), and knowledge around how to behave based on their experience with the vest. One user reported that she had gone past her calibrated maximum without thinking, but the sound feedback told her that she had, potentially exposing her to pain (Singh et al., 2017). This feedback therefore provided an opportunity to learn more about their body and its limitations.

Thus, feedback in the form of data can help all kinds of users and potential users gain insight and raise awareness. Thus, athletes and coaches who are aware of these wearable devices also show interest in intention to adopt and use the data generated by wearables.

\footnotetext{
${ }^{5}$ https://www.motusglobal.com/motusbaseball
} 


\subsection{Quantified Self and Personal Informatics}

As we can see, awareness brought on by new forms of data is attractive to many kinds of people, including patients in pain or overweight, people working dangerous jobs, athletes looking for improvement and a competitive advantage, as well as tech savvy people wanting to stay up to date. Taking this tracking more seriously has generated a category called Personal Informatics, or Quantified Self (Choe et al., 2017).

Beginning in 2007, a group of like-minded people interesting in quantifying their lives adopted the notion of 'self-knowledge through numbers' and began a Quantified Self (QS) movement (Choe, Lee, Lee, Pratt, \& Kientz, 2014). Tracking behaviors and habits has a long history, but the sophistication of computers has allowed tracking to advance in scope and goes by another name in HCI which is personal informatics (PI) (I. Li, Dey, \& Forlizzi, 2010). Choe et al. reported that some of these individuals claimed they were able to identify triggers that had caused them health issues(Choe et al., 2014). Some claim to become more aware of themselves and their environment by paying attention to this new information because for them 'If you cannot measure it, you cannot improve it (Rapp \& Cena, 2016).

However, not all knowledge is welcome and there are downsides to awareness. Epstein et al. found that tracking can reveal perceived shortcomings in behavior with feelings of guilt felt by the user (Epstein et al., 2016). Additionally, fitness trackers have the ability to monitor sleep, and there is a growing number of patients seeking treatment for self-diagnosed sleep problems due to these devices monitoring sleep data and generating anxiety (Baron, Abbott, Jao, Manalo, \& Mullen, 2017). 
Another issue with tracking that Choe et al. found was a risk that their conclusions lacked scientific rigour, potentially leaving them to misunderstand or make the wrong conclusion (Choe et al., 2014). In their research, not all QSers were controlling for variables, though they did claim to have found a solution to a health issue. Ryan et al. found that the experience for tracking is mostly positive, with little risk of negative psychological consequences. (Ryan, Edney, \& Maher, 2019) What Rapp et al. found, however, is that experiences vary by expertise. While experienced users derive benefits from tracking and putting in time, "New potential users are unfamiliar with Personal Informatic technologies and may have a misperception of their limits and potentialities...It is probable that they are not inclined to invest a huge amount of time for managing and understanding their data" (Rapp \& Cena, 2016).

They raise a key point that tracking is time consuming and requires commitment, something they found when they compared naïve/novice users with experienced users (Rapp \& Cena, 2016). These two distinct user groups perceived and used the devices and their data differently. For naïve trackers, a lack of recommendations on how to use the data prevented them from gaining useful insights. The result was their interest in tracking faded (Rapp \& Cena, 2016). "People showed a lack of motivation in navigating their data, not going in deep in understanding them: they quickly visualized some information, attempted some correlations, but were stopped at the first difficulties" (Rapp \& Cena, 2016) Thus, beginners and advanced users experience data differently, and presents itself as a barrier to adoption. As well, there is a danger of making an erroneous conclusion when attempting to make sense of the data presented to the user. 


\subsection{Data Visualization}

Data Visualizations are graphical representations of data that shows and communicates making it easier to understand and derive meaning. Data Visualization researcher Helen Kennedy commented that "As there is more and more data around us, people need to find ways to live with data and visualization is the main way that a lot of non-experts access or come across data" (Bertini \& Stefaner, 2016). The sports world has been using data visualizations to help explain to fans how players and teams are performing (Perin et al., 2018). Research has found that these data visualizations can help raise awareness around various elements of health (Consolvo et al., 2008).

Yet, as Maltese et al. shows there is a difference in ability between novice and expert understanding of visualizations (Maltese, Harsh, \& Svetina, 2015) echoing what Rapp et al. found that naïve, or non-expert users, were not only confused by how to use the data, but as well by the abstract data visualizations (Rapp \& Cena, 2016).

However, in order to understand, interpret, and use these visualizations users need to have a certain level of literacy. The ability to "confidently create and interpret visual representations of data" (Alper, Riche, Chevalier, Boy, \& Sezgin, 2017) is what is known as 'visualization literacy'. Yet, research into data visualization found that the general public has a relatively low level of visualization literacy (Börner, Maltese, Balliet, \& Heimlich, 2016). This presents a challenge to adoption if the average user struggles to interpret visualizations generated by a fitness tracker.

Additionally, Xiong et al. demonstrated how visualizations can reveal many truths and can be interpreted differently (Xiong, van Weelden, \& Franconeri, 2019). Their 
research indicated that what we see and perceive in a visualization may be guided by our background knowledge (See Figure 6). Xiong et al. found that experts in the subject matter mistakenly assumed the novice could see what the expert could see, displaying the cognitive bias known as the curse of knowledge (Xiong et al., 2019).

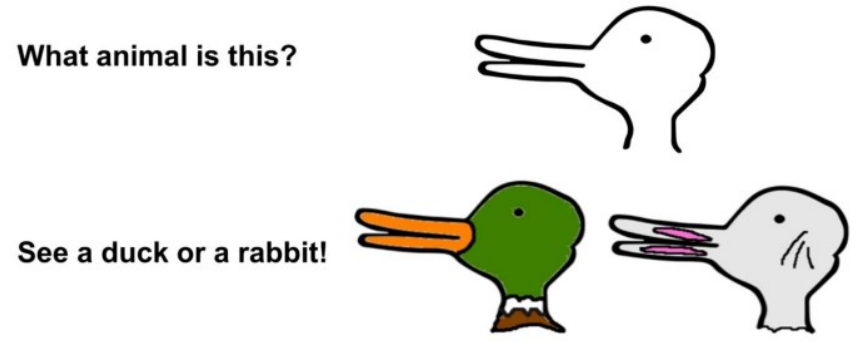

Figure 6. Ambiguous visualization suggesting the same visualization could lead to two different interpretations.

Additionally, researchers are finding that some individuals struggle with simple interpretations, including basic bar and pie charts (Bertini, 2016). As Xiong shows, visualizations can reveal more than one simple truth (See Figure 7) In her example depending on one's perspective, it supports an intervention resulting in a decrease of violent crime, while another perspective may focus on how the current rate is still higher than earlier rates.

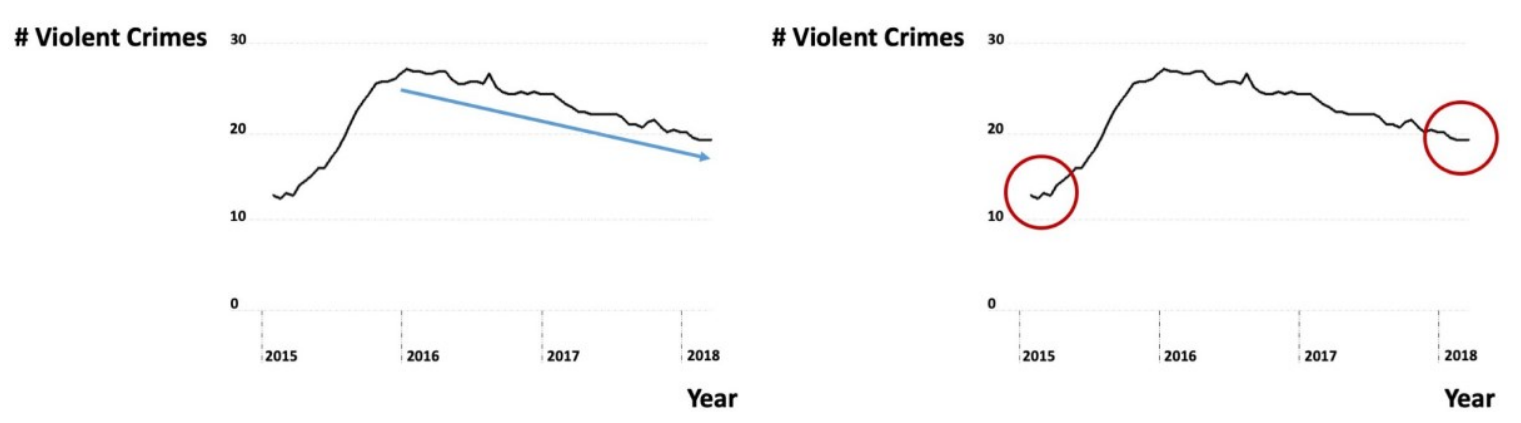

Figure 7. Illustration of how people may focus their attention on different aspects of the graph and draw 2 completely different conclusions (Xiong, 2019) 
Yet, Choe et al. also found that experienced trackers faced issues with making sense

of data. "Data interpretation was a key hurdle for many Q-Selfers...Visualizations were helpful in gaining insights, but again, the learning curve for data manipulation... was very steep.'(Choe et al., 2014). One of Choe et al.'s participant's noted that they don't lack the information, in fact, they are somewhat drowning in it, it is rather they lack the proper tools to interpret the meaning of the data (Choe et al., 2014). Thus, tracking has benefits but beginners and expert trackers experience the data and the visualizations differently, suggesting that 'literate' trackers are able to make more sense of the data but that even experienced trackers struggle as well. What we mean by literacy will need to be explored further.

\subsection{Health Data and Health Literacy}

According to Dan Ledger, author of the white paper on abandonment (Ledger \& Partners, 2014) One of the reasons people cannot make sense of data, and in this case physiological data, is that people are also unaware of their bodies " Most of us have a fairly low health literacy...you really need someone there to translate the data" (Ledger, 2017) What ledger describes as Health literacy is, depending on a chosen definition "The degree to which individuals can obtain, process, understand, and communicate about healthrelated information needed to make informed health decisions." (Berkman, Davis, \& McCormack, 2010). Furthermore, in a study on mHealth to enable military veterans to improve the management of their own health Sharit et al. found that the "interface and functionalities it(the online portal) offers may require that its users have healthy literacy, numeracy, and graph literacy skills" (Sharit et al., 2014). 
As Ledger remarked, if one is lower on the health literacy spectrum or scale, there may be a need to translate, or interpret the data for the user because they cannot do themselves. Wolff said that without the ability to make sense of the data, "there is a risk that the data reader accepts biased interpretations of data as fact, leading to bad choices" (Wolff \& Montaner, 2016) In this case Wolff is referring to what is called "data literacy" which can be defined as " The ability to understand, find, collect, interpret, visualize, and support arguments using quantitative and qualitative data" (Wolff \& Montaner, 2016). The definition we use in this thesis is:

"the ability to understand and use data effectively to inform decisions...skills include knowing how to identify, collect, organize, analyze, summarize and prioritize data. They also include how to develop hypotheses, identify problems, interpret the data, and determine, plan, implement, and monitor courses of action" (Mandinach \& Gummer, 2013)

As we can see Health Literacy and Data literacy overlap with both of them sharing the need to be able to interpret to make informed decisions. Bhargava et al. created an illustration helpful in making sense of these overlapping literacies (See figure 8) (Bhargava et al., 2015) 


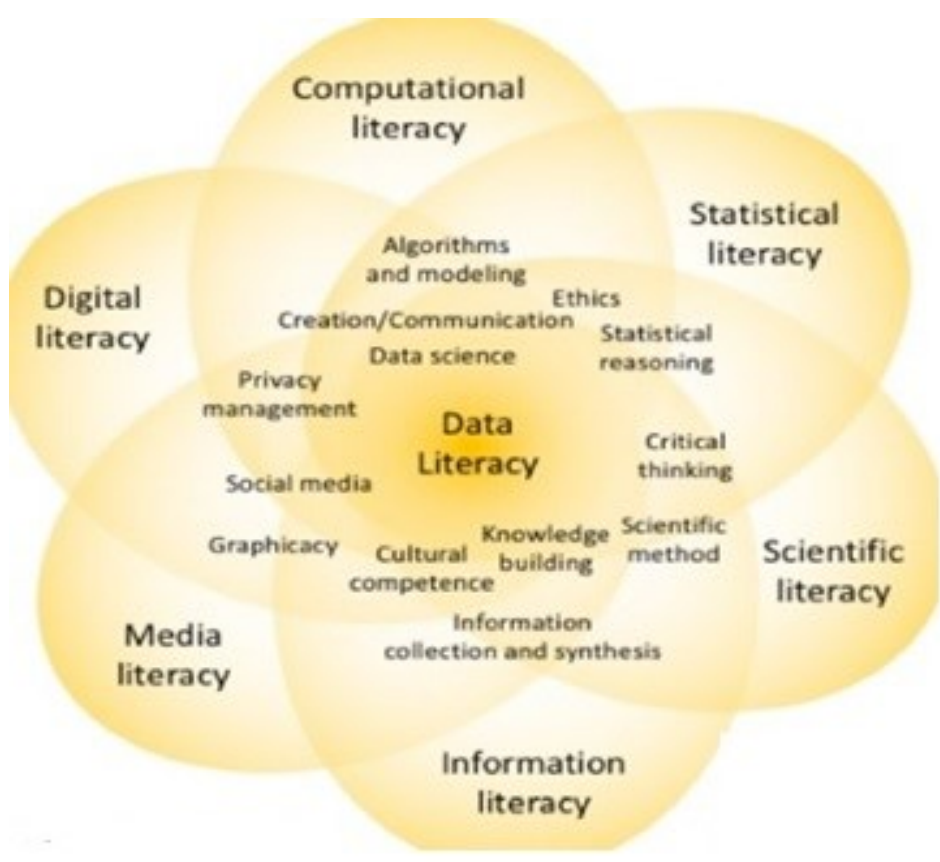

Figure 8. Illustrates overlap of various literacies and their interconnectedness (Bhargava et al., 2015)

Vamos and Klein noticed that tracking was becoming a norm amongst not only Quantified Selfers but the population at large (Vamos \& Klein, 2018). They asked in their commentary, "How 'health literate' do we have to be to reap actionable health benefits from self-tracking? They note that "although new apps are emerging to import multiple datasets to output charts, visualizations, and spreadsheets to examine correlations, human skills, competencies, and motivation, efforts are required to make meaning out of these data (Vamos \& Klein, 2018). Thus, it leads us to wonder about the roles of literacy in influencing abandonment and why people abandon devices given the benefits of data and tracking.

\subsection{Reasons for Abandonment}

Just like research into wearable technology, research into abandonment is a fertile field of study in HCI. Attig et al. conducted a review and group abandonment into many 
categories (see Figure 9) (Attig \& Franke, 2020). Some of the commonly studied categories include data privacy and security, data accuracy and demotivation. Yet, the research also identified a category of "data uselessness", where data interpretation is not comprehensible enough (Attig \& Franke, 2020). Contradicting the pillar of perceived usefulness, if users find certain data useless, it is possible it may lead them to not adopt or abandon wearable trackers. This category overlaps with another one Attig et al. outlined that is of concern to HCI, and that is 'usability.' As Asimakopoulos articulates well "The user experience (UX) that accompanies wearables is critical to helping users interpret, understand, gain motivation and act in their data"(Asimakopoulos et al., 2017). One of their UX heuristics for tracking includes "Giving users a means to explore their gathered data...can make the experience more meaningful” (Asimakopoulos et al., 2017) 
Reasons for activity tracker abandonment identified in systematic literature review.

\begin{tabular}{|c|c|}
\hline Category & Example \\
\hline \multirow[t]{6}{*}{ Usability issues } & Low app usability \\
\hline & Low activity tracker usability \\
\hline & Tracking takes too much mental effort/workload \\
\hline & $\begin{array}{l}\text { Tracking takes too much temporal effort (high maintenance } \\
\text { frequency) }\end{array}$ \\
\hline & Tracking does not fit into daily routine \\
\hline & Technology is too complex \\
\hline Measurement inaccuracy & Measurement errors and perceived inaccuracy \\
\hline \multirow[t]{5}{*}{ Data uselessness } & Data interpretation is not comprehensible enough \\
\hline & Device does not track the personally relevant data/activities \\
\hline & Device tracks useless data/metrics \\
\hline & Data cannot be used as desired \\
\hline & Synchronization with other apps impossible \\
\hline \multirow[t]{5}{*}{ Design/comfort issues } & Poor tracker aesthetics \\
\hline & $\begin{array}{l}\text { Wearing the tracker is uncomfortable/"physical awareness of the } \\
\text { tracker" }\end{array}$ \\
\hline & Wearing the tracker hampers physical activity \\
\hline & Allergic reaction to the wristband \\
\hline & Cumbersome battery charging/short battery life \\
\hline \multirow[t]{4}{*}{$\begin{array}{l}\text { Disruption of tracking } \\
\text { routine }\end{array}$} & $\begin{array}{l}\text { Disrupted tracking because battery was empty or needed } \\
\text { replacement/charge cable missing or broke }\end{array}$ \\
\hline & Disrupted tracking during holidays \\
\hline & User forgot to track ("out of sight, out of mind") \\
\hline & Tracker loss or breakage \\
\hline \multirow[t]{5}{*}{ Demotivation } & Loss of tracking motivation \\
\hline & Loss of motivation for physical activity \\
\hline & Psychological awareness (users become obsessed with the device) \\
\hline & Feedback about failure is demotivating \\
\hline & $\begin{array}{l}\text { Tracker usage led to undesired behavioral adaptation (choosing } \\
\text { specific physical activities over others only because the device can } \\
\text { track them) }\end{array}$ \\
\hline \multirow[t]{3}{*}{ Change in priorities } & $\begin{array}{l}\text { Activity goals have changed (device not able/useful to track new } \\
\text { activities) }\end{array}$ \\
\hline & Personal circumstances have changed (e.g., pregnancy, new job) \\
\hline & Health status has changed (e.g., disease makes tracking impossible) \\
\hline \multirow[t]{3}{*}{ Social comparison } & No or little comparability with users of other devices/apps \\
\hline & Insufficient social interaction (e.g., challenges) \\
\hline & Loss of desire for social comparison \\
\hline Privacy concerns & Concerns regarding personal data transfer \\
\hline $\begin{array}{l}\text { Usage of tracking } \\
\text { altematives }\end{array}$ & $\begin{array}{l}\text { Using a more attractive tracking alternative (e.g., standalone } \\
\text { smartphone app) }\end{array}$ \\
\hline Successful habit formation & Goal achieved ("happy abandonment") \\
\hline
\end{tabular}

Figure 9. Table from Attig et al. outlining reasons why users abandon trackers. 
Shih et al., also found challenges to ease of use and usefulness in their study which found that many participants had problems remembering to put their device on, in many cases because the device needed to be removed to charge (Shih, Han, Poole, Rosson, \& Carroll, 2015). Of particular note, some participants had issues with data management expressing a wish that there was better support for sharing and comparing activity data with other people. They also expressed a desire to receive more interesting and diverse feedback on their physical activities (Shih et al., 2015). These reports suggest some users were not benefiting enough from the data.

Another study found that certain users perceived 'health information tools'(HIT) such as fitness trackers and apps as useful, while others in the study did not. Mackert et al. investigated how health literacy is associated with adoption of these tools (Mackert et al., 2016). They found that patients with low health literacy were less likely to use health information tools or perceive them as easy or useful. HIT adoption was associated with higher health literacy. Thus, it can be further argued that literacies (health, physical, data, etc.) are key components of wearable technology adoption.

\subsection{Research Gap}

A 2017 study by Maher et al. investigated the user experiences of wearable fitness trackers. In it, Maher used a survey to ask 200 current users, and 37 former users to report on reasons for using a tracker and to report on complaints. Both former and current users complained of having problems interpreting the data albeit at low levels. 
Particularly interesting to us were the $8.1 \%$ of former users who complained of having issues, "understanding and interpreting the data." Another 5.4\% of former users complained about "problems navigating supporting websites."(Maher et al., 2017)

Furthermore, Maher et al. found that $29.7 \%$ of users said that the primary reason they abandoned was "I learnt everything I could." Some researchers believe that this may be explained as "happy abandonment" (Clawson, Pater, Miller, Mynatt, \& Mamykina, 2015), though it has not been confirmed that that is indeed a positive, especially if some users mistakenly believe they have learned all they could.

As the literature review suggests, there may be a connection with health and data literacies in influencing people's experiences with wearable fitness trackers. However it has yet to be confirmed that people who stop using, stop because they struggle with data. Various studies suggest some users, in particular, beginners or those of lower levels of literacy struggle the most. The research in Chapter 3 sought to reproduce much of Maher's study with some modifications to delve deeper into the UX of wearable fitness trackers to ascertain the reasons why some abandon, who exactly abandons and whether data interpretation and data visualization is a considerable issue. 


\section{Chapter 3: Survey}

\subsection{Restatement of the problem}

The primary research goal was to investigate why users abandon fitness trackers in 2019 and to compare with data from 2016. Thus, we decided to replicate a survey study conducted by Maher et al. to see if there are any changes, and/or to provide further evidence. We chose the Maher et al. paper because while other papers noted anecdotes of users struggling to make sense of data, Maher et al. included actual numbers that we could compare with. They also provided direct access to their survey, so we were able to ask questions verbatim, which was more advantageous than other studies on abandonment that simply reported their results.

Additionally, we wanted to see if survey respondents struggled to understand, interpret, and make sense of data more than had been reported by Maher et al. so we added questions to the survey to identify if they were in a sense 'data literate'. We chose use Mandinach \& Gummer's definition of Data Literacy which is:

"the ability to understand and use data effectively to inform decisions...skills include knowing how to identify, collect, organize, analyze, summarize and prioritize data. They also include how to develop hypotheses, identify problems, interpret the data, and determine, plan, implement, and monitor courses of action" (Mandinach \& Gummer, 2013)

We are also interested in gaining greater insight into any characteristics about people who decide to abandon their device and what was missing from the experience, so we added new questions pertaining to user experience and design and asked respondents to provide perspectives on what they felt could have made the tracker more beneficial. The researchers created the additional questions themselves, based on the above definition in 
order to assess data literacy. Our hypotheses for Part 1 of the survey are below and address the second research question.

Hypothesis 1: Respondents will report abandoning their device due to struggles with data more than they did in Maher et al.'s study.

Hypothesis 2: Low Fitness individuals who have stopped tracking (LFFUs) will report the most trouble interpreting data.

Hypothesis 3: Respondents with lower physical fitness will report high levels of abandonment

\subsection{Survey Design}

We conducted an online survey with 46 questions to collect data on users' and former users' motivation for tracking, the issues they face, and behavior change. Questions were mandatory and people who were over 18 and had experience using a wearable fitness tracker were qualified to answer our survey. Questions included short form answers, dropdown, as well as Likert scale questions (See Table 1). We based this survey on Maher et al. (Maher et al., 2017) where we used 17 questions verbatim from their work so we could compare our dataset to theirs. The complete survey is in Chapter 6:Appendix B

We added 23 questions that were pertinent to the investigation of data interpretation as well as physical literacy and body awareness. We also modified 6 questions. In comparison to Maher et al.'s survey, we asked users and former users deeper questions about their onboarding experience to delve into whether they were ready for the data. We 
also wanted to know what problems users encountered, and whether they solved them and how. Each iteration of questions underwent pilot testing to design questions that would lead to pertinent, specific answers that help answer our research goals. The pilot testing consisted of four rounds of practice with three college students, and one working professional. Each successive list of questions revealed word choices that lead to vague answers that were then adjusted to better answer the research questions. Qualtrics supported our survey. 
Table 1. List of questions asked during the survey

\begin{tabular}{|c|c|c|c|}
\hline & Maher et al. & Questions added & Modified from Maher et al. \\
\hline Demographics & $\begin{array}{l}\text { 1. How old are you in years? } \\
\text { 2. What is your highest level of education that you have } \\
\text { completed? }\end{array}$ & $\begin{array}{l}\text { 3. In which country are you from? } \\
\text { 4. How would you rate your physical fitness? }(1= \\
\text { low, } 4=\text { high })\end{array}$ & $\begin{array}{l}\text { 5. What gender are you? } \\
\text { (Modified to better suit choices } \\
\text { for gender fluidity) }\end{array}$ \\
\hline $\begin{array}{l}\text { Basic details } \\
\text { on wearable } \\
\text { use }\end{array}$ & $\begin{array}{l}\text { 6. Are you currently using a wearable? } \\
\text { 7. Have you ever used a wearable fitness tracker? } \\
\text { 8. What's the name of the wearable fitness tracker? } \\
\text { 9. For how many months did you use it? } \\
\text { How much do you agree/disagree with the following } \\
\text { statements? Since I started using my wearable I } \\
\text { now.... } \\
\text { 10. Eat healthier } \\
\text { 11. Incorporate more activity in my day } \\
\text { How much do you agree/disagree with the following } \\
\text { statements? } \\
\text { I find the following measure on my wearable } \\
\text { useful... } \\
\text { 13. Active minutes, } \\
\text { 14. Steps } \\
\text { 15. Sleep } \\
\text { 16. Heart rate } \\
\text { 17. Energy burned } \\
\text { 18. Energy consumed (food) }\end{array}$ & $\begin{array}{l}\text { 19. After giving up your wearable fitness tracker, } \\
\text { how many days did you get at least } 30 \text { minutes } \\
\text { of moderate intensity physical activity? } \\
\text { 20. Please list all the wearable fitness trackers } \\
\text { you've used and for how many months you } \\
\text { used it. } \\
\text { 21. Have you ever used a smart garment? } \\
\text { 22. Which smart garment and what did you use it } \\
\text { for? } \\
\text { 23. What have you done with the data generated } \\
\text { by the fitness tracker? Tick all that apply } \\
\text { 24. Before using the wearable fitness tracker, did } \\
\text { you read the manual? } \\
\text { 25. Before using the wearable fitness tracker, did } \\
\text { someone show you how to use it? } \\
\text { 26. Before using the wearable fitness tracker, did } \\
\text { you watch a tutorial? }\end{array}$ & $\begin{array}{l}\text { 27. Before you got your wearable } \\
\text { fitness tracker, in a typical week, } \\
\text { how many days did you get at } \\
\text { least } 30 \text { minutes of moderate } \\
\text { intensity physical activity? } \\
\text { (Modified to address the } \\
\text { American Heart Association's } \\
\text { recommendation that we get } \\
\text { Moderate to Vigorous physical } \\
\text { activity.) } \\
\text { 28. What was the reason you } \\
\text { decided to wear the wearable } \\
\text { tracker in the first place? Tick all } \\
\text { that apply (modified to address } \\
\text { all motivations, not just main } \\
\text { reason.) } \\
\text { Since using my wearable } \\
\text { I now... } \\
\text { 29. Sleep less } \\
\text { 30. Strength train more }\end{array}$ \\
\hline
\end{tabular}




\begin{tabular}{|c|c|c|c|}
\hline & & & $\begin{array}{l}\text { 31. Spend more time learning about } \\
\text { my body. }\end{array}$ \\
\hline $\begin{array}{l}\text { Problems with } \\
\text { trackers }\end{array}$ & $\begin{array}{l}\text { 32. Did you have any complaints with your wearable } \\
\text { fitness tracker? Tick all that apply } \\
\text { 33. What is the reason you stopped using your wearable? } \\
\text { Tick all that apply }\end{array}$ & $\begin{array}{l}\text { How much do you agree/disagree with the } \\
\text { following statements... } \\
\text { 34. I have had trouble interpreting the data } \\
\text { generated by a fitness tracker } \\
\text { 35. I have had trouble deciding what to do with } \\
\text { the data generated } \\
\text { 36. If you had trouble understanding or } \\
\text { interpreting data, what did you have trouble } \\
\text { with? Please give concrete examples } \\
\text { 37. What did you do to solve the problem you } \\
\text { were having? } \\
\text { How much do you agree/disagree with the } \\
\text { following statements - } \\
\text { 38. I can understand graphs well } \\
\text { 39. I can make sense of physiological data } \\
\text { 40. I can plan a course of action based on the } \\
\text { results } \\
\text { 41. With the above data, what can you understand } \\
\text { from the data? What might you do with this } \\
\text { data? } \\
\text { 42. What do you feel is missing from wearable } \\
\text { fitness trackers? What would you like to see } \\
\text { that would increase your likelihood or } \\
\text { maintaining use? }\end{array}$ & \\
\hline
\end{tabular}




\begin{tabular}{|c|c|c|}
\hline $\begin{array}{l}\text { Questions } \\
\text { about physical } \\
\text { literacy }\end{array}$ & & $\begin{array}{l}\text { How much do you agree/disagree with the } \\
\text { following statements? } \\
\text { 3. More knowledgeable about my body } \\
\text { 4. less confident about my physical ability } \\
\text { 5. more aware of my form while I perform } \\
\text { movements } \\
\text { 6. less motivated to improve my fitness }\end{array}$ \\
\hline
\end{tabular}


Included in the survey is a chart showing heart rate data from a story from 2017 (See Figure 10). An Apple Watch user was woken up from his sleep by a 3rd party app that alerted him to an elevated heart rate (Hall, 2017). He did not feel sick but went to the hospital where he was diagnosed with having a heart attack. His doctor told him that without the alert, it is probable he would have died in his sleep. We wanted to see if this kind of data would stand out to fitness tracker users which is common in many fitness trackers. We used the data visualization from the iPhone health app and asked respondents if they could understand the data, and what they might do with that data. They were only informed that this data came from a man while he was sleeping.

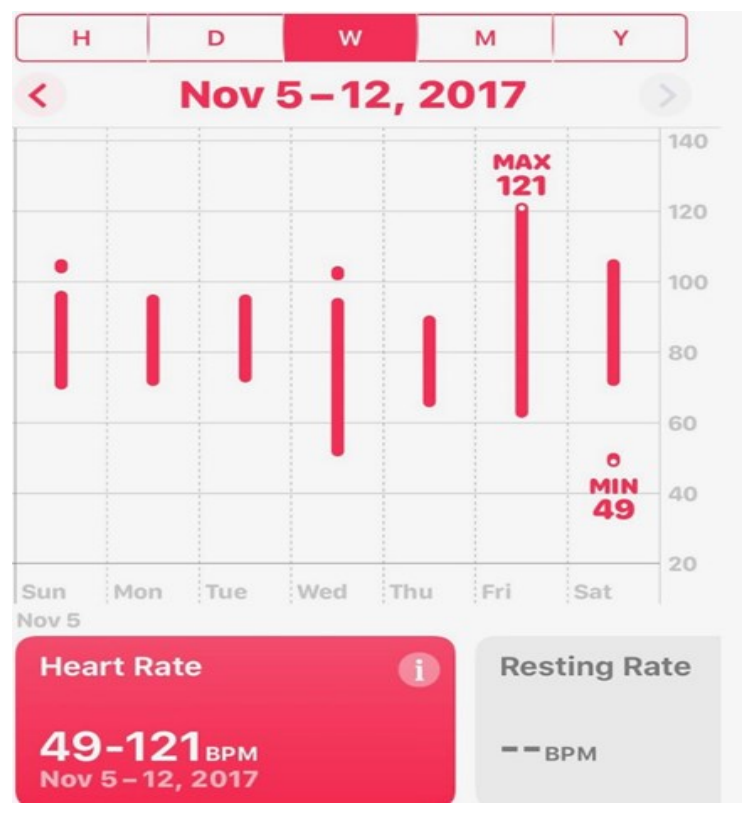

Figure 10. Heart Rate data for a man while he is sleeping. His Apple Watch woke him up after reading 121, which is dangerous for resting heart rate.

\subsection{Recruitment}

Ethics Approval (\#110810) occurred on May 1,2019 and is in Chapter 6:Appendix A Recruitment for users began on May $23^{\text {rd }}$ and lasted until August 22 2019. We recruited 
participants through social media, including Facebook and Twitter, word of mouth, as well as flyers displayed on Carleton University campus and at select City of Ottawa recreation facilities to find probable users of fitness trackers. We entered participants that completed the survey into a draw to win one of two $50 \$$ gift cards.

After 6 weeks of recruitment, we observed that current users $(n=160)$ of wearable devices were disproportionately answering our survey compared to former users $(n=20)$. To balance our dataset, we recruited on Prolific ("Prolific," n.d.), an online resource for participants for online surveys. First, we filtered users by asking them if they ever used a fitness tracker and if they currently use a fitness tracker. Those that answered that they had used a fitness tracker, but were not currently, were then sent a follow-up request. Our statistics on Qualtrics informed us that it took participants an average of 10-11 minutes to complete the survey. Therefore, we offered a fair compensation rate of $\$ 2.30$ based on minimum wage in Ontario which is $14 \$$ per hour.

\subsection{Results}

The results are organized into 2 main parts. Part 1 is a direct comparison between our data and that of Maher et al. to see what changes, if any, present themselves from the 2016 data. As with Maher et al. results will show a raw number as well as a percentage of the totals and note that certain questions allowed multiple responses. In part 2, we further organize our results into 4 categories explained below and report on the new qualitative data gleaned from the additional questions asked in the survey. After illustrating the results, an analysis will follow to draw insights into what our results suggest. 


\subsubsection{Demographics}

In order to qualify for the survey, respondents had to be over 18 and have had experience using a wearable fitness tracker. We include in our data analysis all respondents who answered at least half of the survey questions. In total, we obtained 233 responses. 186 participants were active users while 47 participants were former users. Of the total accepted responses, 97 were males, 132 were females, 1 preferred not to say, and 3 preferred to self-describe (Female to male and genderqueer). The average age was 36.9 years old, while the median was 35 . Of the respondents, 84 indicated their highest level of education was 'postgraduate', 95 said 'undergraduate', while 38 said 'high school', with 16 saying 'other'.

Respondents came from Canada (79), USA (59), the UK (23) with less than 5 from each of the following countries: Australia, Austria, Belarus, Belgium, Bulgaria, Denmark, Ecuador, Finland, France, Germany, Greece, Guatemala, Hungary, India, Iran, Ireland, Italy, Latvia, Malaysia, Malta, Mauritius, Mexico, Morocco, Netherlands, Norway, Pakistan, Peru, Philippines, Poland, Portugal, Serbia, Singapore, South Africa, Spain, Sweden, and Venezuela.

\subsubsection{Part 1: Adoption of Wearable Fitness Trackers}

Maher et al. investigated the main reason for adopting a tracker and found that 'monitoring, activities', 'improving fitness' and 'improving health' were the top 3 (See 
Table 2). Not many users selected to "keep up with technology", for example, yet some users choose to wear a wearable for several a couple or many reasons, and those reasons are sometimes of equal value. Therefore, we decided to ask a similar question to see how the responses may change to take into consideration that some users adopt for several reasons. We asked respondents to tick all motivations, regardless of main reason (See Table 3).

Table 2. Maher et al. showing primary motivation for adopting a tracker

\begin{tabular}{llll}
\hline Motivation & $\begin{array}{l}\text { Former } \\
(\mathbf{n = 3 7 )} \boldsymbol{n}\end{array}$ & $\begin{array}{l}\text { Current } \\
(\mathbf{n}=\mathbf{2 0 0}) \boldsymbol{n} \\
\mathbf{( \% )}\end{array}$ & $\begin{array}{l}\text { Total } \\
(\mathbf{n}=\mathbf{2 3 7}) \boldsymbol{n}(\mathbf{\%})\end{array}$ \\
\hline Monitor activities & $11(29.7 \%)$ & $74(37.0 \%)$ & $85(35.9 \%)$ \\
Improve fitness & $14(37.8 \%)$ & $51(25.5 \%)$ & $65(27.4 \%)$ \\
Improve health & $3(8.1 \%)$ & $40(20.0 \%)$ & $43(18.1 \%)$ \\
Improve appearance & $1(2.7 \%)$ & $1(0.5 \%)$ & $2(0.8 \%)$ \\
Compete with family \& friends & $1(2.7 \%)$ & $6(3.0 \%)$ & $7(2.9 \%)$ \\
To keep up with technology & - & $4(2.0 \%)$ & $4(1.7 \%)$ \\
Other & $5(13.5 \%)$ & $10(5.0 \%)$ & $15(6.3 \%)$ \\
\hline
\end{tabular}

Table 3. Eden-Walker - All motivations for adopting a wearable.

\begin{tabular}{llll}
\hline Motivation & $\begin{array}{l}\text { Former } \\
(\mathbf{n = 4 7 )} \boldsymbol{n}\end{array}$ & $\begin{array}{l}\text { Current } \\
\mathbf{( n = 1 8 6 )} \boldsymbol{n}\end{array}$ & $\begin{array}{l}\text { Total } \\
(\mathbf{(} \mathbf{\%}=\mathbf{2 3 3}) \boldsymbol{n}(\mathbf{\%})\end{array}$ \\
\hline Monitor activities & $28(59.5 \%)$ & $154(82.7 \%)$ & $182(78.1 \%)$ \\
Improve fitness & $26(55.3 \%)$ & $130(69.8 \%)$ & $156(66.9 \%)$ \\
Improve health & $22(46.8 \%)$ & $121(65 \% \%)$ & $143(61.3 \%)$ \\
Improve appearance & $10(21.2 \%)$ & $42(22.5 \%)$ & $52(22.3 \%)$
\end{tabular}




\begin{tabular}{llll} 
Compete with family \& friends & $7(14.8 \%)$ & $45(24.1 \%)$ & $52(22.3 \%)$ \\
To keep up with technology & $11(23.4 \%)$ & $62(33.3 \%)$ & $73(31.3 \%)$ \\
Other & $8(17 \%)$ & $26(13.9 \%)$ & $34(14 \%)$ \\
\hline
\end{tabular}

As we saw from Table 2 and Table 3, respondents across both studies wanted to 'monitor activities' 'improve fitness', and 'improve health' as their top 3 motivations for tracking. We do have to note that the sample size for former users and current users are not equal. Only $20 \%$ of the total respondents were former users. However, based on the numbers we can see that current users report a greater motivation to 'monitor activities', 'improve fitness', and' improve health' than those who abandon their device.

One difference in our data with Maher et al. is that of 'wanting to keep up with technology'. Maher et al. found that the 'wanting to keep up with technology' was not a main reason for adopting a tracker, yet we found that it was a factor for $31.3 \%$ of total respondents, yet more so for current users (33.3\%) than former users $(23.4 \%)$. As the literature suggests, some users will adopt if they are interested in technology (S. Y. Lee \& Lee, 2018). Perhaps people who stop using their device are not as motivated by technology. The challenge then is to ensure they derive benefit from the technology.

\subsubsection{Complaints About WFTs}

Complaints are important because they give insight into what barriers exist to adoption and continued use. We aligned our data next to Maher et al. for comparison (See Table 4). As seen in Table 4, a similar number of people had no complaints about their wearable tracker. Likewise, 'low battery life' continues to be an issue as the biggest complaint at comparable levels with Maher et al. 'Problems uploading data' dropped in our study from $19 \%$ in Maher et al. to only $7.6 \%$ in our study. Another notable difference is 
that more combined users and former users complained that their tracker is uncomfortable, up to $16.3 \%$ from $8.4 \%$. What is particularly noteworthy is that $34 \%$ of former users complained the device was uncomfortable and was the top complaint in our study. This is noteworthy because this is a user experience issue that prevents users from fully benefiting from the device. What is also notable to us for this study is that the complaints about problems interpreting data remained low with only $4.7 \%$ of total respondents for us versus $4.2 \%$ for Maher et al.

Table 4. Comparison of complaints with Eden-Walker and Maher et al. with raw numbers and \% in parentheses

\begin{tabular}{|c|c|c|c|c|c|c|}
\hline \multirow[b]{2}{*}{ Complaints } & \multicolumn{3}{|c|}{ Eden-Walker } & \multicolumn{3}{|c|}{ Maher et al. } \\
\hline & Former $(n=47)$ & Current $(\mathrm{n}=186)$ & Total $(n=233)$ & Former $(n=37)$ & Current $(n=200)$ & Total $(n=237)$ \\
\hline None & $15(31.9 \%)$ & $57(31.1 \%)$ & $72(30.9 \%)$ & $6(16.2 \%)$ & $65(32.5 \%)$ & $71(30 \%)$ \\
\hline Low Battery life & $8(17 \%)$ & $38(20.7 \%)$ & $46(19.7 \%)$ & $11(29.7 \%)$ & $37(18.5 \%)$ & $48(20 \%)$ \\
\hline $\begin{array}{l}\text { Problems uploading data } \\
\text { to supporting software }\end{array}$ & $2(4.2 \%)$ & $12(6.5 \%)$ & $14(7.6 \%)$ & $11(29.7 \%)$ & $34(17 \%)$ & $45(19 \%)$ \\
\hline $\begin{array}{l}\text { Does not go with my } \\
\text { outfit }\end{array}$ & $9(19.1 \%)$ & $27(14.7 \%)$ & $36(15.4 \%)$ & $6(16.2 \%)$ & $38(19 \%)$ & $44(18.6 \%)$ \\
\hline $\begin{array}{l}\text { Inaccurate at recording } \\
\text { data }\end{array}$ & $10(21.2 \%)$ & $32(17.4 \%)$ & $42(18 \%)$ & $6(16.2 \%)$ & $33(16.5 \%)$ & $39(16.5 \%)$ \\
\hline General wear and tear & $5(10.6 \%)$ & $31(16.9 \%)$ & $36(15.4 \%)$ & $8(21.6 \%)$ & $24(12 \%)$ & $32(13.5 \%)$ \\
\hline Technical issues & $6(12.7 \%$ & $18(9.8 \%)$ & $24(10.3 \%)$ & $6(16.2 \%)$ & $23(11.5 \%)$ & $29(12.2 \%)$ \\
\hline Uncomfortable & $16(34 \%)$ & $22(12 \%)$ & $38(16.3 \%)$ & $6(16.2 \%)$ & $14(7 \%)$ & $20(8.4 \%)$ \\
\hline Falls off & $2(4.2 \%)$ & $5(2.7 \%)$ & $7(3 \%)$ & $8(21.6 \%)$ & $9(4.5 \%)$ & $17(7.2 \%)$ \\
\hline $\begin{array}{l}\text { Problem navigating } \\
\text { supporting } \\
\text { website/technology }\end{array}$ & $0(0 \%)$ & $9(4.9 \%)$ & $9(3.8 \%)$ & $2(5.4 \%)$ & $14(7 \%)$ & $16(6.8 \%)$ \\
\hline Other & $8(17 \%)$ & $26(14.2 \%)$ & $34(14.6 \%)$ & $2(5.4 \%)$ & $12(6 \%)$ & $14(5.9 \%)$ \\
\hline Problems with the screen & $2(4.2 \%)$ & $4(2.1 \%)$ & $6(2.5 \%)$ & $3(8.1 \%)$ & $7(3.5 \%$ & $10(4.2 \%)$ \\
\hline Problem interpreting data & $2(4.2 \%)$ & $9(4.9 \%)$ & $11(4.7 \%)$ & $3(8.1 \%)$ & $7(3.5 \%)$ & $10(4.2 \%)$ \\
\hline
\end{tabular}




\subsubsection{Reasons for abandonment}

While complaints present a barrier to a good user experience, they alone do not guarantee abandonment since users can still benefit from devices that have poor battery lives, for example. Maher et al. specifically asked their respondents for the reasons why they abandoned their device, and so did we. We wanted to see if there has been any change in reasons for abandonment in 2019 with 2016. Table 5 outlines the reasons for abandonment.

Table 5. Comparison of reasons for abandonment between the two studies. Respondents could tick multiple options that applied to them.

\begin{tabular}{|l|l|l|}
\hline Reasons for abandonment. & Eden-Walker $(\mathbf{n}=\mathbf{4 7})$ & Maher et al. (n=37) \\
\hline Was not helping with goals & 13 & 5 \\
\hline Did not like it & 10 & 2 \\
\hline It broke & 6 & 8 \\
\hline $\begin{array}{l}\text { Did not know what to do with the } \\
\text { data }\end{array}$ & 5 & - \\
\hline Got lost & 5 & 4 \\
\hline Technical difficulties & 5 & 4 \\
\hline I learnt everything I could & 3 & 11 \\
\hline Could not interpret data & 2 & - \\
\hline I found it intrusive & 2 & 3 \\
\hline Was worried it would break & 2 & 2 \\
\hline Forgot to charge it & & 4 \\
\hline
\end{tabular}




\begin{tabular}{|c|c|c|}
\hline $\begin{array}{l}\text { Experiencing negative } \\
\text { psychological impact }\end{array}$ & & 3 \\
\hline Inconvenient & & 2 \\
\hline $\begin{array}{l}\text { Forgot to turn it on after taking it } \\
\text { off }\end{array}$ & & 2 \\
\hline Information was not important & & 2 \\
\hline Work & & 2 \\
\hline Annoying to charge & & 1 \\
\hline Became too dependent & & 1 \\
\hline Band continuously came undone & & 1 \\
\hline Limited functionality & 2 & 1 \\
\hline $\begin{array}{l}\text { It turned exercise into a chore. I } \\
\text { enjoyed it less. }\end{array}$ & 1 & - \\
\hline $\begin{array}{l}\text { Haven't used a watch or anything } \\
\text { in my wrists in years so I got tired } \\
\text { of having to wear it. }\end{array}$ & 1 & \\
\hline It was difficult to understand & 1 & 2 \\
\hline Stopped exercising as much & 1 & \\
\hline caused wrist irritation & 1 & \\
\hline $\begin{array}{l}\text { Knew I wouldn't really have the } \\
\text { time/availability to improve my } \\
\text { exercise/sleeping habits due to } \\
\text { school. }\end{array}$ & 1 & \\
\hline
\end{tabular}

For our study, the top reason former users stopped tracking was the device was not helping them with their goals, whereas Maher et al. found that participants stopped tracking because they had learnt everything they could. Two other common answers were "they did not like it" and "it broke." They did not like it is vague and needs further inquiry to find out what exactly these former users did not like about their device. 
Our research wanted to identify problems interpreting and making sense of data and found that the $4^{\text {th }}$ most reason given was "Did not know what to do with the data". In this case, it seems the former users could understand and read the data but did not know how to make adjustments or improve that health component. Whereas 2 additional users reported they stopped using the device in part because they could not interpret the data, illustrating that they could not even gain insight from the data.

This does differ from Maher et al. who did report 2 responses that former users abandoned because "It was difficult to understand". It is not clear what exactly was difficult, though it may refer to the data or data visualizations. It may refer to following instructions, or some other reason so, we wanted to explore data interpretation even further, which we do in the next subsection.

\subsubsection{Part 2: 4 Categories}

In this section, we no longer compare our data with Maher et al., as this stage represents unique data generated by our study. We report our data by dividing data into 4 categories. We divided 'former users' and 'current users' and separated further by fitness level into 'low fitness' and 'high fitness'. As the literature suggests, fitness trackers are more commonly purchased by those who are already fit (Piwek et al., 2016). The assumption is those with a higher fitness level are more interested in physiological data, and more literate from a physical and health point of view. We grouped those who responded with a 1 or 2 into a Low Fitness category, while those who selected 3 or 4 into a High Fitness category (See Table 6.) This scale enabled us to avoid answers in the middle and provide an opportunity to investigate whether fitness levels have an impact on 
abandonment as well as interpretation of data. We do acknowledge there is a limitation to this scale, as it is possible respondents have confusion on how to compare themselves to other people. Depending on whether they are comparing themselves to a professional athlete or just a really fit friend of theirs may have influenced their decision.

Therefore

LFFU $=$ Low Fitness Former Users and HFFU $=$ High Fitness Former Users, LFCU $=$ Low Fitness Current Users and HFCU $=$ High Fitness Current Users.

Table 6. Number of respondents broken down by fitness level

\begin{tabular}{|c|c|c|}
\hline Fitness Level & Current Users $(\mathrm{n}=186)$ & Former Users $(\mathrm{n}=47)$ \\
\hline 1 & $9(4.8 \%)$ & $5(10 \%)$ \\
\hline 2 & $52(27.9 \%)$ & $22(46.8 \%)$ \\
\hline 3 & $94(50.5 \%)$ & $12(25.5 \%)$ \\
\hline 4 & $31(16.6 \%)$ & $8(17 \%)$ \\
\hline
\end{tabular}

\subsubsection{Data Literacy and Data interpretation}

As was mentioned earlier, the literature shows that some people struggle to make sense of the data (Lazar et al., 2015; Rapp \& Cena, 2016). We wanted to investigate how well users believed they could interpret data and whether they were able to make sense of it, to display a sense of 'data literacy' and if there are any differences between LFFUs, HFFUs, LFCUs, and HFCUs. As mentioned earlier, the definition of data literacy that I have chosen for this thesis is defined as: 
"the ability to understand and use data effectively to inform decisions...skills include knowing how to identify, collect, organize, analyze, summarize and prioritize data. They also include how to develop hypotheses, identify problems, interpret the data, and determine, plan, implement, and monitor courses of action" (Mandinach \& Gummer, 2013)

Therefore, we first asked respondents how well they believe they can understand graphs, but also how well they can and then plan a course of action based on the results, as being data literate is not just about being able to interpret data, but also act on it in meaningful ways. As we can see in Error! Reference source not found., Figure 12, while all groups agree that they can understand graphs well, they agree slightly less that they can plan a course of action.

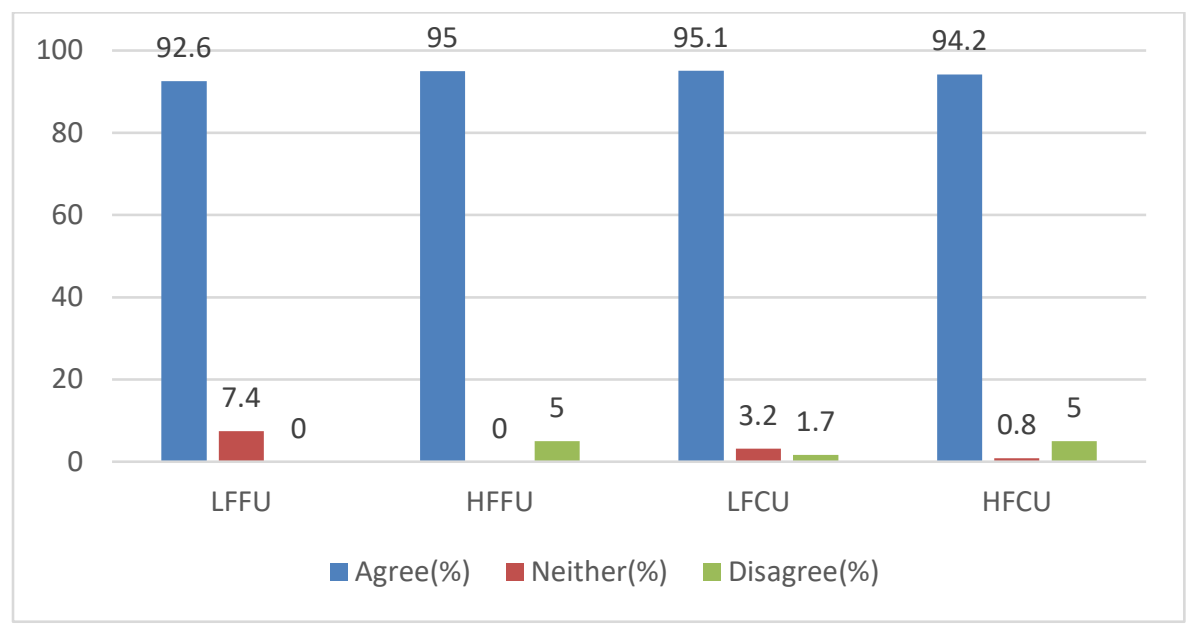

Figure 11. "I can understand graphs well" 


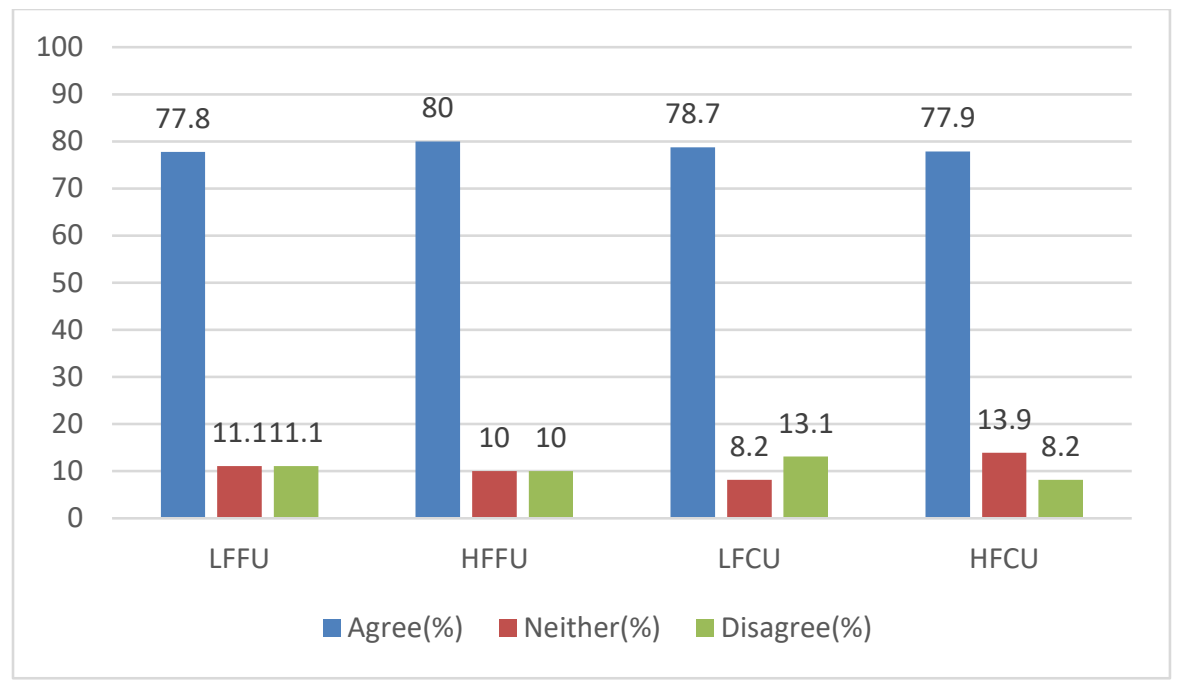

Figure 12. "I can plan a course of action based on the results"

While the difference between Error! Reference source not found. and Figure 12 is small, we asked respondents if they had trouble interpreting data from a WFT and if they had trouble deciding what to do with that data and we found stronger results (Figure 13 and Figure 14). Here, respondents continued to report having little trouble with data, but in Figure 14 we see that for LFFUs more respondents agreed (48\%) than disagreed (41\%), whereas for HFCU the opposite was true with $21 \%$ agreeing to $57 \%$ disagreeing. This suggests the HFCUs are able to make the most sense of the data, while LFFUs are able to make the least sense. 


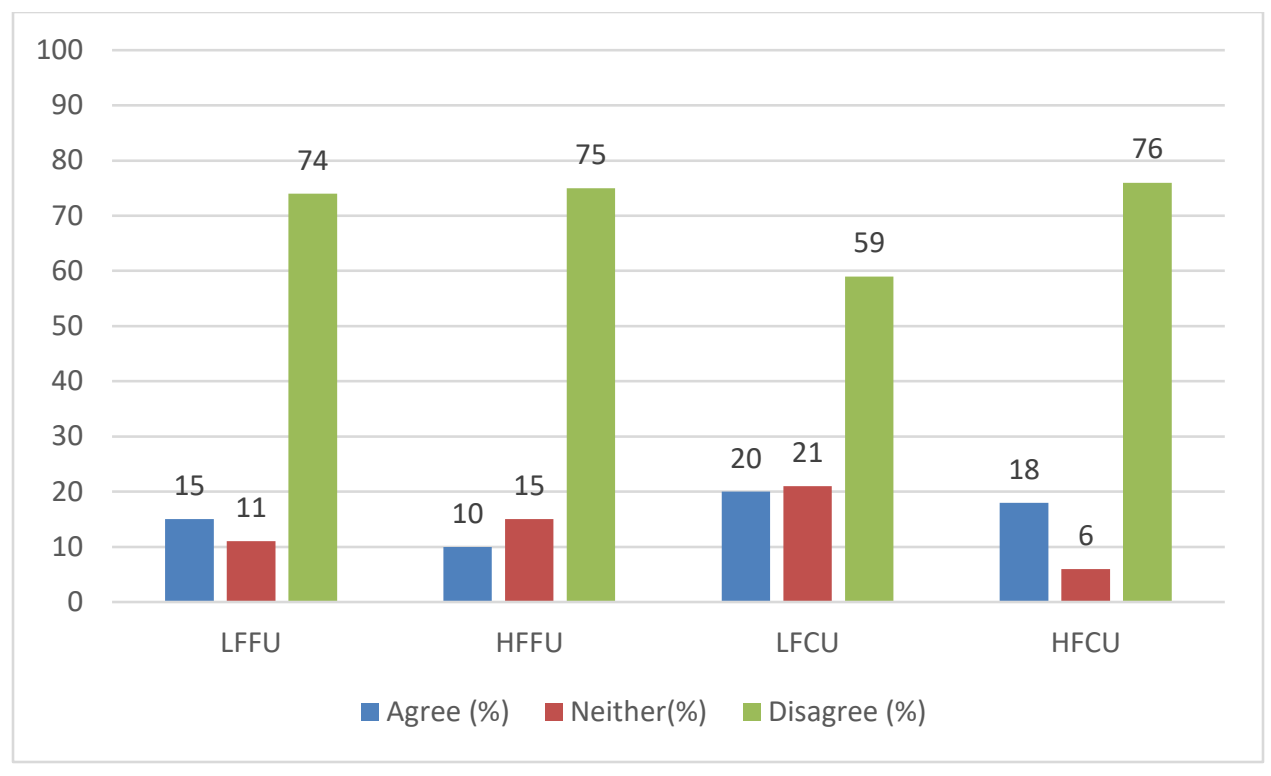

Figure 13. "I have had trouble interpreting the data generated by a fitness tracker"

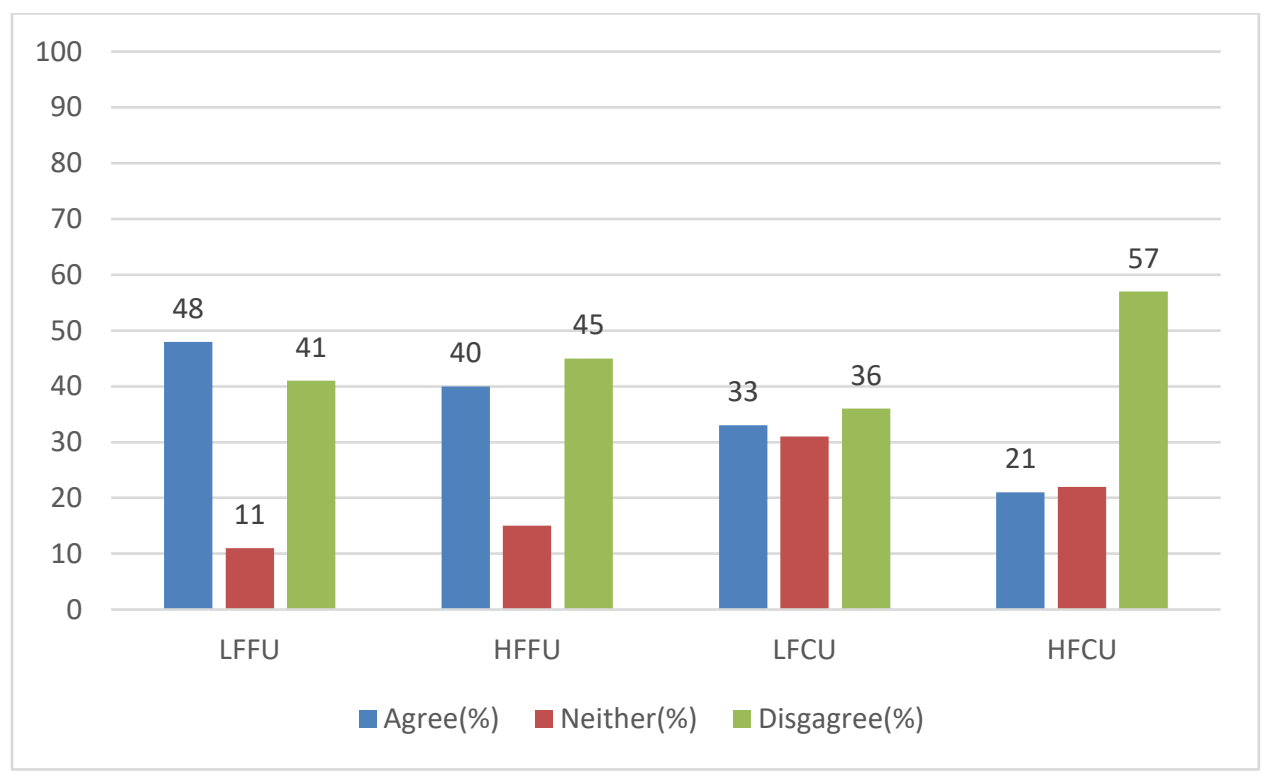

Figure 14. " I have had trouble deciding what to do with the data generated"

We wanted to know what data or visualization users and former users had trouble interpreting so we asked respondents to provide examples of what exactly they struggled, 
if any. Table 7 summarizes with examples of what was challenging, noting that they had insufficient subject domain knowledge, and insufficient direct support to make sense of terminology, visualizations, and metrics. They also expressed that they did not know what to do with the data.

Table 7. If you had trouble understanding or interpreting data, what did you have trouble with?

\begin{tabular}{|l|l|l|}
\hline \multicolumn{1}{|c|}{ Theme } & Example \\
\hline $\begin{array}{l}\text { Insufficient } \\
\text { subject } \\
\text { domain } \\
\text { knowledge }\end{array}$ & $\begin{array}{l}\text { - } 115 \text { "Cadence - what it should be and what the colours indicate?" } \\
\text { - S233 "Understanding fitness vocabulary! I've had to look up for example } \\
\text { what cadence is and what it meant and why it was measured." }\end{array}$ \\
\hline $\begin{array}{l}\text { What to do } \\
\text { - }\end{array}$ & $\begin{array}{l}\text { S150 "How to interpret VO2 max?" } \\
\text { understand Swolf. In running I know my cadence and vertical ratio aren't } \\
\text { good but don't know what to do with the information." }\end{array}$ \\
\hline $\begin{array}{l}\text { - } \\
\text { next? }\end{array}$ & $\begin{array}{l}\text { S149 "I close rings, but what do I do with the data." } \\
\text { calories, in minutes. I don't know what to do with the heart rate that }\end{array}$ \\
cadence none of that information"
\end{tabular}


We asked respondents for their beliefs and perceptions about their ability to interpret graphs, but we also wanted to verify their beliefs by providing an opportunity to interpret a data visualization of heart rate data. Heart rate data is a key health metric that trackers can measure. We asked respondents if they find the heart rate measure helpful to them and report the findings in Figure 15. For all categories, over 75\% agree that heart rate is helpful.

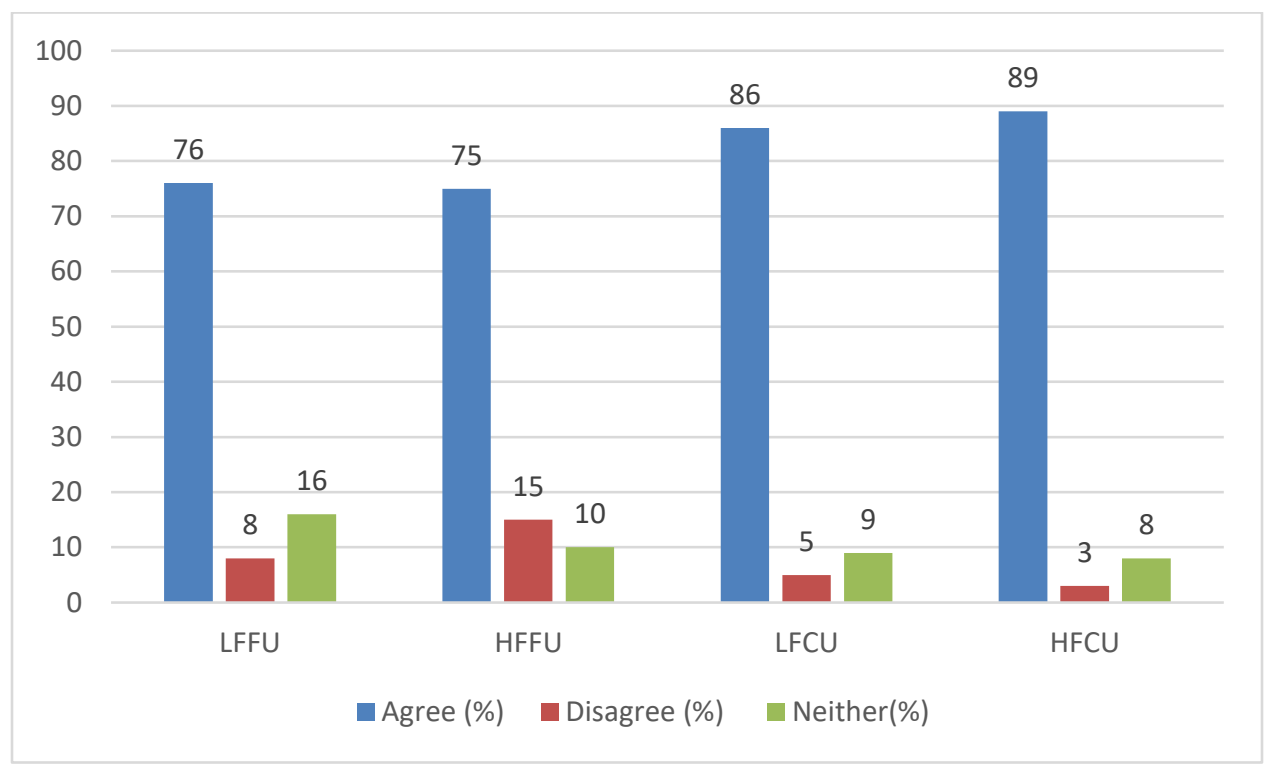

Figure 15. "I find the following measure on my wearable helpful...heart rate."

The respondents report being able to understand graphs well and that heart rate data is valuable, and we gave them an opportunity to interpret some heart rate data for us. We included Figure 10 in our survey and asked respondents to look at the heart rate data and tell us what they could understand and what they might do with the data. We received a variety of interpretations and created 6 categories of responses to best suit the kind of 
answer. They are shown in Table 8 . We grouped the responses into the 4 categories displayed in Table 9, Table 10, Table 11, and Table 12.

Table 8 Categories of responses to the heart rate graph

\begin{tabular}{|l|l|}
\hline Category of response & Definition \\
\hline Medical situation & $\begin{array}{l}\text { These answers directly mentioned that the person should see a } \\
\text { doctor / specialist and that something was wrong }\end{array}$ \\
\hline $\begin{array}{l}\text { Basic Reading / } \\
\text { Incomplete } \\
\text { interpretation }\end{array}$ & $\begin{array}{l}\text { These answers were either a superficial reading of the data or } \\
\text { they lacked a sense of urgency and did not mention acting on } \\
\text { the data. }\end{array}$ \\
\hline Restless / Active & $\begin{array}{l}\text { These answers mentioned that the man must have been } \\
\text { exercising, could not sleep, or was enjoying himself through } \\
\text { alcohol or intimacy }\end{array}$ \\
\hline Nightmare & $\begin{array}{l}\text { These answers mentioned intense dreams or nightmares as the } \\
\text { cause of the high heart rate }\end{array}$ \\
\hline $\begin{array}{l}\text { Do not know what to } \\
\text { do with data }\end{array}$ & $\begin{array}{l}\text { These answers specifically mentioning not knowing how to } \\
\text { use this data, either because they do not know heart rate data } \\
\text { or what the data means. }\end{array}$ \\
\hline $\begin{array}{l}\text { Did not show } \\
\text { understanding }\end{array}$ & $\begin{array}{l}\text { These answers showed their interpretation was wrong (i.e., } \\
\text { this is healthy) or they could not make any sense of it, }\end{array}$ \\
\hline
\end{tabular}

Table 9. LFFUs interpretation of the heart rate graph (\% in parentheses)

\begin{tabular}{|l|l|l|}
\hline Category of response & $\mathrm{N}=25$ & Example \\
\hline Medical situation & $3(12 \%)$ & $\begin{array}{l}\text { (S8) This person may be suffering from sleep apnea } \\
\text { with such a huge spike in heart rate during his sleep. }\end{array}$ \\
\hline $\begin{array}{l}\text { Basic Reading / Incomplete } \\
\text { interpretation }\end{array}$ & $5(20 \%)$ & $\begin{array}{l}\text { (S15) Min heart rate is 49, max is 121 and average } \\
\text { between those. It helps indicate strain heart may be } \\
\text { under. }\end{array}$ \\
\hline Restless / Active & $7(28 \%)$ & $\begin{array}{l}\text { (S21) He slept poorly Friday night, probably tossing } \\
\text { and turning }\end{array}$ \\
\hline Nightmare & $4(16 \%)$ & $\begin{array}{l}\text { (S33) He didn't have a sound sleep in the last 3 days. } \\
\text { He seemed to have a nightmare in Friday. }\end{array}$ \\
\hline $\begin{array}{l}\text { Do not know what to do with } \\
\text { data }\end{array}$ & $2(8 \%)$ & $\begin{array}{l}\text { (S27) I can understand that the red lines show the } \\
\text { heart rate while minutes are shown on the right side. I } \\
\text { am not sure what to do with the data. }\end{array}$ \\
\hline Did not show understanding & $4(16 \%)$ & (S28) This person has a normal heart rate \\
\hline
\end{tabular}

Table 10. HFFUs interpretation of heart rate graph (\% in parentheses)

\begin{tabular}{|l|l|l|}
\hline Category of response & $\mathrm{N}=20$ & Example \\
\hline Medical situation & $1(5 \%)$ & $\begin{array}{l}\text { (S46) He has a high resting pulse and should probably } \\
\text { consult a physician. It could be normal for him, but }\end{array}$ \\
\hline
\end{tabular}




\begin{tabular}{|l|l|l|}
\hline & & $\begin{array}{l}\text { seems awfully high. The dip to 49 would seem normal } \\
\text { for many people but seems like something to monitor } \\
\text { for him. Is it an anomaly or a recurring pattern that } \\
\text { might be a sign. }\end{array}$ \\
\hline $\begin{array}{l}\text { Basic Reading / Incomplete } \\
\text { interpretation }\end{array}$ & $7(35 \%)$ & $\begin{array}{l}\text { (S37) This data tells us about heart rate, resting rate, } \\
\text { and gives statistics of particular days of our activity. }\end{array}$ \\
\hline Restless / Active & $3(15 \%)$ & $\begin{array}{l}\text { (S9) His HR should be at resting, level so he was not } \\
\text { resting. 121 BPM is not resting }\end{array}$ \\
\hline Nightmare & $1(5 \%)$ & $\begin{array}{l}\text { (S25) His heart rate was high overnight on Friday. I } \\
\text { might ask what he was doing before he went to bed on } \\
\text { Friday that caused his heart rate to go so high, or what } \\
\text { happened overnight, maybe he had a bad dream. I } \\
\text { might ask him to compare with sleep satisfaction } \\
\text { scores }\end{array}$ \\
\hline $\begin{array}{l}\text { Do not know what to do with } \\
\text { data }\end{array}$ & $7(35 \%)$ & $\begin{array}{l}\text { (S44) Max and min heart rates recorded through the } \\
\text { week, every night. No idea of what can be done } \\
\text { though. Don't even know if it is correct or incorrect. }\end{array}$ \\
\hline Did not show understanding & $1(5 \%)$ & $\begin{array}{l}\text { (S17) You can see that his heart rate is in a healthy } \\
\text { range. }\end{array}$ \\
\hline
\end{tabular}

Table 11. LFCUs interpretation of heart rate graph (\% in parentheses)

\begin{tabular}{|l|l|l|}
\hline Category of response & $\mathrm{N}=55$ & Example \\
\hline Medical situation & $15(27.3 \%)$ & $\begin{array}{l}\text { (S193) Contact a physician as a resting sleeping heart } \\
\text { rate of 121 BPM is dangerous }\end{array}$ \\
\hline $\begin{array}{l}\text { Basic Reading / Incomplete } \\
\text { interpretation }\end{array}$ & $17(31 \%)$ & $\begin{array}{l}\text { (S166) His heart rate reached its lowest on } \\
\text { Wednesday, and highest on Friday. To plan better } \\
\text { sleeping times. }\end{array}$ \\
\hline Restless / Active & $6(11 \%)$ & $\begin{array}{l}\text { (S129) Man must have consumed alcohol, late night } \\
\text { parties which resulting in higher heart rate while } \\
\text { sleeping. Next he must have a good rest to lower } \\
\text { down his HR }\end{array}$ \\
\hline Nightmare & $7(12.7 \%)$ & $\begin{array}{l}\text { (S152) Man may have had a nightmare on Friday } \\
\text { night }\end{array}$ \\
\hline $\begin{array}{l}\text { Do not know what to do with } \\
\text { data }\end{array}$ & $4(7 \%)$ & $\begin{array}{l}\text { (S77) Heart rate range during sleep. Not sure what to } \\
\text { do with the data though }\end{array}$ \\
\hline Did not show understanding & $6(11 \%)$ & (S101) Gets roughly same amount of sleep a night. \\
\hline
\end{tabular}

Table 12. HFCUs interpretation of heart rate graph (\% in parentheses)

\begin{tabular}{|l|l|l|}
\hline Category of response & $\mathrm{N}=112$ & Example \\
\hline Medical situation & $20(17.8 \%)$ & $\begin{array}{l}\text { (S162) Not resting. Fix that. Make a dr. } \\
\text { appointment. Sleeping heart rate is high. }\end{array}$ \\
\hline $\begin{array}{l}\text { Basic Reading / Incomplete } \\
\text { interpretation }\end{array}$ & $28(25 \%)$ & $\begin{array}{l}\text { (S123) His average resting hr during sleep is about } \\
\text { 75. And his high is 121. Lowest is 49 }\end{array}$ \\
\hline Restless / Active & $24(21.4 \%)$ & $\begin{array}{l}\text { (S130) Friday's sleep appears to be quite restless. } \\
\text { High HR during sleep might indicate poor sleep } \\
\text { performance. }\end{array}$ \\
\hline
\end{tabular}




\begin{tabular}{|l|l|l|}
\hline Nightmare & $11(0.9 \%)$ & $\begin{array}{l}\text { (S231) I'd say either he awoke and needed the } \\
\text { bathroom (hence the accelerated heart rate) or had a } \\
\text { nightmare? }\end{array}$ \\
\hline $\begin{array}{l}\text { Do not know what to do with } \\
\text { data }\end{array}$ & $17(15.1 \%)$ & $\begin{array}{l}\text { (S195) I see what my heart rate zone is while } \\
\text { sleeping. I don't know how I would use the data. }\end{array}$ \\
\hline Did not show understanding & $12(10.7 \%)$ & $\begin{array}{l}\text { (S88) This chart seems confusing to me...I have no } \\
\text { idea }\end{array}$ \\
\hline
\end{tabular}

As we can see throughout the tables, there were a variety of interpretations, incomplete readings, and wrong interpretations based on the fact that this real data is showing a man having a heart attack (Hall, 2017) as explained in Figure 10. Of the total responses $(\mathrm{n}=216), 17.1 \%$ explicitly identified in their response that the data indicated a medical situation. LFCUs showed the highest ability to detect a medical situation with $27.3 \%$, and HFFUs showed the lowest ability at $5 \%$. This suggests that heart rate data interpretation is a complex phenomenon. It may also mean that survey respondents needed to know more about the context of the situation in order to make a more accurate interpretation.

However, it also suggests that the majority of all respondents, including the man in the story do not easily recognize danger, or are more prone to explain it away as nothing to be concerned about, or device error. For example, S207 said "it's pretty unrealistic data". Or S158 said, "maybe a data error on Saturday night." From the story of the heart attack, the surgeon at the hospital who treated the man having the heart attack said that if the man had ignored the Apple Watch alert and gone back to bed, he probably would have died in his sleep. This suggests that in general the survey respondents and the man are showing a limited sense of 'data literacy'. While the man ultimately did go to the hospital, displaying some data literacy, his initial reaction was to question the warning 
and admitted that while waiting in the emergency room felt that he was wasting time and money (Hall, 2017).

\subsubsection{Steps to Ensure Device Understanding}

Since some users skip the onboarding process that often contains information for how to understand the device as well as troubleshoot, we decided to ask them if they were prepared for the data. We asked them if they 1) read the manual, 2) had someone show them how to use it, and/or 3) watched a tutorial. Results are in Figure 16, Figure 17, and Figure 18.

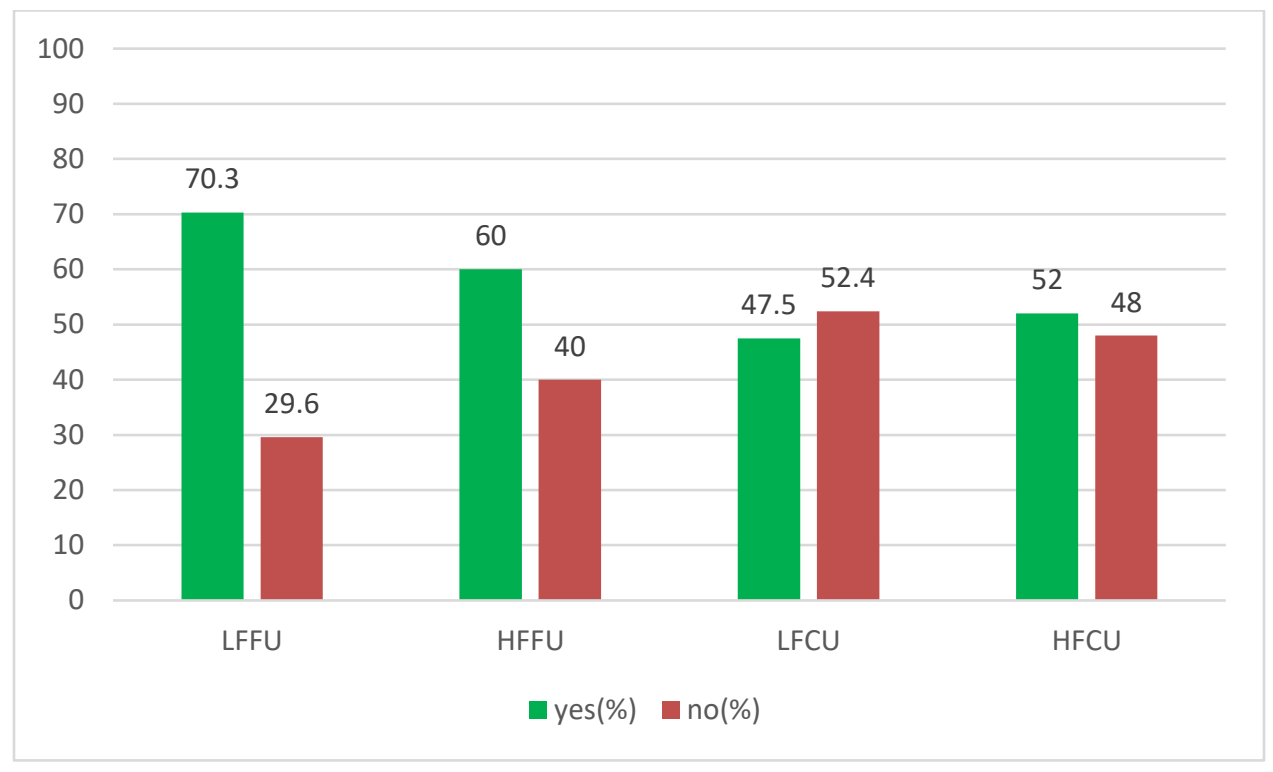

Figure 16. Before using the WFT did you read the manual?

When asked if they read the manual, LFFUs had the highest rate of agreeing at $70 \%$. For both high fitness, and low fitness users, the rate is around $50 \%$. This suggests that reading the manual may not be too helpful and may explain my many appear to skip it. 


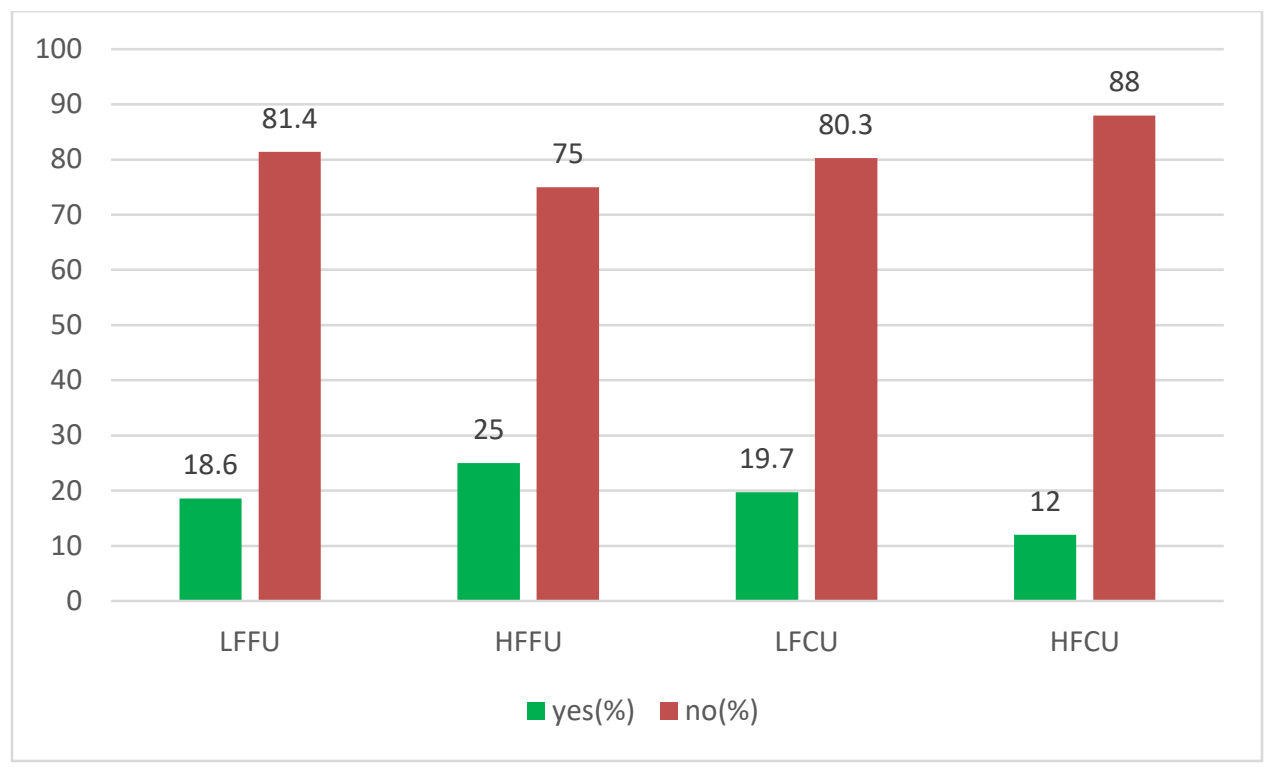

Figure 17. Before using the WFT did someone show you how to use it?

When asked if someone showed them to how use the device, we found that for all categories over $75 \%$ said they did not have someone show them how to use it. This suggests asking for help from someone, like a friend is not a popular form of getting to know a device. It also raises questions whether new users are shown how the device works when they purchase one and whether there is sufficient onboarding. 


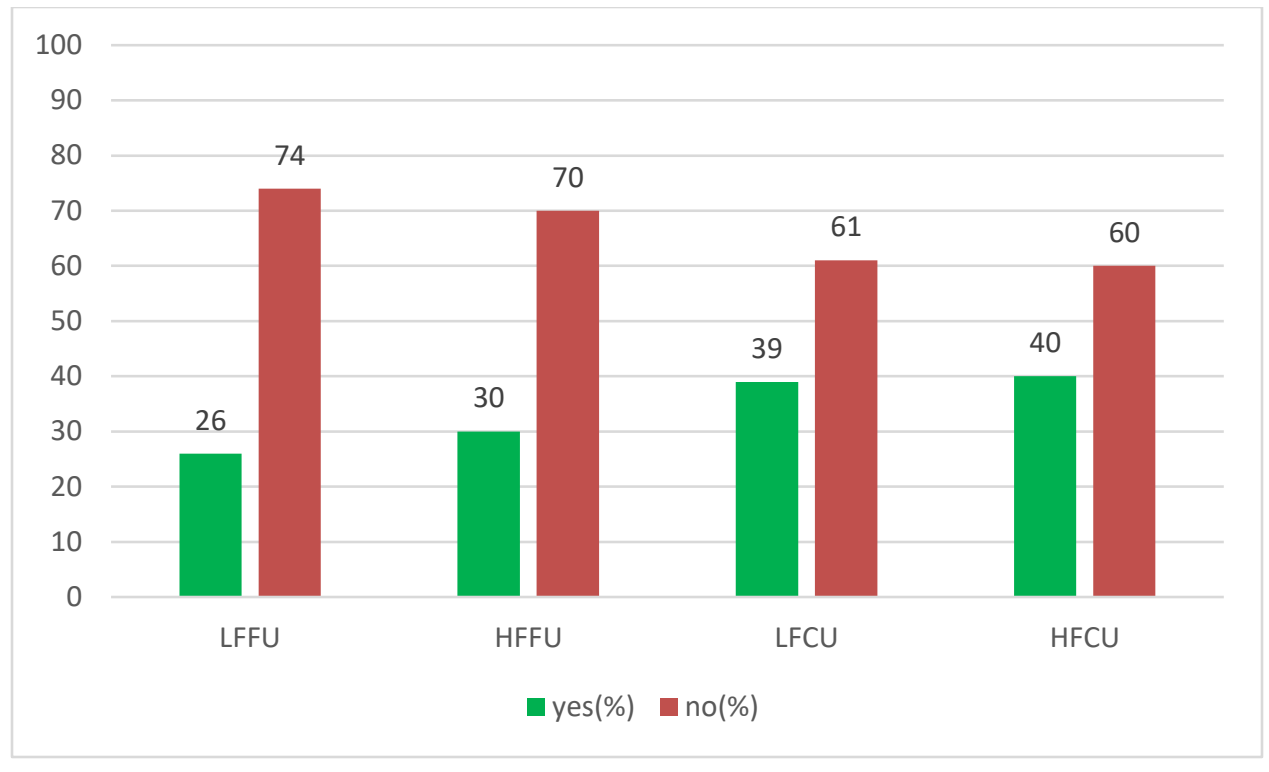

Figure 18. Before using the WFT did you watch a tutorial?

When we asked respondents whether they watched a tutorial, we found some differences. LFFUs and HFFUs show the lowest level of watching a tutorial at $26 \%$ and $30 \%$, respectively. Conversely LFCUs and HFCUs have the highest levels at 39\% and $40 \%$. This suggests that watching a tutorial may be helpful for getting to know the device and how to use the variety of features and make sense of the data.

\subsubsection{Tracking for increasing bodily awareness}

Since WFTs are providing new physiological data to the user, we wanted to know if this stimulated an interest in learning more about the body, or if it helped users with quality of movement. We also wanted to see if there was any difference between the four categories. When asked if the wearable made them feel more knowledgeable about the body, all 4 categories agreed that it did (See Figure 19). 


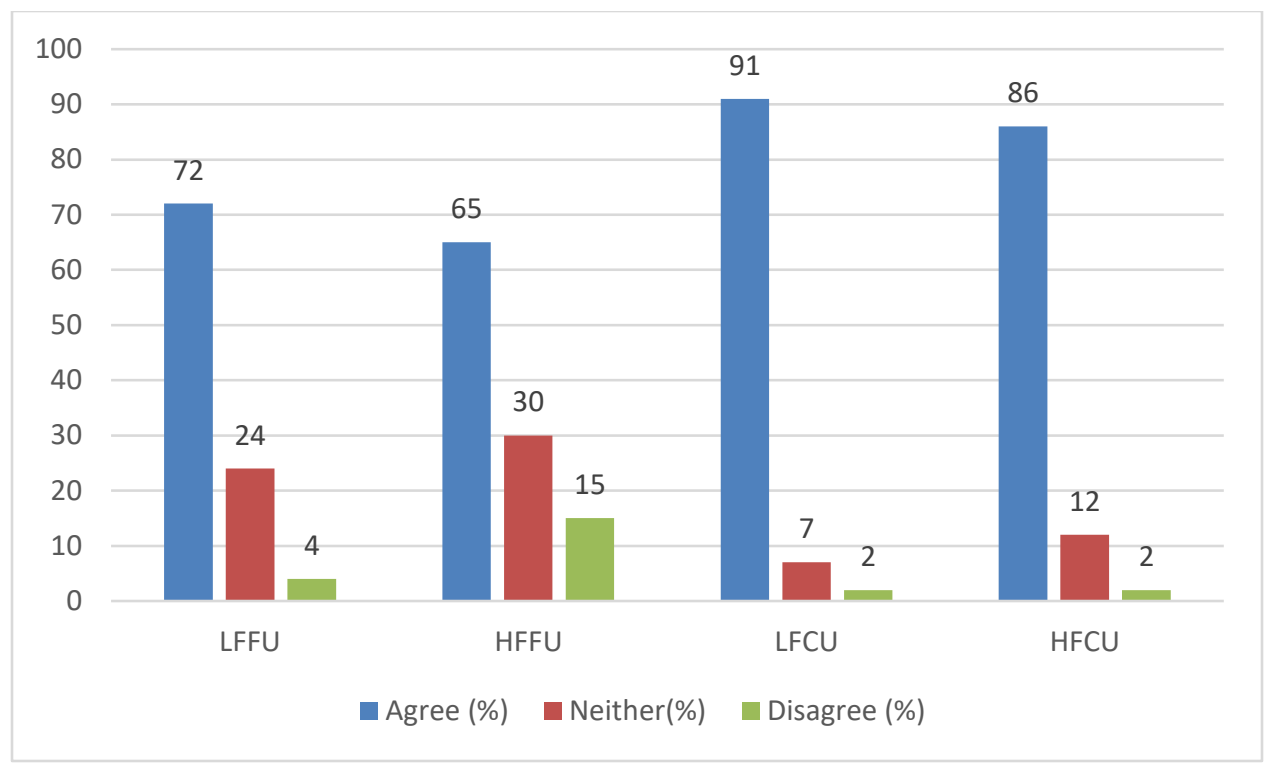

Figure 19. My experience with my wearable made me feel more knowledgeable about my body.

When asked if the wearable made them more aware of their form while they performed movements, however, there was disagreement (See Figure 20). This question sought to find out how respondents felt about whether their tracker provided insight on how they run, or their technique while performing a workout, which provides a sense of quality. In this case, LFCUs and HFCUs agreed more than LFFUs and HFFUs. This suggests that former users appeared to benefit less from how the tracker helped them with their techniques. Perhaps this a benefit that reveals itself over time, as they invest more in improving, training, and becoming healthier. 


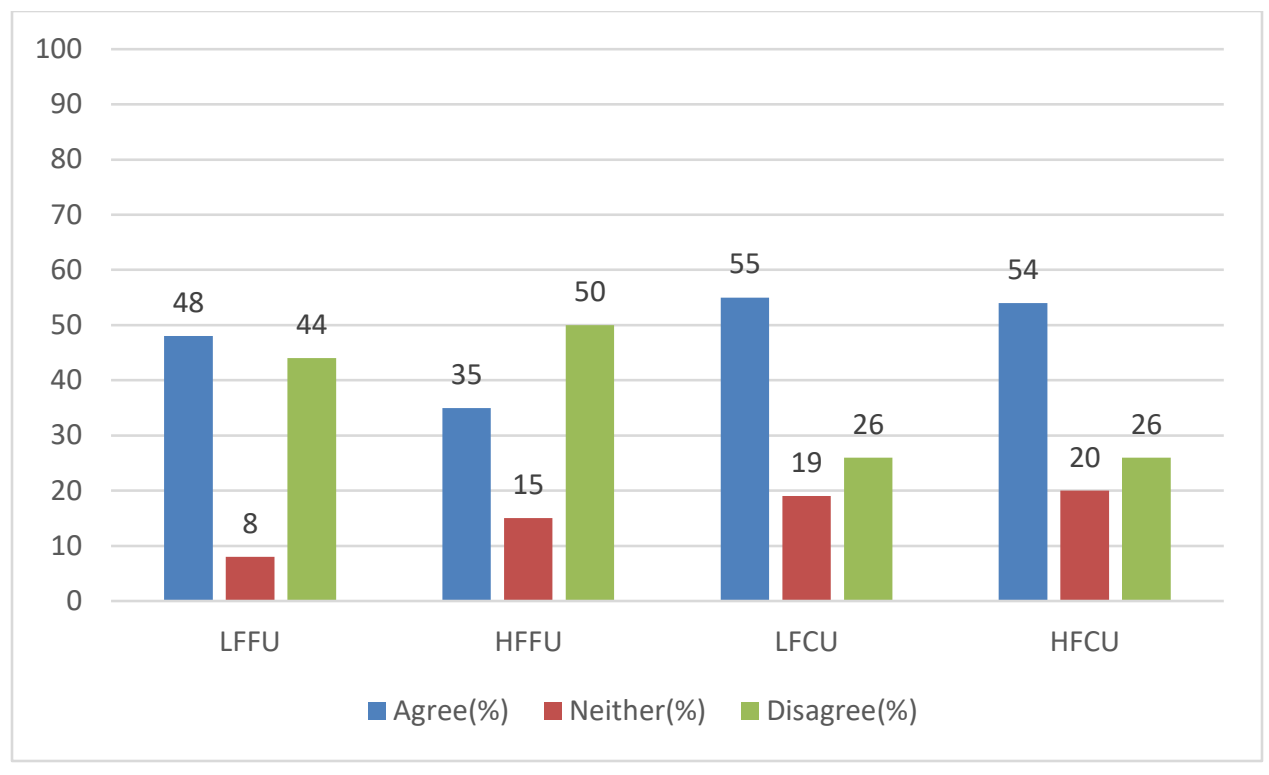

Figure 20. "My experience with the wearable made me feel more aware of my form while I perform movements."

We also asked respondents if the wearable helped influence their interest in learning about their bodies Figure 21. By wanting to learn more about their bodies, the tracker would therefore have played a role in helping them increase their bodily awareness. We found that HFCUs had the highest level with $64.3 \%$ agreeing, while LFFUs showed the lowest level at $28 \%$. This suggests further that WFTs play a role in helping users learn more about their bodies. 


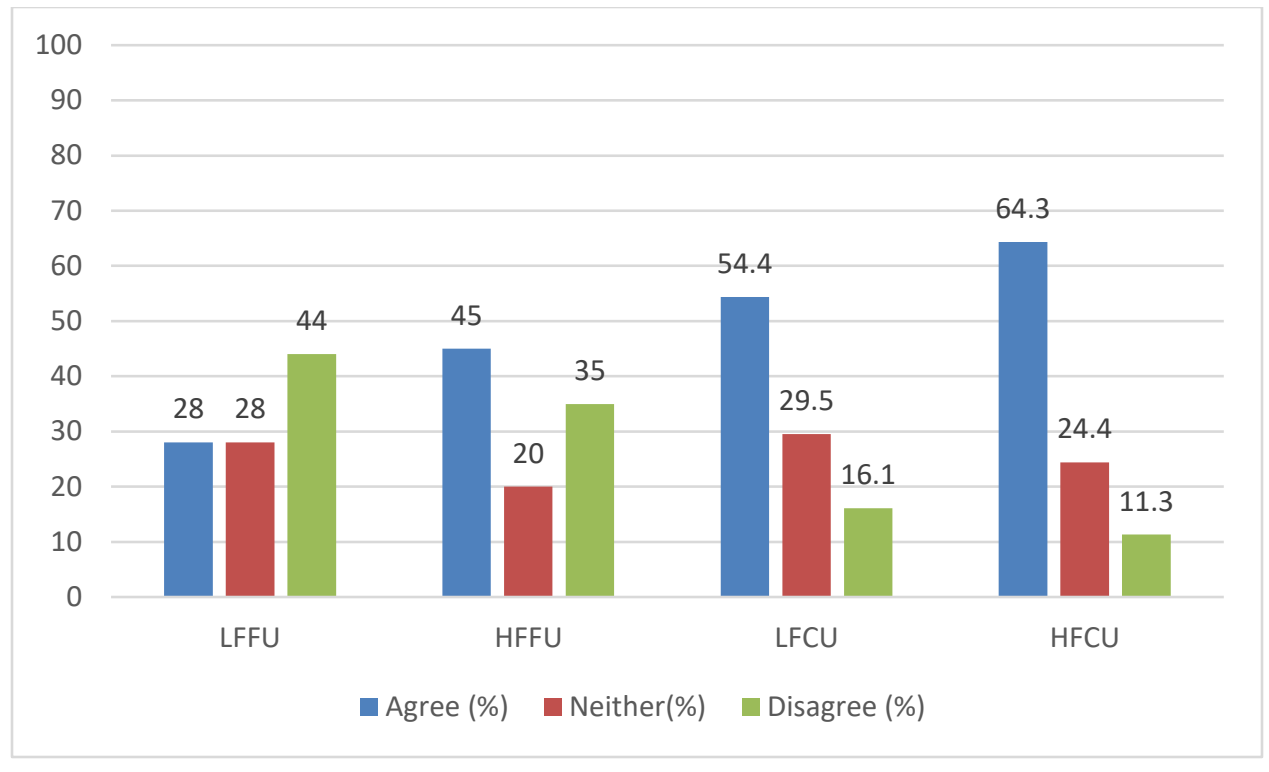

Figure 21. Since using my wearable, I now spend more time learning about my body.

\subsection{Discussion}

The survey allowed us to make a number of findings, which we discuss here. First, we summarize the key points, relate to the literature and discuss the implications based on those findings and identify questions that the findings raise. A more elaborate discussion of the points are addressed in Chapter 5 .

The first finding is that the top reasons for adopting a WFT is to monitor activities, improve fitness, and improve health as Maher et al. found. However, former users appeared less motivated to than current users. It may be easier to abandon when one is less motivated. The top reason why former users abandoned their device was because it was not helping them reach their goals.

Our results found that trackers are uncomfortable to wear, so while they may have been motivated to use the tracker, and since it was uncomfortable and not helping them reach those goals, it was time to stop wearing the tracker. We then found that former users 
reported reading the manual, but not watching a tutorial, whereas current users reported watching a tutorial, and less so reading the manual. It is possible that watching the tutorial is more engaging and helpful than the manual, which is typically text-laden and visually unappealing. Due to this, perhaps former users were not prepared for the data.

However, former users reported that they believed they were able to make sense of data in general as seen in Figure 11, but then admitted they struggled to make sense of the fitness data in Figure 13 and Figure 14. This would suggest that perhaps the context and content of data play a role in how well people can interpret data. When we tested users and former users, we found that all appeared to struggle to interpret heart rate data, despite those claims that they are able to interpret graphs well.

One thing that stood out to us was how users and formers complained of very fitness specific content. Users reported that they could not make sense of vocabulary like 'cadence', 'productivity', or VO2 Max. These terms are common in fitness circles such as competitive cycling or running where small advantages can me the difference between winning and losing a race. It seems that some of these devices are marketed for the elite user, though anyone is able to purchase one since there is no certification, or prerequisites required.

They also complained that trackers did not provide ways to improve. This is certainly an issue because if the data is not actionable, then we would argue that data is of low value, if not potentially harmful. As S21 remarked, "Telling me my sleep sucks without suggestions for improvement isn't helpful.” 


\subsubsection{Reasons for Abandonment}

One major difference reported between the two studies was on reasons for why users abandoned. In Maher's study, the top reason given was "I learnt everything I could" at $29 \%$, yet only $6.3 \%$ of users in our study chose this reason. The top reason given at $27.6 \%$ of users was "It wasn't helping with my goals" and then second reason was that they just "did not like it". This suggests a misalignment with what users are expecting and what companies are creating or marketing to users. It is possible that without proper guidance, users, especially novices are buying a tracker that does not help them. It is also possible that the goals set are not achievable with the tracker alone. There needs to be greater research into why people choose a particular tracker and whether they have unrealistic or realistic goals for that tracker. If they purchase the tracker at a store, does the salesperson explain how it can help them reach their goals? Should that individual set up an appointment to meet with a representative of Fitbit, or Apple Watch so that there is a better alignment, or is that what the manual and online forms should do?

Durability or fear of breaking the device was also reported in both our study $\left(3^{\text {rd }}\right.$ reason) and that of Maher et al. These devices can cost as low as \$25 US or upwards of $\$ 400$ US $^{6}$ which means they are an investment for many people. In combination with the finding that trackers can be uncomfortable, buying protective casings for trackers like people do with their phones is an unlikely solution. As technology advances, harder stronger materials may reduce the number of broken devices.

\footnotetext{
${ }^{6}$ https://www.pcmag.com/picks/the-best-fitness-trackers
} 


\subsubsection{Data Literacy and Interpretation}

The 4th reason provided that was noteworthy for our study was that of former users "did not know what to do with the data". 15 Respondents of the 27 we grouped into LFFUs "did not do anything with the data" while 6 of those 15 also reported not knowing what to do suggesting they were unable to make sense of the data and were low on the spectrum of literacy. As for HFFUs, only 6 of 20 "did not do anything with the data" which suggests they had more awareness of what to do with their data. This may suggest that those with high fitness are more able to make sense of physiological data because it is subject matter that they may already be familiar with, though our small sample size prevents us from being conclusive.

Looking at Figure 13 and Figure 14, we see that 74\% of LFFUs disagreed with the question "I have had trouble interpreting the data," yet only $41 \%$ disagreed with the question, "I have had trouble deciding what to do with the data", suggesting that these former users could read the data, but could not plot a course of action, which is a key component of data literacy as indicated by Mandinach et al., and Wolff et al. (Mandinach \& Gummer, 2013; Wolff \& Montaner, 2016). Furthermore, when asked to provide an example of struggling to make sense of data S21 wrote, "Telling me my sleep sucks without suggestions for improvement is not helpful". Additionally, S13 added "Data seemed inaccurate and vague, didn't know what to do with that data" illustrating that LFFUs have trouble interpreting data. 
For HFFUs, $75 \%$ disagreed that they struggle interpreting data, but only $45 \%$ disagreed that they had trouble deciding what to do with the data. This suggests that both high and low fitness former users struggle with deciding what to do with the data. For example, S46 remarked, "Visualizations too coarse, e.g. easy to see $\min /$ max heart rate hour by hour, but hard to see the actual unaggregated curve over time". This speaks to our second research question, "Do people have trouble interpreting the data generated by their wearable fitness tracker and it suggests that former users do not know what they should do. The implication is that these users need to be better supported while they use the trackers. They need recommendations and suggestions, as Lazar et al. and Meyer et al. mentioned (Lazar et al., 2015; Meyer, Beck, Wasmann, \& Boll, 2017). If devices cannot do this, then it raises the question of whether experts can help provide those kinds of suggestions.

Another interesting finding is that LFFUs have issues interpreting data, yet some users may be overestimating their literacies levels. With regards to Error! Reference source not found. and Figure 12, 92\% agreed that they can understand graphs well, as well and $78 \%$ agreed that they can plan a course of action. Yet, when given the opportunity to apply their knowledge and make sense of the heart rate data in provided in Figure 10 only 4 of 27 respondents were able to detect a cause for concern. S8 offered, "This person may be suffering from sleep apnea with such a huge spike in heart rate during his sleep.” Or S3 who said, "I would be concerned that his heart rate was so fast on Friday."

This is interesting because $76 \%$ agreed to the question "I find the heart rate measure on my wearable useful", yet they are limited in their ability to interpret the data and derive meaningful insight. The same is true for HFFUs whose results are similar with 
LFFUs. Only s46 suggested, "He has a high resting pulse and should probably consult a physician. It could be normal for him but seems awfully high. The dip to 49 would seem normal for many people but seems like something to monitor for him. Is it an anomaly or a recurring pattern that might be a sign".

It should be noted that in total, only $17 \%$ of respondents were able to correctly identify this as a medical situation requiring a consultation with a doctor. Now, the limitation for this result is that heart rate data may not be content that all users are familiar with, even though many trackers have the capability, and especially because all 4 categories agreed that the measure of heart rate is helpful (Figure 15). Also to be noted is that users of these devices are not specialists and that it may be unreasonable to expect them to interpret their data. However, in combination with the earlier results that people believe they can make sense of charts, it does suggest that people think they are more capable than they really are. This is called the Illusion of Explanatory depth (Rozenblit \& Keil, 2002) where "People feel they understand complex phenomena with far greater precision, coherence, and depth than they really do". It is perhaps more reasonable to expect users to be more careful with interpreting data, and be actively seeking our professionals who can help them make sense of their data.

It is important to be able to understand how a useful feature on WFT is often misinterpreted by users. This is especially relevant because the man in the true story also seemed to downplay the seriousness of the issue, thinking he was wasting time by going to the doctor (Hall, 2017). It is one thing to know about the usefulness of a feature, it is quite 
another to be able to interpret the meaningfulness of the feature. Therefore, this analysis provides a very important insight - as Wolff posits, "Data, itself, has little value...The value is provided through interpretation in a given context... Without data literacy, there is a risk that the data reader accepts biased interpretations of data as fact, leading to bad choices." (Wolff \& Montaner, 2016). This suggests that heart rate data, while deemed useful, is perhaps not well understood, and that goes across the fitness spectrum. It also indicates that companies need to design a better way to provide this meaningful insight. It raises the question of who is responsible for data and acting on it.

Lastly, of the 235 respondents only 4 had ever used a smart garment. S37 tried a smart suit by Samsung for sports, S113 used a 2TRACE for monitoring health while S204 used a smart vest from Hexoskin for research purposes. It appears that smart garments, like clothing and other accessories like rings are still slow to gain popularity in the market. Incidentally, a Canadian astronaut wore a Hexoskin vest while on board the International Space Station in 2019 (Chua, 2019), so greater exposure to the public may help spur interest in this market.

From the results we can see a suggestion that some respondents overestimate their abilities when it comes to understanding visual information and informing decisionmaking. While some fitness trackers are basic and only show simple charts of heart rate, we saw that other trackers display more abstract concepts like 'productivity' or sleep levels which confuse some users. What is missing from this discussion are in-depth conversations with former users to see what exactly was confusing for them and to hear their explanations and opinions on trackers. Since the commercial market for wearable is set to increase in 
breadth and depth, it would be valuable to see how to help beginners understand the onboarding process to limit premature abandoning and enhance well-being.

Chapter 4 provides such an opportunity to investigate former users through in depth semistructured interviews. 


\section{Chapter 4: Study 2: Semi-Structured Interviews}

The survey in chapter 3 helped generate a baseline to compare reasons in 2019 with those found by Maher et al. in 2017. However, users in Maher's study were unable to elaborate on why and provide further, richer insight. Therefore, we decided to complement the survey with in person semi-structured interviews that gave former users of wearable devices opportunities to expand on their challenges. This also afforded an opportunity to further investigate how users interpret the data and the data visualizations generated by the devices and to probe what exactly was difficult.

We informed our study through established HCI methods that articulates semistructured interviews as helping "understanding current needs and practices and evaluating the effects of new technologies in practice" (Blandford, Furniss, \& Makri, 2016). Blandford et al. also notes that semi-structured interviews allow the interviewees to expand on their hopes for future technology (Blandford et al., 2016), which this thesis in particular is concerned with due to the constant evolution of wearable technology for activity. Semi structured interviews also allows researchers to better discover interviewees' perceptions (Blandford et al., 2016) which are more difficult to capture in a survey that has no opportunity for follow-ups.

\subsection{Study Design}

The study was composed of two parts. Part 1 consisted of gathering participants' experiences with trackers and why they abandoned their device (See Table 13). We also provided an opportunity for participants to interpret the same graph from the survey (Figure 
10). We also wanted to explore the burgeoning field of wearables and decided to demonstrate two forms of wearable garments / accessories in part 2. In this part, the researcher demonstrated a pair of smart shorts as well as a smart insole that function similarly to fitness trackers by providing feedback in the form of data. We asked participants to engage with the data and data visualizations to gain insight into their user experience and offer opinions and perspectives (See Table 14). The choice to conduct semistructured interviews allowed the interview to proceed down particular lines of thought based on each participant's experiences, in line with HCI methods (Blandford et al., 2016).

We decided that the researcher would demonstrate the wearable due to sanitary purposes, and the interviewee would interact with the data generated. We conducted these semi-structured interviews with 16 former users of fitness trackers and the interviews lasted between 45 minutes and 60 minutes.

\section{Table 13. Questions asked in Part 1}

\begin{tabular}{|l|l|}
\hline Experiences with & 1. What are some of the devices you've been using? \\
trackers & 2. Did you buy it or was it a gift? \\
3. Did you read the manual? \\
4. Did you watch a tutorial? \\
5. What did you use it for? \\
6. What did you do with the data? \\
7. What are the reasons you stopped using? \\
8. Why is step count important to you? \\
9. If you don't reach your step goal, what do you do? \\
10. Did you have any issues interpreting the data? \\
11. Are there other wearable technologies that you are aware of that \\
12. Are there different metrics (other than heart rate, calories burned) \\
13. Can you make sense of this data / chart? \\
\hline
\end{tabular}

Table 14. Questions from part 2

\begin{tabular}{|l|l|}
\hline $\begin{array}{l}\text { Questions from interacting with } \\
\text { Stridalyzer and Athos }\end{array}$ & $\begin{array}{l}\text { 1. } \begin{array}{l}\text { Who could benefit from these wearable } \\
\text { technologies? }\end{array} \\
\text { 2. Could it be used in the activity you like to } \\
\text { do in any way? }\end{array}$ \\
\hline
\end{tabular}




\begin{tabular}{|l|l|}
\hline & $\begin{array}{l}\text { 3. How could this data be helpful? } \\
\text { 4. Can you make sense of this data? } \\
\text { 5. What about a compulsory tutorial? } \\
\text { 6. What do you think of the user interface? } \\
\text { 7. What is missing that would make it }\end{array}$ \\
& $\begin{array}{l}\text { 8. How could these be leveraged to improve } \\
\text { technique? }\end{array}$ \\
9. Is this a missed opportunity to help \\
lower-literate individuals?
\end{tabular}

Part 2 consisted of experiencing two new wearable fitness technologies. While fitness trackers like the Fitbit generate data on heart rate and step counts, for example, there are new wearables that are generating data on how the body moves and quality of movement, as opposed to strictly quantity. The literature is beginning to look at how wearables are being used in running and there appears to be a need for better assistive feedback provided to the runner (Jensen \& Mueller, 2014). Thus, one of the wearables we chose to demonstrate is a smart insole that has pressure sensors embedded in them to gather data on how users are placing their weight while walking and running. We used the insoles called Stridalyzer ${ }^{7}$ (See Figure 22 and Figure 23)

${ }^{7}$ http://retisense.com/ 


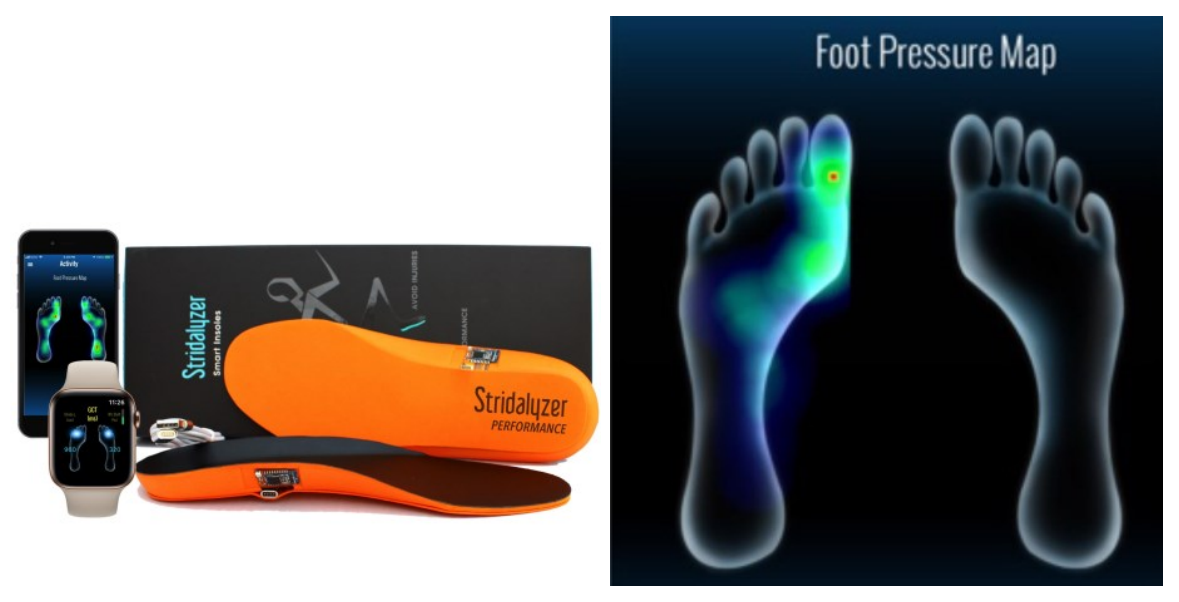

Figure 22. Stridalyzer smart insoles and app interface with heat map on the right ${ }^{8}$

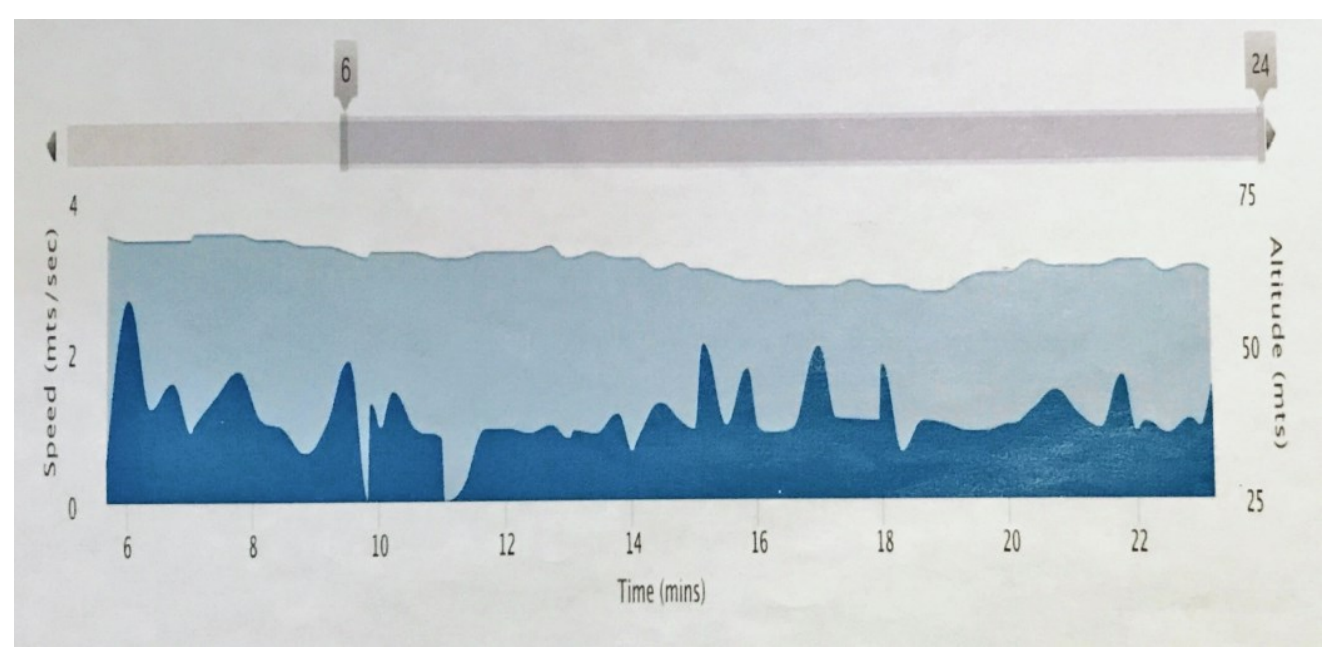

Figure 23. Data visualization of feedback from Stridalyzer insole

During the study, the researcher demonstrated turning the insole on and off and explained the charging process, pairing the insoles with the app and then proceeded to place them in their shoes. For 20 seconds the researcher jogged on the spot which and immediately generated data in the form of a heat map (see Figure 22). After completing the jog, the researcher then connected to the online web portal for Stridalyzer, accessed the account and displayed the running data seen in Figure 23 and Figure 23.

${ }^{8}$ http://retisense.com/ 
The other wearable we chose to demonstrate measures how much the muscles of the body are being used in particular movements. Athos ${ }^{9}$ created a pair of smart shorts that are embedded with sensors that use electromyography (EMG) to record the electrical activity in muscles (See Figure 24). Developing stronger muscles supports movements used in dance, outdoor recreation and sports. Thus, we chose to use this second wearable to see how participants interact with this kind of data.

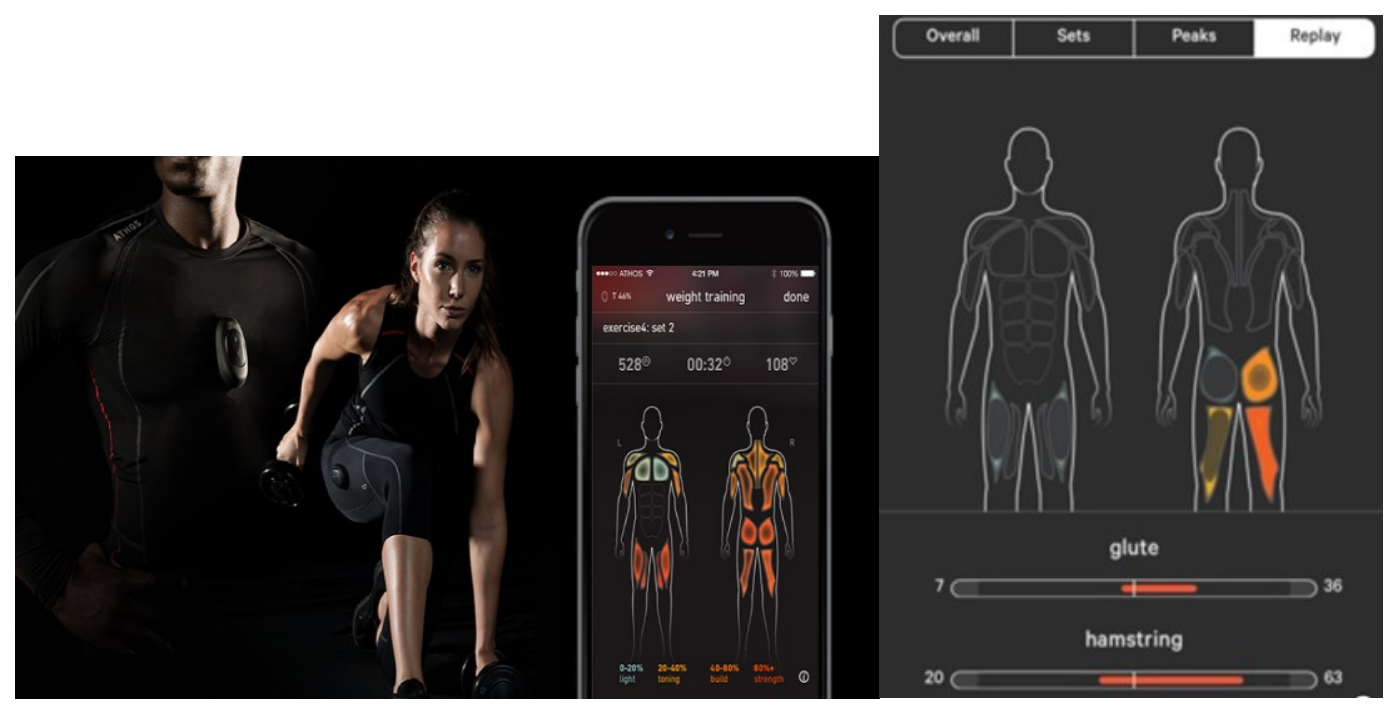

Figure 24. Athos smart shorts and app interface showing a heat map of muscles being used. Yellow indicates less effort, while orange equals more intense effort.

While already wearing the shorts with the device attached, we introduced the product through the already downloaded app and noted there is a calibration process set up to provide more accurate results. The researcher then performed a series of squats and lunges over 30 seconds that generated a heat map of the muscle's activity seen in Figure 24. The participant was able to view the data on the researcher's phone through the app.

\footnotetext{
${ }^{9}$ https://shop.liveathos.com/
} 
Ethics Approval (\#110810) occurred on May 1, 2019, and we compensated participants $\$ 15$ for their time. For ethics details see Chapter 6:Appendix A

\subsection{Recruitment}

We recruited participants via social media as well as through word of mouth beginning on June 23, 2019. Participants had to have experience using, and then abandoning, a wearable fitness tracker. We included those that abandoned but had either upgraded or obtained a different tracker in order to account for 'happy abandonment'. In all, 16 participants met the criteria and met with the researcher on campus at Carleton University, with one interview taking place at Ottawa City Hall.

\subsection{Demographics}

\begin{tabular}{|l|l|l|l|l|}
\hline Participant & Age & Gender & Type of device & Length of usage \\
\hline P1 & 24 & Male & Fitbit & 6 months \\
\hline P2 & 29 & Female & Fitbit & Less than 1 year \\
\hline P3 & 58 & Female & Fitbit & 2 years \\
\hline P4 & 25 & Female & Fitbit & 8 months \\
\hline P5 & 29 & Male & Garmin & Less than 1 year \\
\hline P6 & 68 & Male & Fitbit & A few months \\
\hline P7 & 22 & Male & Fitbit & 3 or 4 months \\
\hline P8 & 61 & Male & Polar & 1 year 6 months \\
\hline P9 & 22 & Male & Fitbit & 2 months \\
\hline P10 & 21 & Female & Garmin & 4 to 6 months \\
\hline P11 & 48 & Male & Fitbit & 9 months \\
\hline P12 & 20 & Fitbit & 3 months \\
\hline
\end{tabular}




\begin{tabular}{|l|l|l|l|l|}
\hline P13 & 21 & Female & Samsung & 2 months \\
\hline P14 & 22 & Male & Fitbit & 7 months \\
\hline P15 & 26 & Female & Garmin & 1 year \\
\hline P16 & 22 & Male & Fitbit & 3 months \\
\hline
\end{tabular}

We had 10 males and 6 females with the average age being 32.3. 11 participants used a Fitbit, while 3 used a Garmin, 1 Polar and 1 Samsung. The average length of usage was 8 months.

\subsection{Results}

First, we organize our results to answer research question 1, why did former users abandon their device. Then, we address research question 2 by analyzing their responses to the same question provided in the survey about heart rate data as well as the data visualizations provided by the 2 wearable devices. We then organize the rest of the interviews based on thematic analysis to answer research question 3 as well as other key findings.

\subsubsection{Reasons for Abandonment}

For 6 of the users, the fitness tracker was not helping them improve a particular aspect of their health. P3 was gifted a Fitbit and used it to track sleep because she wanted to improve it. She said that she has not been getting quality sleep for many years. However, the sleep data did not state how she could improve her sleep, so it was of little value. P6 likewise found the Fitbit to be very limiting and was only using step counts. Since he 
routinely walked with his wife who did track her steps, he decided he did not track them himself since he reasoned his step count was close enough with hers. P13 said that the tracking capabilities did not help much at all and stopped paying attention to notifications. For these individuals, the data provided was limited and often the same. An example provided by P6 was the number of steps it took to reach work from home never changed. For P6, the data was interesting the $1^{\text {st }}$ time, but after the tenth time, it was no longer generating insights.

Furthermore, P15 wanted to improve her health, yet found the disadvantages outweighed the advantages. Instead of feeling good about tracking step counts, she became fixated on keeping up with others, or became frustrated when she forgot to wear her device. P5 and P13 encountered a situation where a training partner wanted to start the session over because they had not turned on their device. For P13, this was specifically exasperating for her because she reasoned the point of the Fitbit was to tell her and her partner to walk and they were already walking

P4, 5, and 8 upgraded to a better device and passed on their old device to a friend or family member. P16 had only borrowed the device and had to return it. P4 and P8's strap broke, which limited their ability to use it, with P4 stating that the replacement band was expensive and was a barrier.

\subsubsection{Interpretation of Heart Rate Data}

We wanted to give interviewees an opportunity to interpret the heart rate graph and speak aloud their thoughts and experience. We also wanted to see how well they could make sense of the data. We grouped the answers according to a system created by Bertin 
who started there three levels on which a graph may be interpreted: elementary, intermediate, and comprehensive (Boy, Rensink, Bertini, \& Fekete, 2014a). Elementary refers to simple reading of the information, while the intermediate level hints at a detection of relationships. Lastly, the comprehensive level allows for inferring relationships based on both data and background knowledge.

Based on this interpretation we found 9 participants at an elementary level, 5 at an intermediate level, and 2 at a comprehensive level. The elementary level participants were able to read the numbers, but did not offer an explanation as to why the heart rate was so high, what may have caused it, and what it could mean. Intermediate level participants expressed concern and suggested possibly a nightmare or stress but were ultimately wrong in their interpretation. Comprehensive level participants noted quickly that the data was not good and indicated sleep apnea, or a heart condition which demonstrated to us that they could make sense of the data.

\subsubsection{Interpretation of Visualizations Generated by Other Fitness Trackers}

Since many respondents from the survey appeared to overestimate their ability to interpret data, we decided to provide users in the interview with more opportunities to look at some data and data visualizations from other wearable trackers (See Figure 23 and Figure 24). We found that participants generally struggled to make sense of the data, noting that it was unclear if the data was good or bad. For Figure 23, the subject matter data was difficult to make sense of, as well as how the data was presented. Since there were no labels indicating good or bad, interviewees had no basis for comparison. 
P3 could not make sense of the numbers from the smart shorts asking, "What's the rating? What is it comparing it to?" However, she did appreciate the heat map of the human body and noted it would be more beneficial than numbers or bar graphs because it gives a visual of what muscles she would be using whenever she was moving. However, she also added that she would not likely buy the smart shorts for just that purpose. P5 also said it was hard to understand the insole data and noted that with his experience working in shoe sales that only those who were a serious athlete would value the data. Those that were recreational would wonder what the point of the data was.

When looking at the data on 'arch stress', and 'ground contact time' P8 said that the first thing he would need to know is what the optimum would be and what he was supposed to be attaining. He indicated that it would be useful for him if it helped him understand if he was over or under pronating while he ran. He said he was not sure how he would interpret the data since he did not know what he was looking for. P4 remarked that there was clearly more stress being put on the heel, but that it did not say if that is a good thing. P4 said "I feel like it's average that everyone can see a graph and get an understanding like, oh, yeah, "this one is big, This one small" but, finding out a kind of understanding why something is a certain way. Not everyone can see that".

P16 remarked that the graph was showing him what the data was, but not telling him how to improve it. P10, a swimming instructor was also unable to make sense saying she did not know what the numbers meant. P9 remarked that he loves graphs but found the insole chart 'daunting'. P9 also said that his Fitbit app would tell him how long his different levels of sleep were, but that it never told him what was good. 
The consensus was that the visualizations were lacking context for participants to situate themselves. To further understand what former users had in common we established themes about the user experience, critiques, and possible recommendations.

\subsubsection{Lack of Awareness}

Throughout the interview process, a clear theme emerged that we classified having or lacking awareness. By awareness we mean the interviewees did not know how to take full benefit from their device. For example, P9 only found out by accident that his Fitbit had a "treadmill" feature after he bumped his arm against a wall. He had not read the manual or watched a tutorial, so the result was discovering features by accident. P8 also had a poor user experience at first because his golf tracker did not behave the way he assumed it would. The tracker could detect how far away he and his ball were from the hole, which was his goal. In his example he knew the precise distance of the hole because he had played that golf course many times and knew that the distance was a certain length, yet his device was consistently generating the wrong numbers. He said that he almost returned the device when he decided to call the company who promptly informed him that he needed to calibrate the device by switching modes from the imperial system to the metric system since the device was American. After calibrating it successfully calculated the distance, but the story illustrates that without the initial calibration, the data appeared to be incorrect.

Another form of awareness was that of what constitutes how much physical activity one should get. P13 kept track of her steps and chose a unique number goal of 8888 steps, because it was close enough to what she thought was the real goal of 10,000 steps. 
However, this goal is not validated scientifically (Mull, 2019) so her goal may or may not result in helping her achieve her goals.

Another level of awareness or lack thereof was revealed by P15 who was so intent on meeting her goal that she severely injured her leg while running and had to take a few months break from activity. In this case she was said, she ignored the pain in order to keep pace with her running partner though she did say the Athos shorts or a similar technology may have been able to convince her to stop if the device warned her of the stress being placed on her leg muscles and tendons.

All of these examples show a user with inadequate initial knowledge when using the devices or exercising. P9 admitted that it was maybe ignorance on his part since he did not read the manual and had not read up on what kind of sleep he was supposed to be having. Whereas P11 noted that if you put in some effort to get to know the device, you are bound to get more out it.

Since we found in the survey that $53 \%$ of respondents did not read the manual, we asked interviews how they felt about a compulsory tutorial that would ensure they know how to fully use and understand the device. P9 admitted that he thought a compulsory tutorial would be irritating at the beginning but felt he would be much more appreciative of it in the long run. Incidentally, this would have helped P9 discover the different modes on his Fitbit instead of finding out by accident. P8 remarked, "I would find that really valuable, if there was kind of a way that steers you towards learning more just to get the most out of the device. Because I know there were a lot of things about my device that I just don't even know about. Everyone once and awhile I'll stumble upon it and think, well, that's really neat, I wish I'd known". However, P13 disagreed and her initial reaction was 
that that too many people would not buy-in and may actually hasten abandonment. She said part of the attraction of the device is the ease-of-use because you can turn it on immediately and start using. Furthermore, P2 said a mandatory tutorial would be frustrating though P11 asked, “why would you buy a car, if you don't have a license? You want to be able to get the maximum utility out of it" making the point that if you are going to invest in a service or product, you should know how it works.

\subsubsection{Mindset Limitation}

When we asked participants who they thought could benefit from these wearables, the initial reaction was professional or elite athletes. Indeed, a representative from Athos confirmed that their clientele were almost exclusively college-level athletes and professionals (Athos, 2019). Athos had attempted to market to the average person, however they found the device was soon abandoned and because of it decided to focus on elite athletes only. This echoes what Piwek et al. noted when they said that fitness trackers tend to be purchased by those who are already active (Piwek et al., 2016). 5 Interviewees suggested patients in rehabilitation could also benefit. P3 called them 'toys' and thought that professional athletes would benefit from these new devices. When asked if she thought, school children could benefit because many children are not very athletic, she replied that she did not think so. P8 also thought only serious people, like professionals or high-level collegiate athletes would benefit, or parents trying to get an edge for their children in the competitive sports world. P4 said that these would be huge in the athletic world.

P6 saw potential for both devices to help golfers with their technique citing that a good golf swing happens when there is a weight transfer from the back foot to the front 
foot. The insoles would be able to reveal whether the user was transferring weight, and crucially, at the right time. "If you have a replay, you could see the weight transfer, because that is important in any sports activity, weight transfer, follow through, what muscles are being triggered and when they are being triggered, would be important..." If a video could be synchronized with the data, then he could see "There's weight on my right side, but not at the right time...the sequence is not correct"

P5 did acknowledge without prompt that he thought children could benefit. When pressed whether it was a missed opportunity to have lower physically literate children use the device to establish a baseline, some participants agreed it was a missed opportunity. P13 admitted that she was the physical education student who struggled with sports and proper technique whose running style she described as clunky.

\subsection{Discussion}

We briefly report on the results and what we learned from the interviews. First, we address the reasons for abandonment, and then look at how interviewees interpreted the data and visualizations before we report on who could benefit from the new wearable technologies.

\subsubsection{Abandonment}

What emerged from the interviews was that participants stopped using their devices for a variety of reasons, as is the case in the literature. For 3 of the interviewees, the tracker was too basic and did not offer them much more than step counts and after a while the users became bored with that data. One user felt that the data was unable to help them improve their sleep, and so the device was not of any benefit. The data itself did not provide insight, 
and the device did not appear to offer enough support. Furthermore, the participants did not know where to find answers or it did not mean enough to them to look. Though, 3 other interviewees upgraded to new devices, which illustrates that newer versions provide incentive to continue tracking. The strap broke, which made wearing the device difficult and 2 interviewees did not want to pay for a replacement strap. It is noteworthy that the device was too basic, because that echoes what Maher et al. found in their study that the top reason for abandoning was they have learned all they could. As P6 said, once you know how many steps it takes to go somewhere, it does not change. However. New features and metrics continue to be released that may inspire former users to try again, but as long as they meet the goals of that user. It seems there needs to be a better way to match interested individuals with the correct kind of tracker.

\subsubsection{Interpretation and Data Literacy}

The results showed again that interpreting heart rate data may pose a challenge to most users. Only 2 of 16 users could identify from the data that a medical condition was occurring in the data. We also found that some of the visualizations were not intuitive enough to generate insight and ended up confusing participants. However, the heat maps provided by both devices were intuitive and participants remarked that they would find it useful, especially in sports and rehabilitation. What remained unclear though was what their target was. The heat maps did not indicate what the goal should be, or what a dangerous level was. P13 thought pop-ups could be utilized to bring awareness to the user to alert them to a change or a danger point. Many participants supported a mandatory tutorial to ensure a sense of data literacy, and one component that could be considered is 
to have an assessment in place. As the tutorial component is borrowed from the video game industry, perhaps a level system with an assessment could be leveraged to ensure users sufficiently understand the data before they can be exposed to new features. P9 thought there was too much data that was presented at once, and felt overwhelmed. Perhaps a graduated roll out of data and features would allow for users to ensure they can make sense of all of the data and not just the summary statistics like calories burned and steps counted. Zhao et al. found more engagement through a gradual release of features (Zhao et al., 2017)

\subsubsection{Themes}

One of the themes that arose was that of a lack of awareness around what the device could do, or how the devices could help them. Users treated the devices like a novelty, rather than a serious training device that requires time and effort to understand and gain value from. Participants discovered features by accident which is a fault for the company's design or user experience. Likewise, participants did not appear to seek out knowledge to learn more about how their device could help them.

The two wearables that we demonstrated had quite an effect on some participants who expressed intrigue, and surprise at the capability of the devices to showcase new data and accompanying visualization. The heatmaps were especially inspiring to some participants. However, gaining insight from the wearable was very difficult, though participants did offer ideas on how the device or similar devices could help certain groups of users, namely elite athletes. This revealed a second theme of mindset limitation that assumed the devices would benefit mostly elite athletes. It seemed to escape almost all participants that the devices could be leveraged to help lower physically literate people 
learn about their bodies through wearable technology. HCI researcher Florian Mueller noted that exertion is not just about maintaining health and warding off disease(Mueller, Byrne, Andres, \& Patibanda, 2018). Within the emerging HCI of today, the felt, lived body is paramount in engaging with the world. As such, wearable technology could be better designed to enhance joy or movement, not just to count steps and reward burning calories. What remains to be explored is whether these wearables can help enhance physical literacy, but what this research appears to confirm is that in order to benefit from the wearable, the user will need to have a certain data literacy. They will need to be better supported by the company to ensure the user makes genuine insight on understanding their body and developing body awareness.

When it became clear that many users struggled to fully grasp all of the capabilities, I asked them what they thought of a mandatory tutorial. Tutorials are a common component of video games and prepare the new player to understand the game mechanics in order to have success with it. According to Anderson et al., tutorials increased play time by as much as $29 \%$ if the game was complex, but did not improve player engagement if the game was simple and the mechanics could be discovered by the user through experimentation (Andersen et al., 2012). As these devices become more complex, including not so intuitive sleep scores and readiness scores, I wondered if users thought that a mandatory tutorial was a good idea, and the result was mixed. While admitting that it would be irritating at first, participants supported the idea in theory noting that there are likely features that they are unaware of. When considering Maher's study, it was interesting that the top reason for abandonment was that former users had learned all that they could because it is possible 
they were unaware of other features. These topics are expanded on in the following chapter 5 which combines the results and discussion from Chapter 3 and Chapter 4.

Summary

\begin{tabular}{|c|c|}
\hline Themes: & \\
\hline Lack of Awareness & $\begin{array}{l}\text { - Almost abandoned due to lack of } \\
\text { calibration } \\
\text { - Discovered features by accident } \\
\text { - Did not know what some features } \\
\text { meant }\end{array}$ \\
\hline Mindset Limitation: & $\begin{array}{l}\text { - Useful for elite athletes only } \\
\text { - Only for people already motivated }\end{array}$ \\
\hline Mandatory tutorial & $\begin{array}{ll}\text { - } & \text { Mixed feelings } \\
\text { - } & \text { Irritating at first, beneficial later } \\
\text { - } & \text { Users would abandon before } \\
\text { completion }\end{array}$ \\
\hline Heat Maps & - Intuitive and easily understood \\
\hline Scaffolding & $\begin{array}{l}\text { Lack of labels on charts made } \\
\text { interpretation impossible }\end{array}$ \\
\hline
\end{tabular}

\section{Chapter 5: Discussion}

With the combination of the survey and the semi-structured interviews, there are several results worth noting and discussing. The results are briefly summarized here and then elaborated upon further below with implications and recommendations, followed by limitations to our work. We finish with a note on future work based upon the results.

\subsection{Summary of Findings for the Survey}


The survey found that the top reason why former users stopped using their device was that it was not helping them reach their goals. This was a different finding from Maher et al. that found that users stopping using their device because they felt they had learned everything they could. The $4^{\text {th }}$ highest reason for why former users stopped using was that they 'did not know what to do with the data'. This is a problem that is further confirmed with other questions we asked. Namely, while all users and former users said that interpreting the data is not a problem for them, in comparison, all users and former users especially LFFUs agreed they had trouble deciding what to do with the data.

Furthermore, only $17 \%$ of all the respondents were able to correctly identify that the data in the Apple Watch chart showed a medical situation, even though 94\% percent indicated they could interpret graphs well. This suggests that making sense of the data and acting on it, which is a component of data literacy according to Mandinach et al., is indeed a problem. It is even more so a problem since users and former users appear to overestimate their abilities with respect to data literacy.

We also found that users former users alike lacked support when it comes to understanding their data. Explanations provided by the device, or supporting software, was often inadequate. Part of the problem appears to be related to how well the new user prepares to handle the data, since only $51.6 \%$ of users and $66 \%$ of former users read the manual associated with the device. However, what appears to be more important for predicting sustained use is watching a tutorial, where $40 \%$ of users did, but only $27 \%$ of former users did. Another unexpected finding was that complaints about devices being uncomfortable increased compared with Maher et al. data from 2016. Only 4 of 233 respondents had ever worn a smart garment. 


\subsection{Summary of Key Findings for the Interviews}

Interviewees abandoned their devices because the devices were not helping them meet their goals, did not generate insight or offer how to improve, or upgraded to a newer device. Much like the survey, interviewees struggled to identify that the data implied a medical situation with only 2 of 16 correctly identifying a medical situation for the graph, while 5 could sense that the heart rate was high, and 9 did not know what the data meant.

Interviewees were interested, excited, and impressed by the two wearable technologies demonstrated, and for almost all it was their first-time hearing about a wearable garment. However, none of the interviewees could make sense of the data visualizations at first glance in part because of a lack of domain knowledge. Interviewees felt that mandatory tutorials to ensure safe and correct interpretations show promise, with some indicating it would be a good idea for future iterations of wearable technology. Most interviewees' initial thoughts about who could benefit from the 2 wearables were for 1) professional athletes and 2) rehabilitation. One suggested 'children' as a possible target audience, while others later considered it after prompting. Interviewees indicated an interest in acquiring future wearable technology but admitted that price point was a factor.

\subsection{RQ1: Why do users abandon wearable fitness trackers in 2019?}

The survey suggested that the top reason why former users abandoned their device revolved around the theme of disappointment. The device failed to live up to expectations, or the device could not do what the user was hoping for to match goals. It speaks to a lack of alignment between what the device offered and what the user was expecting/hoping for. 
Interesting, there was a difference in the number of complaints between Maher's survey and ours. For both studies $30 \%$ reported having no complaints, yet for former users it was only $16.2 \%$ in Maher's study, yet $31.9 \%$ in ours. It is possible that as the awareness and options of wearable trackers increases, users have more to compare to.

One of the interesting reasons provided for abandoning in the survey that matches with some of the recent literature is that it turned exercise into a chore, and they enjoyed activity less. As Toner argued, focusing on the numbers takes the embodied sensations of activity out and potentially hinders one's enjoyment (Toner, 2018). Interviewees and survey respondents mentioned if they did not complete their activity goals near the end of the day, they would act to ensure they did, for example, pace around the room. While it is possible to enjoy this activity, it is also possible that the fear of missing a streak, or disappointment of not reaching a goal weighs more heavily. Additionally, more features and sophistication provide greater reasons to complain about, for example, newer abilities like sleep tracking, or heart rate variability. However, many users were satisfied with what the device could do, so it depends on the reason why someone adopted a device in the first place.

Another reason that emerged was that people stopped using their device because the strap on the device broke and they reported it was costly to replace. The fear of breaking the device also paradoxically was a reason people stopped using. While inexpensive trackers now exist, and are becoming more reliable (Degroote et al., 2019) trackers are generally expensive electronics. It is conceivable that users were already beginning to sour on the device since it did not meet their goals, and once it broke, signaled the end of usage. 
After their device broke, it is possible they decided it was too expensive to replace, and/or relative to the value of the product.

However, for some interviewees upgrading was a reason they stopped using their device, which is a 'happy abandonment' as referenced in the literature (Clawson, Pater, Miller, Mynatt, \& Mamykina, 2015). Respondents and interviewees reported moving on to a newer upgraded device, with some passing on their older model to friends and family.

With the proliferation of fitness trackers marketed by traditional brands and newer companies, more and more potential users are being given the opportunity to experience wearable technology and the reasons for abandonment are evolving as new iterations fix usability issues, while unfortunately generating new ones. Next, we review our hypotheses here.

Hypothesis 1: Respondents will report abandoning their device due to struggles with data more than they did in Maher et al.'s study.

When looking at Table 4 of complaints, our data was (4.7\%) compared with Maher et al. (4.2\%). Additionally, when looking at Table 5, 8 of 47 former users abandoned because they struggled to make sense of the data or it was difficult to understand. Maher reported only 2 of 37 . The results suggest a confirmation of our hypothesis.

\subsection{RQ2: Do people have trouble interpreting the data generated by their} wearable fitness tracker? Is misinterpretation contributing to abandonment?

Survey respondents did admit they did not know how to interpret heart rate data which confirms what Lazar et al. found when they said that participants did not know what 
to do with their data. One participant noted that the device generated heart rate data, but no sense of what it meant to be within a given range (Lazar et al., 2015). The results appear to verify what Meyer et al. found when they said that some participants wanted to have tailored interpretations and be provided a diagnosis (Meyer et al., 2017).

One of the most interesting findings was that people claimed with certainty they could interpret graphs well. In the survey, 94\% either strongly agreed or somewhat agreed that they can understand graphs well, yet only $17 \%$ correctly identified that the user should consult medical attention. While not everyone has background knowledge in heart rate, it is a core feature of fitness trackers. It suggests that perhaps users are not as knowledgeable about heart rate as device companies assume they are.

It also suggests a deeper issue, and that is it is easy to overestimate our abilities. Known as the Illusion of Explanatory Depth which says that most people feel they understand the world with far greater detail than they actually do (Rozenblit \& Keil, 2002). Users may believe they are better at interpreting data than they actually are and the concern is that they may misinterpret data. If and when users are having a serious physical episode and their wearable indicates there is something wrong, will these people be able to interpret the data and react accordingly?

The smart insole was designed to give users feedback on the quality of their steps. In this case the insole provided feedback on what the company called 'arch stress' or 'heel stress'. When we asked interviewees what to make of the charts, none of them were able to use the data by itself, albeit these are not common indicators. They needed a context, or a comparison to draw any insight. The interviews confirmed that some data is difficult to 
interpret and requires content specific knowledge which the interviewees said should be better supported. This result confirms what Choe et al. found when they said the key hurdle to gaining insights is data interpretation (Choe et al., 2014). We would add that sufficient domain knowledge is a key factor in being able to correctly interpret.

This lack of support prompted us to ask interviewees whether a compulsory tutorial would be a good idea to help scaffold understanding. 6 interviewees agreed that a compulsory tutorial would be good for them personally, or for others more generally. While admitting that a lengthy tutorial would be a barrier to use, it seems that there needs to be research into how long, and how sophisticated a tutorial should be in order to better prepare new users for the data. Video games are good avenues of research since games often include a tutorial, with many no longer including a hard copy manual.

As Mandinach et al. defined that data literacy included knowing what to do with data (Mandinach \& Gummer, 2013) the fact that so many respondents and interviewees did not know what to do with certain data suggests that they may not be as data literate as they think they are, or, more importantly, not as literate as they need to be in order to use the device to its full capacity. One suggestion by P6 was that there be a kind of notification provided to the user that they are using only a certain percentage of the device, for example $60 \%$. This awareness may spur motivation to explore further what the device could do, whereas without it users tend to stick to what they know. This also ties in with what Lazar found "there was often no instruction or prompting given to users on how to analyze collected data. Participants were not interested in quantifying behavior just for the sake of getting a number; they wanted to know what to do with that number" (Lazar et al., 2015) 
Another possible solution to the literacy issue comes in the form of an assessment. As mentioned in the literature (Börner, Bueckle, \& Ginda, 2019; Boy, Rensink, Bertini, \& Fekete, 2014b; Galesic \& Garcia-Retamero, 2011b) an assessment would situate users. Perhaps a company could embed an assessment to establish when a user has mastered an understanding of the data. New features would be unlocked once this assessment had been passed, ensuring users are prepared for the new data. A short, mandatory tutorial could then expose them to the data visualization, with pop-ups offering explanations, as suggested by P13, to draw attention to specific details necessary.

Interviewees did not possess the knowledge to be able to know if the data showed a problem or not. For casual users it is unlikely they can understand the data without guidance and the manuals provided by Athos and Stridalyzer were insufficient within an hour time frame. It appears that time must be invested in learning about the data to be able to make sense of it, and the device maker should be aware and properly scaffold.

With respect to the wearable shorts, the heat map proved to be more useful and usable, in that interviewees thought they could accurately see which muscles were being used. It would appear that having lower levels of data literacy is indeed a barrier, in particular to fully making use of the device. This underutilization could factor into abandonment since Maher et al. found as their top complaint that they had learnt all they could. It is more likely they could have learned more.

Hypothesis 2: Low Fitness individuals who have stopped tracking (LFFUs) will report the most trouble interpreting data. 
Looking at Figure 14 we see that for LFFUs more respondents agreed (48\%) than disagreed (40.7\%), whereas for HFCUs the opposite was true with $20.4 \%$ agreeing to $57 \%$ disagreeing. This suggests the HFCUs are able to make the most sense of the data, while LFFUs are able to make the least sense. This supports our hypothesis.

Hypothesis 3: Respondents with lower physical fitness will report high levels of abandonment.

Of the 47 respondents who abandoned, 27 were grouped as LFFUs and 20 as HFFUs. The biggest category were those who selected 2 out of 4 at $46 \%$ of all respondents, confirming our hypothesis that those who abandon are on the lower fitness level.

\subsection{RQ3: Are there any identifying features about former users that is different from current users? How can wearables cater to more users?}

One of the noteworthy differences between former users and users was comfort level. $34 \%$ of former users complained the tracker was uncomfortable, whereas only $11.7 \%$ of current users had the same complaint. One survey respondent who stopped using their device said that trackers were not for him in their current form since he does not like wearing things on his wrist. This is relevant since the statistics of watch wearing shows a decrease. In $2005,52 \%$ of teenagers wore watches, but by 2015 , only $25 \%{ }^{10}$. It is possible that users like tracking, but do not like to wear a watch, and partly because watches are

\footnotetext{
${ }^{10} \mathrm{https}$ :/minnesota.cbslocal.com/2015/07/22/good-question-how-many-people-still-wear-watches/
} 
uncomfortable, or some cases cause skin irritation as found in Maher as well as our study. This finding also confirms what Lazar et al. found when they noted that participants quickly abandoned their device if they deemed it uncomfortable (Lazar et al., 2015). Combined with complaints of skin irritation, and straps that break (Maher et al., 2017), it appears that designs of wearables need to take greater care in developing products that are comfortable, and for many kinds of users all with different kinds of body shapes and sizes.

Another interesting result came when we asked the survey respondents how much they agreed that the wearable helped them spend more time learning about their body. While $34 \%$ of former users agreed with the statement, for the users still using it was 55\%. This suggests trackers help people learn more about themselves. Broken down further is that for those that rated themselves as high fitness level agreed more with the statement than those that rated themselves as low fitness. For HFFUs (45\%) was still higher than LFFUs (28\%), whereas for HFCUs (65\%) was higher than LFCUs (53\%). This suggests that perhaps fitness trackers cater more to people who are already fit echoing the literature (Piwek et al., 2016; Spiel et al., 2018). Though, people who are already fit may already be inclined to learn more about their bodies.

Motivating people who are not interested in becoming fit has been and continues to be a challenge, despite the awareness that being fitter is associated with healthier lives, physically, cognitively, and emotionally. As the interviewees noted, Athos and Stridalyzer primarily cater to elite athletes, yet we believe this perception is limited and misses out on the opportunity to address the health crisis raised at the outset of this thesis. 
Part of this crisis stems from youth as we saw with young people getting a $\mathrm{D}+$ in physical activity (ParticipACTION, 2018). In our opinion, one of the ways to reduce abandonment would be through the introduction to youth via a formal instruction process. One question this thesis research raised is "Where and When should data literacy be introduced?" and "How do we ensure data literacy?" so that we can ensure that users of wearable devices correctly gain insight to benefit themselves and others. Wolff explains that "Data literacy is increasingly considered to be a life skill...and individuals more frequently make judgments from data and make decisions regarding the use of their own personal data" (Wolff \& Montaner, 2016). Therefore, Wolff argues that school is the natural place stating "the general view is that the foundation for creating a data literate society starts in school... and it is suggested to teach data literacy as a cross curricular subject, incorporating it into subjects such as science and geography"(Wolff \& Montaner, 2016). Here, Wolff makes the point that data literacy can be found in subjects like science, and we would add Physical Education, since as Zimmermann-Niefield et al. show, trackers can be used by students generating their own data to learn machine learning (ZimmermannNiefield, Shapiro, \& Kane, 2019). Furthermore, skills like shooting a basketball are based on math and physics (Fontanella, 2006), so a case can be made that data literacy belongs in Physical Education, helping students learn to make sense of their data.

Equally important with data literacy is data visualization literacy as Borner et al. found that students had trouble making sense. "The results show that while most participants have a strong interest in science, math, and art, many have a hard time naming and interpreting visualizations.” (Börner et al., 2016) 
What we think is crucial to this step is a mindset change. Recently researchers proposed the term "Wellth" to describe a focus on health as a foundation for performance rather than as a preventative for illness (Churchill \& Schraefel, 2015). The state of the brain is mirrored in the state of the rest of the system to which it is attached. This "inbodied" connection is something our dominant sedentary work paradigm ignores... and is injuring us, costing us our quality of life. (Schraefel, 2015) Toner noted our overemphasis on the body as an object and argued this contributes to an 'anesthetization' of the human experience (Toner, 2018). Mueller et al. noted that new voices are raising concerns that the current body-based designs are almost entirely treating the human body as an object that falls ill and can only be saved from dying thanks to technology (Mueller et al., 2018) Instead, Mueller et al. raised the idea from the German language of two words both representing the body, yet one the mere physical body while the other as the living body, that we both have a body and are a body (Mueller et al., 2018). Do wearable fitness trackers elevate the 'living body'? Hook et al. would say no and critiqued the idea that "by placing some sensors on our body and then having the data fed back to us, we are supposed to be able to change our bad habits, become healthy and beautiful, and live a long life." (Höök, 2015). They continue and lay out the philosophy that HCI is recently embracing called somaesthetics:

"A key premise of the somaesthetic philosophy is the insight that all of our experiences and interactions with the world happen through our body. Learning how to know and better use our bodies is as important as educating our minds. This applies both to the motoric system, such as when learning to ride a bike, and to the sensory system, learning to interpret and make sense of our bodily experiences. Thus, by increasing our body awareness through engaging in various forms of training, we can become more perceptive and aware in the physical world in which we live and act. Through such training, we may enjoy novel playful, engaging, pleasurable experiences, as well as painful ones." 
Can trackers become more involved in the embodied self and building body awareness? The smart shorts and smart insoles we used in our thesis and the other wearable inventions, such as the vibrotactile yoga pants ${ }^{11}$ provide opportunities to investigate the Qualified Self, trackers that develop skill and technique, flow and timing (Buthe, Blanke, Capkevics, \& Troster, 2016).

In summary, we argue that the field of HCI and Digital Media has a role to play in advocating for body centric, human-centric designs that help raise the level of awareness, and not just focus on physical activity that wearable fitness trackers do. We conclude with some new questions generated as well as a section of recommendations based on our research and the literature. This thesis generated many new questions to explore going forward including:

1) How should data be presented?"

2) Given the possibility that people think they are more data literate than they are, how do we proceed?

3) How do we ensure data literacy?

4) Where and when should Data Literacy and Data Visualization Literacy be introduced?

5) Who is responsible to ensure users understand the data, the user or the company?

6) Are there wearables specifically for physical, movement, and health literacies?

\footnotetext{
${ }^{11}$ (https://www.wearablex.com/).
} 
Lastly, our work further supports those of Lazar et al. who said that users lack the skill and expertise to interpret the data (Lazar et al., 2015). We found that with respect to heart rate data, as well as the data visualizations generated by the smart insoles, interviewees lacked the domain-specific knowledge to make sense of 'gait' and other physiological data related to the foot and running. Our work also confirms that fitness trackers worn on the wrist can be uncomfortable as Michaelis et al. found (Michaelis et al., 2016). Our finding that only 4 of the 233 respondents tried a wearable garment generated a new finding that smart garment market has not matured yet. Our work also supports the research that novices, or those that report lower fitness, struggle more with data than experts, or higher fitness. Rapp found that novices struggled more with data visualizations than experts (Rapp \& Cena, 2016).

\subsection{Recommendations}

Based on the literature and the research we conducted we have recommendations for better user experience with wearable fitness trackers and wearable technology going forward. The recommendations pertain to both users and the companies / researchers designing interactions and argue that both play roles in improving the experience.

\subsubsection{First Recommendation}

One of the first recommendations we have is to explore a tier system for trackers that match with each individual's current digital, data, and movement literacies. As a possible way of structuring the Tier System, wearable tech companies could introduce several levels like Beginner, Intermediate, and Advanced user. This recommendation is 
based on Buszard et al. who found that adjusting the size of sports equipment to meet the physical development of the individual, or scaling, allowed for greater motor skill development than regular sized equipment (Buszard et al., 2020). Thus, adjusting the tracker to meet the level of the user would allow users to chart their progress as they show a readiness for new features and visualizations.

To understand in detail how the system would work, we may look at other spheres where such structures are currently deployed for overall development. One example would be akin to the martial art system of advancing through stages of development ${ }^{12}$. What is noteworthy about that system is there is an evaluation done to prove the martial artist is ready for the next level. Since respondents and interviewees complained at times of being overwhelmed with data, this would ensure a manageable amount. In addition to introducing several levels to ease-in users, what may also prove beneficial is providing an assessment before allowing users to graduate to the next level. This assessment is our second recommendation.

\subsubsection{Second Recommendation}

The introduction of an appraisal in the tracking system could determine the data literacy level and guide accordingly. Data literacy assessments already exist in academia (Börner et al., 2019; Boy et al., 2014a; Galesic \& Garcia-Retamero, 2011a) and in industry and public service (Bonikowska, Sanmartin, \& Frenette, 2019). These assessments could provide feedback to the user about their understanding of the device. This echoes one of the suggestions in the interviews that there could be a notification to the user regarding

\footnotetext{
${ }^{12}$ https://jitsucanada.com/new-students/beginners.php\#5
} 
what percentage of features the user was using informing them that they may be underutilizing the device's capabilities.

An interesting point about assessments is it does not have to be used with the tier system and could be a standalone improvement. This assessment technique may provide insight and benefits to users all by itself through the feedback mechanism. For example, Apple watch users earn 'awards' based on their performance over a period of time ${ }^{13}$. Introducing a similar system based on assessment and not performance may provide the user the motivation to keep going. Research also suggests that gradually rolling out features helps with sustained engagement (Zhao et al., 2017). Therefore, once the user demonstrates sufficient literacy, providing awards may prove to be a motivational feedback to keep users engaged. Using assessment with the Tier system may have more impactful results.

The design of the next generation of wearables could be done in collaboration with these assessments built in, unlocking new features. Too many people only learn a few key features. With the tier system, while the users may feel forced to engage with the assessments or perform consistently to reach the next level, we may have to focus on the silver lining of those users, that silver lining being gaining data knowledge/ literacy and engagement in the long term.

Another insight we had during our survey was that $53 \%$ of all respondents skipped reading the manual provided with the trackers. The manual usually contains steps and procedures for calibration/onboarding at the outset. But given that all users have varied data literacy levels, one may suggest that users should be onboarded with the help of professionals who can help ensure that new users fully understand the data and how to

\footnotetext{
${ }^{13} \mathrm{https}$ ://support.apple.com/en-ca/HT205406
} 
interpret it. Ellis et al. also suggested that public health professionals should play a role by coming together with technology designers to improve wearable interventions (Ellis \& Piwek, 2018) and we concur.

\subsubsection{Third Recommendation}

Hence, our third recommendation would be a better collaboration between wearable tech companies and professionals, such as doctors, physiotherapists and teachers. This recommendation also stems from our first-hand experiences with the customer care support departments of these tracking companies. In one such experience, we tried to contact Apple support for help us interpret the heart rate data, but they said they could not due to legal liability. While Apple can be lauded for helping to save lives, in my opinion, not being able to support the users to fully understand their products may be counterproductive. This also highlights that there is a gap between supporting users and companies trying to steer clear of legal ramifications. But more attention needs to be placed in ensuring emergency notifications are not ignored. Since we can agree that ignoring warnings may be unwise for the users, we recommend the collaboration of experts and/or on-call doctors helping users interpret their data responsibly. GetaMoveOn, an interdisciplinary group of researchers, including $\mathrm{HCI}$, tasked with transforming health through digital technology likewise agrees and recommends that "an app in combination with a brief in-person activity counselling session can help people to stick with their

physical activity program and increase their activity in the short and longer term." (Getamoveon, 2019). However, there will need to be buy-in from the medical community. A recent study in the United Kingdom found that $52 \%$ of medical students in their final year were unaware of the current exercise guidelines (Radenkovic, Aswani, Ahmad, 
Kreindler, \& Robinson, 2019) illustrating that while we may want to have collaboration, we will need to convince various stakeholders to come together.

In relation to the onboarding processes and manuals, another beneficial way of onboarding users is via tutorials, which are common in the video game industry to help new users. This brings us to our fourth recommendation. A suggestion worth exploring, in our view, is a form of compulsory tutorial which ensures that users know all of the capabilities of the device before they begin to use it. A compulsory tutorial may turn people off, so we recommend it is gamified as Li et al. found that gamification of a tutorial was more engaging. (W. Li, Grossman, \& Fitzmaurice, 2012) Gamification is also having success with the popular immersive running app Zombies, Run! ${ }^{14}$ whereby the user runs and a story about being chased by zombies unfolds.

\subsection{Limitations:}

There are a few limitations with our studies that we mention here. For our survey study, our sample size of former users made up only $20 \%$ of total respondents as it was more difficult to recruit former users than current users. Another limitation with those former users is that some of them may have permanently abandoned, while others abandoned but then acquired another device. Their answers may be different. One of the research questions wanted to know whether individuals struggled to make sense of the data, and to act on that data. As with any term, there are multiple definitions of what is called Data Literacy or being data literate. We chose the definition espoused by Mandinach and

\footnotetext{
${ }^{14}$ https://play.google.com/store/apps/details?id=com.sixtostart.zombiesrunclient\&hl=en_CA
} 
Gummer (Mandinach \& Gummer, 2013) which includes a component of being able to interpret data as well as to plan courses of action in order to assess where our respondents and interviewees fall on a spectrum. We based much of our analysis on one graph featuring heart rate data, however, not everyone is deeply familiar with heart rate data so a more thorough assessment featuring multiple visualizations with multiple domains of content would reveal more conclusively how literate they truly are. Furthermore, using an assessment that had been validated would also lead to more conclusive results. Future work would entail such a thorough inquiry.

Additionally, our fitness scale used in the survey of 1-4 is limited by the way respondents may have interpreted the scale when they thought about how they compared themselves with others. Was a 4 a professional athlete, or was a 4 a very fit person they know, which may have influenced whether they gave themselves a 3 , or even a 2 ? Furthermore, this self-report nature also revealed that some respondents provided answers in the survey that indicated they did not take the questions seriously, spoiling their entire answer. They were subsequently removed from the results. Other responses contained sometimes conflicting answers.

Another limitation with the studies pertained to the 2 wearable devices featured in the interviews. Due to sizing, cost, and sanitary constraints we chose to demonstrate the wearable with the researcher, and not the actual participants. While they were able to see the wearable in action and could interact with the data on the researchers iPhone and laptop computer, their engagement was potentially affected. For example, reports from the survey and interviews found that a not uncommon complaint of wearables is their comfort level. 
As the researcher I can say the shorts were very tight, and the insoles did not feel natural, but the participants were unable to provide that direct feedback.

On one occasion the recording of an interview was interrupted by opening the app for the wearable and was only discovered after the fact. The participant and I went over the questions, but some data was lost. 


\section{Chapter 6: Conclusion}

We conducted a 2-part study that consisted of an online survey and in depth semistructured interviews to look into why people abandon wearable fitness trackers. Our survey consisted of 233 total respondents, including 47 people who no longer wear a fitness tracker, from individuals around the world. Our subsequent interviews of 16 former users helped provide deeper insight and allowed us to understand what kinds of issues they faced that were raised in the survey. These datasets and the analyses contribute to an understanding of why users decide to abandon, and what user experiences can help the HCI and Digital Media community's design and develop newer devices with better interfaces creating more meaningful experiences.

Former users complained that their devices were not helping them reach their goals, broke, or were uncomfortable. We also found that the data generated by the devices can be hard to interpret, or even harder to act on and that some users were not adequately supported. However, some users did not sufficiently prepare themselves by taking the time to engage with the manuals, tutorials, or have someone show them how to use the device optimally.

Recommendations were not always provided to the user demonstrating a poor user experience and a barrier to sustained use. They reported that in order to understand their

device more they had to find answers on their own, which suggests that companies that make trackers need to improve their support system. One idea that was explored was whether a compulsory tutorial would ensure users understand all features, as well as 
assessments built-in to the device software to ensure users are literate enough to be able to understand this sensitive data that could save lives, but only when understood. Our research suggests the majority of trackers and former trackers potentially overestimate their ability to make sense of data. Future work includes designing a tutorial with different lengths to identify an ideal length that provides scaffolding but is not too long that it becomes a barrier. The smart insoles that were designed for running could be expanded to help with other sports, like ice hockey or skiing.

The interviews also revealed the potential for other kinds of wearable technology to teach sports or help with rehabilitation, and a discussion surrounding a mindset change is introduced to support the idea that wearable technology should be investigated for its abilities to help people learn more about themselves and challenge the research community to support users through multiple modalities. 


\section{Bibliography}

Ahmed, W. (2019, October 8). Alcohol's effect on sleep, recovery and performance. Retrieved from https:/www.whoop.com/thelocker/podcast-43-alcohol-affects-sleeprecovery-performance/

Alper, B., Riche, N. H., Chevalier, F., Boy, J., \& Sezgin, M. (2017). Visualization literacy at elementary school. Conference on Human Factors in Computing Systems - Proceedings, 2017-May, 5485-5497. https://doi.org/10.1145/3025453.3025877

Andersen, E., O’Rourke, E., Liu, Y. E., Snider, R., Lowdermilk, J., Truong, D., ... Popović, Z. (2012). The impact of tutorials on games of varying complexity. Conference on Human Factors in Computing Systems - Proceedings, (Pajitnov 1984), 59-68. https://doi.org/10.1145/2207676.2207687

Asimakopoulos, S., Asimakopoulos, G., \& Spillers, F. (2017). Motivation and User Engagement in Fitness Tracking: Heuristics for Mobile Healthcare Wearables. Informatics, 4(1), 5. https://doi.org/10.3390/informatics4010005

Athos. Personal communication., (2019).

Attig, C., \& Franke, T. (2020). Abandonment of personal quantification: A review and empirical study investigating reasons for wearable activity tracking attrition. Computers in Human Behavior, 102(September 2019), 223-237. https://doi.org/10.1016/j.chb.2019.08.025

Baron, K. G., Abbott, S., Jao, N., Manalo, N., \& Mullen, R. (2017). Orthosomnia: Are some patients taking the quantified self too far? Journal of Clinical Sleep Medicine, 13(2), 351-354. https://doi.org/10.5664/jcsm.6472

Berkman, N. D., Davis, T. C., \& McCormack, L. (2010). Health Literacy: What Is It? 
Journal of Health Communication, 15(sup2), 9-19.

https://doi.org/10.1080/10810730.2010.499985

Bertini, E. (2016). Data Stories: Data Visualization Literacy with Jeremy Boy, Helen Kennedy and Andy Kirk. Retrieved from https://datastori.es/69-data-visualizationliteracy-with-jeremy-boy-helen-kennedy-and-andy-kirk/

Bertini, E., \& Stefaner, M. (2016). Data Visualization Literacy with Jeremy Boy, Helen Kennedy and Andy Kirk. Retrieved from https://datastori.es/69-data-visualizationliteracy-with-jeremy-boy-helen-kennedy-and-andy-kirk/

Bhargava, R., Deahl, E., Letouzé, E., Noonan, A., Sangokoya, D., \& Shoup, N. (2015). Beyond Data Literacy: Reinventing Community Engagement and Empowerment in the Age of Data. (September).

Blandford, A., Furniss, D., \& Makri, S. (2016). Qualitative HCI Research: Going Behind the Scenes. Synthesis Lectures on Human-Centered Informatics, 9(1), 1-115. https://doi.org/10.2200/s00706ed1v01y201602hci034

Bonikowska, A., Sanmartin, C., \& Frenette, M. (2019). Data literacy: What it is and how to measure it in the public service. (11). Retrieved from http://publications.gc.ca/collections/collection_2019/statcan/11-633-x/11-633x2019003-eng.pdf

Börner, K., Bueckle, A., \& Ginda, M. (2019). Data visualization literacy: Definitions, conceptual frameworks, exercises, and assessments. Proceedings of the National Academy of Sciences of the United States of America, 116(6), 1857-1864. https://doi.org/10.1073/pnas.1807180116

Börner, K., Maltese, A., Balliet, R. N., \& Heimlich, J. (2016). Investigating aspects of 
data visualization literacy using 20 information visualizations and 273 science museum visitors. Information Visualization, 15(3), 198-213.

https://doi.org/10.1177/1473871615594652

Boy, J., Rensink, R. A., Bertini, E., \& Fekete, J.-D. (2014a). A Principled Way of Assessing Visualization Literacy To cite this version : A Principled Way of Assessing Visualization Literacy. IEEE Transactions on Visualization and Computer Graphics, 20(12). https://doi.org/10.1109/TVCG.2014.2346984

Boy, J., Rensink, R. A., Bertini, E., \& Fekete, J. D. (2014b). A principled way of assessing visualization literacy. IEEE Transactions on Visualization and Computer Graphics, 20(12), 1963-1972. https://doi.org/10.1109/TVCG.2014.2346984

Browne, K., \& Anand, C. (2013). Gamification and serious game approaches for introductory computer science tablet software. ACM International Conference Proceeding Series, 50-57. https://doi.org/10.1145/2583008.2583015

Buszard, T., Garofolini, A., Reid, M., Farrow, D., Oppici, L., \& Whiteside, D. (2020). Scaling sports equipment for children promotes functional movement variability. Scientific Reports, 1-8. https://doi.org/10.1038/s41598-020-59475-5

Buthe, L., Blanke, U., Capkevics, H., \& Troster, G. (2016). A wearable sensing system for timing analysis in tennis. BSN 2016 - 13th Annual Body Sensor Networks Conference, 43-48. https://doi.org/10.1109/BSN.2016.7516230

Chan, C. B., Ryan, D. A. J., \& Tudor-Locke, C. (2004). Health benefits of a pedometerbased physical activity intervention in sedentary workers. Preventive Medicine, 39(6), 1215-1222. https://doi.org/10.1016/j.ypmed.2004.04.053

Chatterjee, A., \& Gupta, D. (2018). A study on the factors influencing the adoption / 
usage of wearable gadgets. RTEICT 2017 - 2nd IEEE International Conference on Recent Trends in Electronics, Information and Communication Technology, Proceedings, 2018-Janua, 1632-1635. https://doi.org/10.1109/RTEICT.2017.8256875

Choe, E. K., Lee, B., Zhu, H., \& Riche, N. H. (2017). Understanding self-reflection: How people reflect on personal data through visual data exploration. ACM International Conference Proceeding Series, 173-182. https://doi.org/10.1145/3154862.3154881

Choe, E. K., Lee, N. B., Lee, B., Pratt, W., \& Kientz, J. A. (2014). Understanding quantified-selfers' practices in collecting and exploring personal data. Conference on Human Factors in Computing Systems - Proceedings, 1143-1152. https://doi.org/10.1145/2556288.2557372

Choi, B., Hwang, S., \& Lee, S. H. (2017). What drives construction workers' acceptance of wearable technologies in the workplace?: Indoor localization and wearable health devices for occupational safety and health. Automation in Construction, 84(May), 31-41. https://doi.org/10.1016/j.autcon.2017.08.005

Choi, J., \& Kim, S. (2016). Is the smartwatch an IT product or a fashion product? A study on factors affecting the intention to use smartwatches. Computers in Human Behavior, 63, 777-786. https://doi.org/10.1016/j.chb.2016.06.007

Churchill, E. F., \& Schraefel, M. C. (2015). mHealth + proactive well-being = wellth creation. Interactions, 22(1), 60-63. https://doi.org/10.1145/2690853

Clawson, J., Pater, J. A., Miller, A. D., Mynatt, E. D., \& Mamykina, L. (2015). No longer wearing: Investigating the abandonment of personal health-Tracking technologies on craigslist. UbiComp 2015 - Proceedings of the 2015 ACM International Joint 
Conference on Pervasive and Ubiquitous Computing, 647-658.

https://doi.org/10.1145/2750858.2807554

Consolvo, S., Klasnja, P., McDonald, D. W., Avrahami, D., Froehlich, J., Legrand, L., ... Landay, J. A. (2008). Flowers or a robot army?: Encouraging awareness \& activity with personal, mobile displays. UbiComp 2008 - Proceedings of the 10th International Conference on Ubiquitous Computing, 54-63. https://doi.org/10.1145/1409635.1409644

Degroote, L., Hamerlinck, G., Poels, K., Maher, C., Crombez, G., De Bourdeaudhuij, I., ... DeSmet, A. (2019). Low-Cost Consumer-Based Trackers to Measure Physical Activity and Sleep Duration Among Adults in Free-Living Conditions: Validation Study (Preprint). JMIR MHealth and UHealth. https://doi.org/10.2196/16674

Ellis, D. A., \& Piwek, L. (2018). Failing to encourage physical activity with wearable technology: what next? Journal of the Royal Society of Medicine, 111(9), 310-313. https://doi.org/10.1177/0141076818788856

Epstein, D. A., Caraway, M., Johnston, C., Ping, A., Fogarty, J., \& Munson, S. A. (2016). Beyond abandonment to next steps: Understanding and designing for life after personal informatics tool use. Conference on Human Factors in Computing Systems - Proceedings, 1109-1113. https://doi.org/10.1145/2858036.2858045

Fontanella, J. (2006). Nothing but net? In The Physics of Basketball.

Foundation, H. and S. (2018). How much physical activity do you need? Health Seekers, 501(c), 2-4. Retrieved from https://www.heartandstroke.ca/get-healthy/stayactive/how-much-physical-activity-do-you-need

Galesic, M., \& Garcia-Retamero, R. (2011a). Graph literacy: A cross-cultural 
comparison. Medical Decision Making, 31(3), 444-457.

https://doi.org/10.1177/0272989X10373805

Galesic, M., \& Garcia-Retamero, R. (2011b). Graph Literacy. Medical Decision Making, 31(3), 444-457. https://doi.org/10.1177/0272989X10373805

Getamoveon. (2019). Enabling better health for all: the role for digital technologies to help people move more and stay healthier for longer A response from the GetaMoveOn Network + to Advancing our Health : prevention in the 2020s. Retrieved from https://getamoveon.ac.uk/media/pages/publications/preventiongreen-paper/2325449509-1570702637/enabling-better-health-for-all.pdf

Guthold, R., Stevens, G. A., Riley, L. M., \& Bull, F. C. (2019). Global trends in insufficient physical activity among adolescents: a pooled analysis of 298 population-based surveys with 1.6 million participants. The Lancet Child \& Adolescent Health, 4(November 21), 1-13. https://doi.org/10.1016/S23524642(19)30323-2

Hall, Z. (2017, December 17). How Apple Watch saved one man's life — and how it's empowering him after his heart attack. 9to5Mac. Retrieved from https://9to5mac.com/2017/12/15/apple-watch-saves-life-managing-heart-attack/

Health Spending. (2018). Retrieved from The Canadian Institute for Health Information website: https://www.cihi.ca/en/health-spending

Höök, K. (2015). Somaesthetic Design. Interactions, 22(4). https://doi.org/https://dl.acm.org/doi/10.1145/2770888

Jensen, M. M., \& Mueller, F. F. (2014). Running with technology: Where are we heading? Proceedings of the 26th Australian Computer-Human Interaction 
Conference, OzCHI 2014, 527-530. https://doi.org/10.1145/2686612.2686696

John Hopkins Medicine. (n.d.). Ulnar Collateral Ligament (UCL) Injuries of the Elbow. Retrieved from John Hopkins Medicine website:

https://www.hopkinsmedicine.org/health/conditions-and-diseases/ulnar-collateralligament-ucl-injuries-of-the-elbow

Joon, K. K., \& Dong-Hee, S. (2015). An acceptance model for smart watches: Implications for the adoption of future wearable technology. Internet Research, 25(4), 527-541. https://doi.org/10.1108/IntR-05-2014-0126

Kehaulani Goo, S. (2015). The art and science of the scatterplot. Pew Research Center. Retrieved from https://www.pewresearch.org/fact-tank/2015/09/16/the-art-andscience-of-the-scatterplot/

Lamkin, P. (2018). Smart Wearables Market To Double By 2022: \$27 Billion Industry Forecast. Retrieved from https://www.forbes.com/sites/paullamkin/2018/10/23/smart-wearables-market-todouble-by-2022-27-billion-industry-forecast/\#3631ddaf2656

Lazar, A., Tanenbaum, T. J., Koehler, C., \& Nguyen, D. H. (2015). Why We Use and Abandon Smart Devices. 635-646. https://doi.org/https://doi.org/10.1145/2750858.2804288

Lazard, A. J., Watkins, I., Mackert, M. S., Xie, B., Stephens, K. K., \& Shalev, H. (2016). Design simplicity influences patient portal use: The role of aesthetic evaluations for technology acceptance. Journal of the American Medical Informatics Association, 23(e1), e157-e161. https://doi.org/10.1093/jamia/ocv174

Ledger, D. (2017). Risk Roundup: Furture of wearables. Retrieved from 
https://riskgroupllc.com/future-of-wearables/

Ledger, D., \& Partners, E. (2014). < Endeavour-Partners-Inside-Wearables-Part-2-July2014.pdf>. (June).

Lee, H., \& Lee, Y. (2017). A look at wearable abandonment. Proceedings - 18th IEEE International Conference on Mobile Data Management, MDM 2017, 392-393. https://doi.org/10.1109/MDM.2017.70

Lee, S. Y., \& Lee, K. (2018). Factors that influence an individual's intention to adopt a wearable healthcare device: The case of a wearable fitness tracker. Technological Forecasting and Social Change, 129(January), 154-163.

https://doi.org/10.1016/j.techfore.2018.01.002

Lemire, J. (2019, August 2). New Study Suggests Motus Sensors Can Take the Guesswork Out of Pitching and Save Arms. Retrieved from Sporttechie website: https://www.sporttechie.com/mlb-baseball-motus-sensors-pitcher-exertion-loadmanagement/

Li, I., Dey, A., \& Forlizzi, J. (2010). 2010-A Stage-Based Model of Personal Informatics Systems-ianli-chi-stage-based-model.pdf.

Li, W., Grossman, T., \& Fitzmaurice, G. (2012). GamiCAD: A gamified tutorial system for first time AutoCAD users. UIST'12 - Proceedings of the 25th Annual ACM Symposium on User Interface Software and Technology, 103-112.

Lounassalo, I., Hirvensalo, M., Kankaanpää, A., Tolvanen, A., Palomäki, S., Salin, K., ... Tammelin, T. H. (2019). Associations of leisure-time physical activity trajectories with fruit and vegetable consumption from childhood to adulthood: The cardiovascular risk in young finns study. International Journal of Environmental 
Research and Public Health, 16(22), 1-17. https://doi.org/10.3390/ijerph16224437

Lunney, A., Cunningham, N. R., \& Eastin, M. S. (2016). Wearable fitness technology: A structural investigation into acceptance and perceived fitness outcomes. Computers in Human Behavior, 65, 114-120. https://doi.org/10.1016/j.chb.2016.08.007

Mackert, M., Mabry-flynn, A., Champlin, S., Donovan, E. E., Dean, W., \& Keeton, A. (2016). Health Literacy and Health Information Technology Adoption: The Potential for a New Digital Divide Corresponding Author : 18, 1-16. https://doi.org/10.2196/jmir.6349

Maher, C., Ryan, J., Ambrosi, C., \& Edney, S. (2017). Users' experiences of wearable activity trackers: A cross-sectional study. BMC Public Health, 17(1), 1-8. https://doi.org/10.1186/s12889-017-4888-1

Maltese, A., Harsh, J. A., \& Svetina, D. (2015). Data visualization literacy: investigating data interpretation along the novice-expert continuum. Journal of College Science Teaching, p. vol. 45. https://doi.org/10.2307/j.ctvzgb8c7.19

Mandinach, E. B., \& Gummer, E. S. (2013). A Systemic View of Implementing Data Literacy in Educator Preparation. Educational Researcher, 42(1), 30-37. https://doi.org/10.3102/0013189X12459803

Melugin, H. P., Larson, D. R., Fleisig, G. S., Conte, S., Fealy, S. A., Dines, J. S., ... Camp, C. L. (2019). Baseball Pitchers' Perceived Effort Does Not Match Actual Measured Effort During a Structured Long-Toss Throwing Program. American Journal of Sports Medicine, 47(8), 1949-1954. https://doi.org/10.1177/0363546519850560

Meyer, J., Beck, E., Wasmann, M., \& Boll, S. (2017). Making Sense in the Long Run: 
Long-Term Health Monitoring in Real Lives. Proceedings - 2017 IEEE

International Conference on Healthcare Informatics, ICHI 2017, 285-294.

https://doi.org/10.1109/ICHI.2017.11

Michaelis, J. R., Rupp, M. A., Kozachuk, J., Ho, B., Zapata-Ocampo, D., McConnell, D. S., \& Smither, J. A. (2016). Describing the user experience of wearable fitness technology through online product reviews. Proceedings of the Human Factors and Ergonomics Society, 1072-1076. https://doi.org/10.1177/1541931213601248

Mueller, F., Byrne, R., Andres, J., \& Patibanda, R. (2018). Experiencing the body as play. Conference on Human Factors in Computing Systems - Proceedings, 2018April, 1-13. https://doi.org/10.1145/3173574.3173784

Mull, A. (2019). What 10,000 steps will really get you. The Atlantic. Retrieved from https://www.theatlantic.com/health/archive/2019/05/10000-steps-rule/590785/

Nürnberger, A., Seising, R., \& Wenzel, C. (2009). On the fuzzy interrelationships of data, information, knowledge and wisdom. Annual Conference of the North American Fuzzy Information Processing Society - NAFIPS.

https://doi.org/10.1109/NAFIPS.2009.5156466

ParticipACTION. (2018). The Brain + Body Equation: Canadian kids need active bodies to build their best brains. The 2018 ParticipACTION Report Card on Physical Activity for Children and Youth. 1-114. Retrieved from https://www.participaction.com/sites/default/files/downloads/the_participaction_rep ort_card_on_physical_activity_for_children_and_youth_-_2018.pdf

Perin, C., Vuillemot, R., Stolper, C. D., Stasko, J. T., Wood, J., \& Carpendale, S. (2018). State of the Art of Sports Data Visualization. Computer Graphics Forum, 37(3), 
663-686. https://doi.org/10.1111/cgf.13447

Piwek, L., Ellis, D. A., Andrews, S., \& Joinson, A. (2016). The Rise of Consumer Health Wearables: Promises and Barriers. PLoS Medicine, 13(2), 1-9. https://doi.org/10.1371/journal.pmed.1001953

Portz, J. D., Bayliss, E. A., Bull, S., Boxer, R. S., Bekelman, D. B., Gleason, K., \& Czaja, S. (2019). Using the technology acceptance model to explore user experience, intent to use, and use behavior of a patient portal among older adults with multiple chronic conditions: Descriptive qualitative study. Journal of Medical Internet Research, 21(4). https://doi.org/10.2196/11604

Radenkovic, D., Aswani, R., Ahmad, I., Kreindler, J., \& Robinson, R. (2019). Lifestyle medicine and physical activity knowledge of final year UK medical students. $B M J$ Open Sport and Exercise Medicine, 5(1), 1-5. https://doi.org/10.1136/bmjsem-2019000518

Raichlen, D., \& Alexander, G. (2020). Why Your Brain Needs Exercise. Scientific American, 322(1), 26-31. Retrieved from https://www.scientificamerican.com/article/why-your-brain-needs-exercise/

Rapp, A., \& Cena, F. (2016). Personal informatics for everyday life: How users without prior self-tracking experience engage with personal data. International Journal of Human Computer Studies, 94, 1-17. https://doi.org/10.1016/j.ijhcs.2016.05.006

Rapp, A., \& Tirassa, M. (2017). Know Thyself: A Theory of the Self for Personal Informatics. Human-Computer Interaction, 32(5-6), 335-380. https://doi.org/10.1080/07370024.2017.1285704

Ridgers, N. D., Timperio, A., Brown, H., Ball, K., Macfarlane, S., Lai, S. K., ... Salmon, 
J. (2018). Wearable activity tracker use among australian adolescents: Usability and acceptability study. JMIR MHealth and UHealth, 6(4).

https://doi.org/10.2196/mhealth.9199

Roan, S. (2019, June 4). A prescription for exercise. UCI News. Retrieved from https://news.uci.edu/2019/08/05/a-prescription-for-exercise/

Rosen, L. D., Lim, A. F., Felt, J., Carrier, L. M., Cheever, N. A., Lara-Ruiz, J. M., ... Rokkum, J. (2014). Media and technology use predicts ill-being among children, preteens and teenagers independent of the negative health impacts of exercise and eating habits. Computers in Human Behavior, 35(1), 364-375.

https://doi.org/10.1016/j.chb.2014.01.036

Rozenblit, L., \& Keil, F. (2002). The misunderstood limits of folk science: an illusion of explanatory depth Leonid Rozenblit* and Frank Keil. Online, 26(October 2009), 521-562. https://doi.org/10.1207/s15516709 $\operatorname{cog} 2605$

Ryan, J., Edney, S., \& Maher, C. (2019). Anxious or empowered? A cross-sectional study exploring how wearable activity trackers make their owners feel. BMC Psychology, 7(1), 1-8. https://doi.org/10.1186/s40359-019-0315-y

Schraefel, M. c. (2015). From field to office. Interactions, 22(2), 32-35. https://doi.org/10.1145/2732479

Schüll, N. D. (2016). Data for life: Wearable technology and the design of self-care. BioSocieties, 11(3), 317-333. https://doi.org/10.1057/biosoc.2015.47

Sharit, J., Lisigurski, M., Andrade, A., Karanam, C., Nazi, K., Lewis, J., \& Ruiz, J. (2014). The roles of health literacy, numeracy, and graph literacy on the usability of the VA's personal health record by veterans. Journal of Usability Studies, 9(4), 173- 
193.

Shih, P. C., Han, K., Poole, E. S., Rosson, M. B., \& Carroll, J. M. (2015). Use and Adoption Challenges of Wearable Activity Trackers. IConference Proceedings, (1), 1-12. Retrieved from https://www.ideals.illinois.edu/handle/2142/73649

Shin, G., Jarrahi, M. H., Fei, Y., Karami, A., Gafinowitz, N., Byun, A., \& Lu, X. (2019). Wearable activity trackers, accuracy, adoption, acceptance and health impact: A systematic literature review. Journal of Biomedical Informatics, 93(October 2018), 103153. https://doi.org/10.1016/j.jbi.2019.103153

Singh, A., Bianchi-Berthouze, N., \& Williams, A. C. (2017). Supporting Everyday Function in Chronic Pain Using Wearable Technology. Proceedings of the 2017 CHI Conference on Human Factors in Computing Systems - CHI '17, 2017-May, 3903-3915. https://doi.org/10.1145/3025453.3025947

Spiel, K., Kayali, F., Horvath, L., Penkler, M., Harrer, S., Sicart, M., \& Hammer, J. (2018). Fitter, happier, more productive? The normative ontology of fitness trackers. Conference on Human Factors in Computing Systems - Proceedings, 2018-April, 110. https://doi.org/10.1145/3170427.3188401

Stables, J. (2020, April 15). Best fitness tracker 2020: steps, sleep and HR monitoring wearables. Wareable. Retrieved from https://www.wareable.com/fitnesstrackers/the-best-fitness-tracker

Stafford, S. P. (2009). Data, information, knowledge, and wisdom. Knowledge Management, Organizational Intelligence And Learning, And Complexity, 3, 179.

Thompson, W. R. (2019). Worldwide Survey of Fitness Trends for 2020. ACSM's Health and Fitness Journal, 23(6), 10-18. https://doi.org/10.1249/FIT.0000000000000526 
Toner, J. (2018). Performance Enhancement \& Health Exploring the dark-side of fitness trackers : Normalization, objectification and the anaesthetisation of human experience. Performance Enhancement \& Health, 6(2), 75-81. https://doi.org/10.1016/j.peh.2018.06.001

Tudor-Locke, C., Hatano, Y., Pangrazi, R. P., \& Kang, M. (2008). Revisiting “how many steps are enough?" Medicine and Science in Sports and Exercise, 40(7 SUPPL.1). https://doi.org/10.1249/MSS.0b013e31817c7133

Vamos, S., \& Klein, K. (2018). Our self-tracking movement and health literacy: are we really making every moment count? Global Health Promotion, 25(2), 85-89. https://doi.org/10.1177/1757975916660674

Vogel, L. (2017). Overweight or overfat? Many Canadians are both. CMAJ : Canadian Medical Association Journal = Journal de l'Association Medicale Canadienne, 189(37), E1202-E1203. https://doi.org/10.1503/cmaj.109-5472

Wittfeld, K., Jochem, C., Dörr, M., Schminke, U., Gläser, S., Bahls, M., ... Grabe, H. J. (2020). Cardiorespiratory Fitness and Gray Matter Volume in the Temporal, Frontal, and Cerebellar Regions in the General Population. Mayo Clinic Proceedings, 95(1), 44-56. https://doi.org/10.1016/j.mayocp.2019.05.030

Wolf, P., Menzel, F., \& Rennhak, C. (2018). An Extension of the Technology Acceptance Model tailored to Wearable Device Technology. Munich Business School Working Paper Series.

Wolff, A., \& Montaner, J. J. C. (2016). Creating an Understanding of Data Literacy for a Data-driven Society. 12, 9-26.

Xiong, C. (2019). Same Data, Multiple Perspectives: Curse of Expertise in Visual Data 
Communication. Medium. Retrieved from https://medium.com/multiple-viewsvisualization-research-explained/same-data-multiple-perspectives-curse-ofknowledge-in-visual-data-communication-d827c381f936

Xiong, C., van Weelden, L., \& Franconeri, S. (2019). The Curse of Knowledge in Visual Data Communication. IEEE Transactions on Visualization and Computer Graphics, PP(c), 1-1. https://doi.org/10.1109/TVCG.2019.2917689

Yang, R., Shin, E., Newman, M. W., \& Ackerman, M. S. (2016). When Fitness Trackers Don ' $t$ 'Fit ': End - User D ifficulties in the Assessment of Personal Tracking Device A ccuracy. (September). https://doi.org/10.1145/2750858.2804269

Young, L. (2018, September 24). Canada's obesity rate has doubled since the 1970s. What happened? Retrieved from https://globalnews.ca/news/4456664/obesity-incanada/

Zhao, Z., Ali Etemad, S., \& Arya, A. (2016). Gamification of exercise and fitness using wearable activity trackers. Advances in Intelligent Systems and Computing, 392, 233-240. https://doi.org/10.1007/978-3-319-24560-7_30

Zhao, Z., Arya, A., Whitehead, A., Chan, G., \& Etemad, S. A. (2017). Keeping users engaged through feature updates: A long-term study of using wearable-based exergames. Conference on Human Factors in Computing Systems - Proceedings, 2017-May, 1053-1064. https://doi.org/10.1145/3025453.3025982

Zimmermann-Niefield, A., Shapiro, R. B., \& Kane, S. (2019). Sports and machine learning: How young people can use data from their own bodies to learn about machine learning. XRDS: Crossroads, The ACM Magazine for Students, 25(4), 4449. https://doi.org/10.1145/3331071 


\title{
Appendix A
}

\section{Ethics Approval and forms}

\author{
- Carleton \\ । \\ Canada's Capital University \\ Office of Research Ethics \\ 503 Robertson Hall | 1125 Colonel By Drive \\ Ottawa, Ontario K1S 5B6 \\ 613-520-2600 Ext: 4085 \\ ethics@carleton.cs
}

\section{CERTIFICATION OF IN STITUTIONAL ETHICS CLEARANCE}

The Carleton University Research Ethics Board-B (CUREB-B) has granted ethics clearance for the research project described below and research may now proceed. CUREB-B is constituted and operates in compliance with the Tri-Council Policy Statement: Ethical Conduct for Research Involving Humans (TCPS2).

Ethics Protocol Clearance ID: Project \# 110810

Research Team: Simon Eden-Walker (Primary Investigator)

Dr. Audrey Girougrd (Research Supervisor)

Project Title: Interpreting data generated by Wearable Fitness Trackers.

Funding Source (If applicable):

\begin{tabular}{ll|l} 
TAwards File & Title \\
\hline 106735 & Design and Evaluation of Screen-less Deformable User & Interfaces \\
\hline
\end{tabular}

Effective: May 01, 2019

Expires: May 30, 2020.

Please ensure the study clearance number is prominently placed in all recruitment and consent materials: CUREB-B Clearance \# 110810.

\section{Restrictions:}

This certification is subject to the following conditions:

1. Clearance is granted only for the research and purposes described in the application.

2. Any modification to the approved research must be submitted to CUREB-B via a Change to Protocol Form. All changes must be cleared prior to the continuance of the research.

3. An Annual Status Report for the renewal of ethics clearance must be submitted and cleared by the renewal date listed above. Failure to submit the Annual Status Report will result in the closure of the filelff funding is associated, funds will be frozen. 
4. A closure request must be sent to CUREB-B when the research is complete or terminated.

5. During the course of the study, if you encounter an adverse event, material incidental finding. protocol deviation or other unanticipated problem, you must complete and submit a Report of Adverse Events and Unanticipated Problems Form, found here:

https://carleton.ca/researchethics/forms-and-templates/

Failure to conduct the research in accordance with the principles of the Tri-Council Policy Statement. Ethical Conduct for Research Involving Humans 2ndedition and the Carleton University Policies and

Procedures for the Ethical Conduct of Research may result in the suspension or termination of the research project.

Upon reasonable request, it is the policy of CUREB, for cleared protocols, to release the name of the PI, the title of the project, and the date of clearance and any renewal(s).

Please contact the Research Compliance Coordinators, at ethics@carleton.ca, if you have any questions.

CLEARED BY:

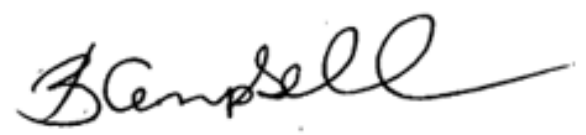

Bernadette Campbell, PhD, Chair, CUREB-B

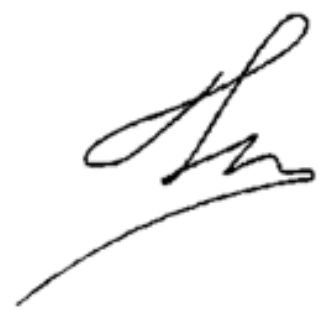

Natasha Artemeva, PhD, Vice-Chair, CUREB-B
Date: May 01, 2019 
This Form is for research projects meeting all the following criteria. If you have any doubt about whether your study may use this form, or questions about its completion, please contact the Research Ethics Office at ethics@carleton.ca or by phone to 6135202600 ext. 2517 (CUREB A) or ext. 4085 (CUREB B).

1. The risks to participants are very low;

2. No research procedures involve any physically invasive intervention;

3. Participants are legally capable of consenting on their own behalf, and are free from coercion or undue influence;

4. Any accidental or intentional disclosure of the participants' responses would not reasonably place participants at risk of criminal or civil liability, harmful retaliation, or be damaging to the participants' emotional or financial well-being, employability, or reputation;

5. The study does not involve recruitment by a third party; and

6. The study does not involve deception or providing incomplete information to participants.

By submitting the Form, the Lead Researcher and academic supervisor, if any, attests that the Project meets all of the above requirements and to the Declarations in Section 6 of this Form.

\section{Project Title and Team}

\subsection{Submission Date: $\mathbf{4} / 2 / 2019$}

1.2 Project Title: Interpreting data generated by Wearable Fitness Trackers.

1.3 Lead Researcher (name, email, department, institution) Technology

Simon Eden-Walker, simonedenwalker@cmail.carleton.ca, School of Information
1.4
Academic Supervisor
Not Applicable
Dr. Audrey Girouard

1.5 Project Team Members

1.6 TCPS CORE Tutorial: TCPS training is required for all researchers. Attach Completion Certificates or justify any cases in which researchers have not completed the TCPS tutorial.

\section{Project Description}

\subsection{Is this Project Funded? $\bigotimes$ Yes $\square$ No If Yes, by whom?}

NSERC Discovery grant - CURO $\$ 106735$

2.2 Study Goal: briefly explain the primary objective(s) of the current study.

The primary objective is to determine what kind of data users are interested in getting from a wearable fitness device and how exactly it should be displayed in order to be useful and usable.| 


\subsection{Study Rationale and Expected Benefits: Why should the study be done? What are the} benefits, and to whom?

The results will inform the wearable fitness technology industry which is still in its infancy. It will further help the design of future wearables by understanding how potential users would like to use the data that is generated and to display it in a way that is easy to digest and interpret. Users may benefit by increasing the awareness of their health and performance leading to healthier and happier and better-informed populace.

\subsection{Overview of Methodology and Participant Interactions: Briefly describe the study methodology and what will be required of participants for this study.}

This study will be conducted in 2 phases.

The first phase involves conducting a survey of users who have previously and or currently use wearable fitness trackers. Participants will be asked to answer questions asking about their experiences and perspectives using wearable fitness trackers. The second stage involves using semi-structured interviews of participants and asking them similar questions from the survey and elaborating on answers provided by the survey.

The phase two participants will also be asked to wear a wearable fitness tracker and be asked to perform a simple exercise task of running on the spot for a short period of time (e.g. 30 seconds) and performing squats to generate fitness data. The data will then be analyzed by the participant to assess understanding and usability. Participants will be asked to interpret the data generated as shown by the interface. Participants will be videotaped in order to be assessed later for usability issues.

\section{Participants and Informed Consent}

\subsection{Description of the participants and any inclusion/exclusion criteria:}

For stage one, participants that are eighteen years of age or older will be recruited online via social media, as well as at select City of Ottawa recreation facilities, and around Carleton campus. Participants who haven't used a wearable fitness tracker in the past will be excluded.

Participants for stage two will be recruited from Carleton University, and City of Ottawa recreation facilities. Physical Flyers will be displayed around campus as well as online flyers will be posted on social media. Two groups are being targeted, one groups which is physically active and exercises on a regular basis. The other group will be those that do not identify as exercising on a regular basis. Participants with experiences using wearable fitness will be surveyed and interviewed to gain their perspective in order to learn how to better design wearable fitness trackers and interfaces in the future. 


\subsection{How many participants do you plan to recruit?}

For phase 1 , we are anticipating around 100 responses. For the second phase, 20 participants, with ideally 10 in each group will be recruited.

3.3 Describe how participants will be recruited including how contact information will be obtained. How will participants be made aware of the study, where will recruitment materials be located, and how may participants express their interest? Attach a copy of any recruitment materials including oral scripts, recruitment posters, emails and social media postings, etc.

Participants will be recruited via the Facebook group "Carleton Research Participants", as well as other social media. Flyers will also be posted on campus at select locations, as well select City of Ottawa recreation facilities. Flyers and invitations will include contact information of the lead researcher.

3.4 Describe any compensation or remuneration for participants and indicate when participants will receive the compensation. What happens to compensation if a participant withdraws early?

Participants who complete the survey for phase 1 will be entered into a draw to win one of two gift cards ( $\$ 50$ value each)- while participants who participate in phase 2 will be compensated $15 \$$. Only those that complete phase 2 of the study will be compensated the 15

3.5 Describe the process for a participant to withdraw their data after collection, and the time limits, if any.

Participants will not be allowed to withdraw after their data has been submitted.

3.6 Describe the process of obtaining informed consent from participants and include a copy of the consent form(s) and materials. If signed consent is not to be used, justify the alternative method chosen.

Participants in phase one will electronically sign a consent form prior to starting the study. Participants in phase 2 will be asked to complete a written consent form before the study has commenced.

\section{Data Collection, Use, and Storage}

4.1 Describe how data will be collected and any instruments to be used. Provide a copy of any questionnaires, surveys, interview guides or other data collection materials.

Survey data will be collected via Qualtrics using the website Amazon Mechanical Turk. Interview data will be videotaped and transcribed by the lead researcher. Survey and Interview material is attached.

4.2 Aside from the PI, who will have access to research data?

- Supervisor (Dr. Audrey Girouard)

4.3 Describe the identifiability of research data, including how codes or pseudonyms will be assigned.

Data will contain information that directly identifies participants. 


\section{RESEARCH INVOLVING VERY LOW RISK}

Data will contain information that may indirectly identify participants.

Data will be coded with the code key stored securely and separate from identifying information.

Data will be de-identified (anonymized) with any identifiers destroyed. will be coded.

For the first study, the data will be de-identified. For the second study, participants data

4.4 Describe the physical (e.g. locked filing cabinet) and/or technical safeguards (e.g. Encryption) that will be used to securely store the collected data. Where will data be stored?

Data will be kept under lock and key in a cabinet in the Creative Interactions Lab, Human Computer Interaction building at Carleton.

4.5 After project completion, describe whether and how the data will be stored for future use. If shared, with whom? If made public, how (e.g. online)? If archived, provide details. Describe any restrictions on access. Will personal identifiers be deleted and when? If data will be destroyed, when? Will participant contact information be kept for future recruitment? (Include data disposition plans in the consent materials).

kept.

Data will not be retained beyond 5 to 7 years. Participant contact information will not be

\section{Attachments}

5.1 Please indicate any attached materials.

ITCPS 2 Tutorial Course on Research Ethics (CORE) tutorial certificate for each team member Sample letters of information, recruitment materials, consent forms and/or scripts, debriefing forms Sample of data collection instruments (survey questionnaires, test instruments, etc.)

Supervisor approval form (if applicable)

Permission letters from partner organizations (if applicable)

\subsection{Provide a brief rationale if an attachment(s) is not available at time of submission.}

6. Declarations

- The information in this Form is correct and accurately describes the research project.

- No recruitment or data collection for this protocol will start before receiving ethics clearance.

- I (we) will carry out this project in accordance with the information in this Form and the other submitted documents. No changes will be made to the research project as described in this protocol without clearance from the Research Ethics Board. 


\section{RESEARCH INVOLVING VERY LOW RISK}

- I will promptly notify the Research Ethics Board of any ethical breaches or concerns, adverse events, unanticipated problems or complaints that arise relating to this research project.

7. Comments

Do you have any comments or suggestions to improve this form?

| 


\section{Research Consent Form for Phase 2}

\section{Name and Contact Information of Researchers:}

Simon Eden-Walker - simonedenwalker@cmail.carleton.ca

Carleton University, School of Information Technology

Tel.: 613-668-1618

Email: simonedenwalker@cmail.carleton.ca

Supervisor and Contact Information: Audrey Girouard - audreygirouard@ cunet.carleton.ca

\section{Project Title}

Interpreting data generated by Wearable Fitness Trackers

Project Sponsor and Funder (if any)

$=106735$

\section{Carleton University Project Clearance}

Clearance $=: 110810 \quad$ Date of Clearance: May $1^{\text {st }}, 2019$

\section{Invitation}

You are invited to take part in a research project because you have experience using wearable devices. The information in this form is intended to help you understand what we are asking of you so that you can decide whether you agree to participate in this study. Your participation in this study is voluntary, and a decision not to participate will not be used against you in any way. As you read this form, and decide whether to participate, please ask all the questions you might have, take whatever time you need, and consult with others as you wish.

\section{What is the purpose of the study?}

Data generated by fitness apps, smart garments, and wearable fitness trackers are rich and helpful for users who are monitoring health or seeking to improve performance. However, interpreting the data that is generated and displayed is not always clear and leads to confusion and potentially abandonment. This study hopes to understand to what data users are hoping to be generated and how it should be displayed in order to be useable and of value.

\section{What will I be asked to do?}

If you agree to take part in the study, we will ask you to:

Participate in a case study using a wearable fitness tracker. You will be asked to perform a simple, low risk exercise to generate data. You will then be asked to interpret the data that is presented. You will also be asked to participate in a semi-structured interview to gain insight into the experience. The study is 
expected to take less than an hour on Carleton campus. The interview will be videotaped in order to see how users interact with fitness tracker and the user interface.

Risks and Inconveniences

Participants will perform a low intensity exercise( squatting, running on the spot), so there is low risk of injury.

\section{Possible Benefits}

You may not receive any direct benefit from your participation in this study. However, your participation may allow researchers to better understand how wearable fitness trackers are designed in the future

\section{Compensation/Incentives}

You will be compensated for your participation in this study at $15 \$$

\section{No waiver of your rights}

By signing this form, you are not waiving any rights or releasing the researchers from any liability.

\section{Withdrawing from the study}

If you withdraw your consent during the course of the study, all information collected from you before your withdrawal will be discarded.

\section{Confidentiality}

We will remove all identifying information from the study data as soon as possible.

We will treat your personal information as confidential, although absolute privacy cannot be guaranteed. No information that discloses your identity will be released or published without your specific consent. Research records may be accessed by the Carleton University Research Ethics Board in order to ensure continuing ethics compliance.

All data will be kept confidential, unless release is required by law (e.g. child abuse, harm to self or others).

The results of this study may be published or presented at an academic conference or meeting, but the data will be presented so that it will not be possible to identify any participants unless you give your express consent.

You will be assigned a code [or pseudonym] so that your identity will not be directly associated with the data you have provided. All data, including coded information, will be will be kept in a passwordprotected file on a secure computer.

Your data will be stored and protected by Carleton, but may be disclosed via a court order or data breach. We will password protect any research data that we store or transfer.

\section{Data Retention}

Your de-identified data will be retained for a period of 5 years and then securely destroyed. 


\section{New information during the study}

In the event that any changes could affect your decision to continue participating in this study, you will be promptly informed.

\section{Ethics review}

This project was reviewed and cleared by the Carleton University Research Ethics Board [B]. If you have any ethical concerns with the study, please contact Dr. Bernadette Campbell, Chair, Carleton University Research Ethics Board (by phone at 613-520-2600 [ ext. 4085 for CUREB B] or by email at ethics@carleton.ca).

\section{Statement of consent - print and sign name}

I voluntarily agree to participate in this study. Yes_._Ne

I agree to be (audio/video recorded) _ Xesmons

Signature of participant / Date

Research team member who interacted with the subject

I have explained the study to the participant and answered any and all of their questions. The participant appeared to understand and agree. I provided a copy of the consent form to the participant for their reference.

Signature of researcher / Date 


\title{
Have you ever used a wearable fitness tracker?
}

\author{
Win one of two $\$ 50$ gift cards!
}

To participate you must be:

- At least 18 years old

-Comfortable in the English Language

Have used, or are using, a wearable fitness tracker( e.g Fitbit, Apple Watch, etc.)

Follow the link and complete the survey at:

\section{bit.ly/2JXtvRI}

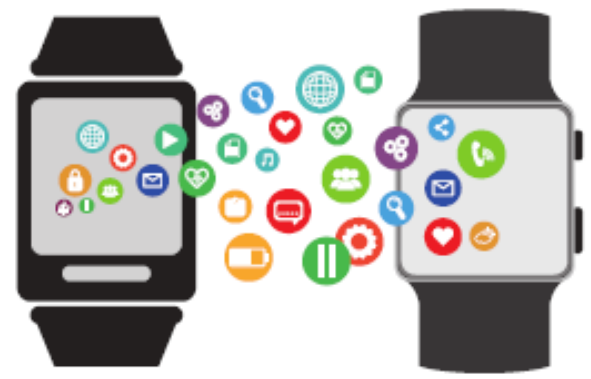

This is an online study that should take around 10-15 minutes. You will be asked to answer questions around your experience with Fitness apps, fitness trackers and wearable smart garments

Please contact the researcher, Simon Eden-Walker, for more details on this study at simon.edenwalker@carleton.ca

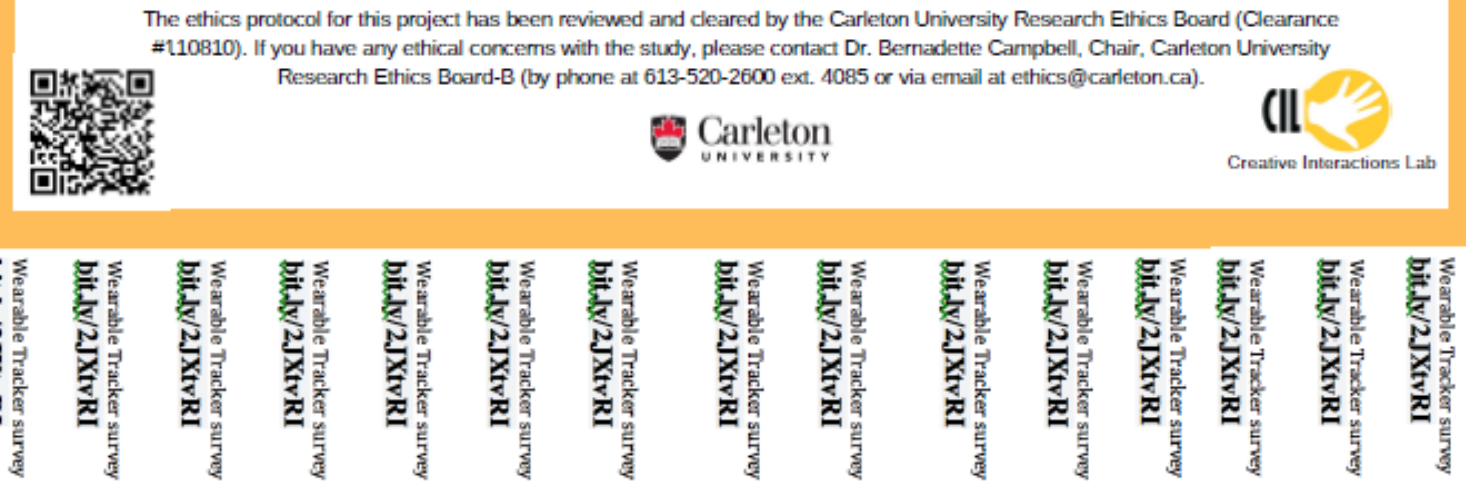




\section{Have you ever abandoned using a wearable fitness tracker?}

To participate you must be:

- At least 18 years old

-Comfortable in the English Language

Have used and given up wearing a wearable fitness tracker (Fitbit, Apple Watch, etc.)
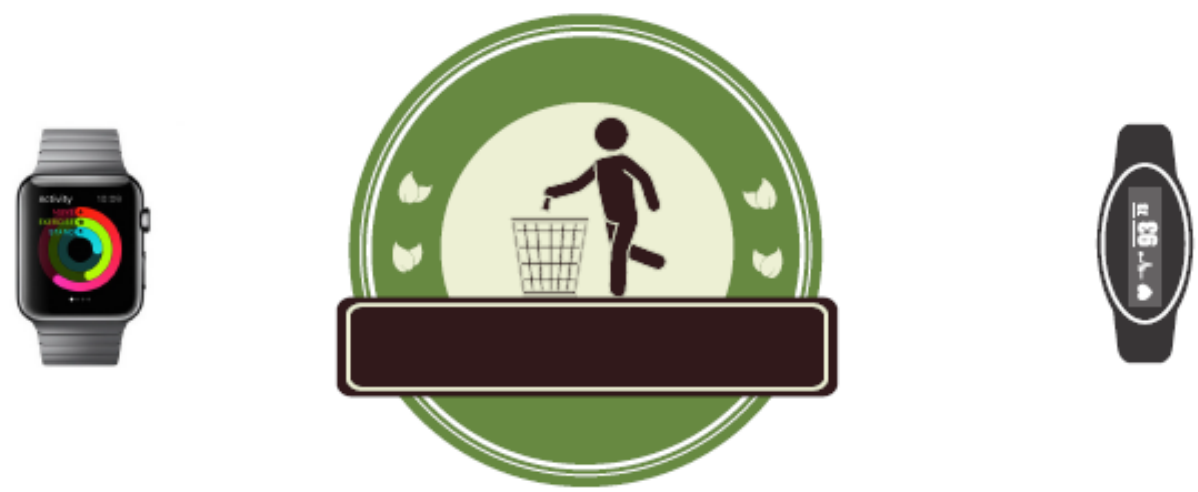

This is study takes place at Carleton University and should take around 60 minutes. You will be asked to wear your wearable fitness tracker(if you still possess it) and generate data through short exercise.

We will then conduct an interview around your experiences with the device.

You will be compensated $\$ 15$ for participating.

Please contact the researcher (Simon Eden-Walker) for more details or on this study or setting up an appointment at (simon.edenwalker@carleton.ca)

The ethics protocol for this project has been reviewed and cleared by the Carleton University Research Ethics Board (Clearance \#10810). If you have any ethical concerns with the study, please contact Dr. Bernadette Campbell, Chair, Carleton University Research Ethics Board-B (by phone at 613-520-2600 ext. 4085 or via email at ethics@carleton_ca).

\section{- Carleton}

(II

Creative Intoractions Lab
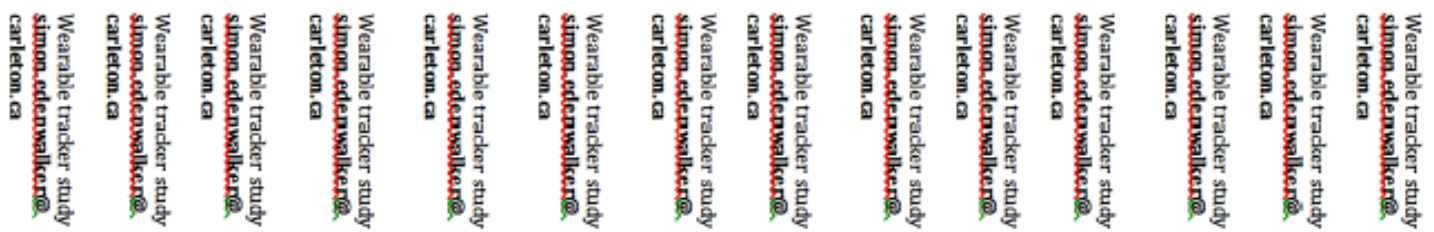


\title{
Appendix B
}

Survey for Part 1

\section{Experiences using Wearable Fitness Trackers}

\author{
Consent Research Consent Text for Survey Name and Contact Information of \\ Researchers: Simon Eden-Walker, Carleton University, School of Information Technology \\ Tel.: 613-668-1618 Email: \\ simonedenwalker@cmail.carleton.ca \\ Supervisor and Contact Information: Dr. Audrey Girouard AudreyGirouard@cunet.carleton.ca \\ Project Title: \\ How do we interpret data generated by Wearable Fitness Trackers. \\ Project Sponsor and FunderNSERC Discovery grant - CURO \#106735 Carleton University \\ Project Clearance \\ CUREB-B Clearance \# 110810 \\ Date of Clearance: May 1st 2019
}

We are asking you to complete this survey because you have experience using a wearable fitness tracker and your perspective is valuable. This survey is being conducted by Simon EdenWalker of the Carleton University School of Information Technology working under the supervision of Dr. Audrey Girouard. The study is funded by NSERC Discovery grant - CURO \#106735 Completing the survey will enter you into a draw for a chance to win one of two $\$ 50$ gift cards.

\section{Objectives and Summary:}

The aim of this study is to better understand how users understand and interpret data. Data generated by fitness apps, smart garments, and wearable fitness trackers are rich and helpful for users who are monitoring health or seeking to improve performance. However, interpreting the data that is generated and displayed is not always clear and leads to confusion and potentially abandonment. This study hopes to understand what data users are hoping to be generated and how it should be displayed in order to be useable and of value. We estimate that the survey will take about 10-15 minutes to complete. Your participation in this survey is voluntary, and you may choose not to take part. Not all questions need to be answered ( e.g. do not apply to you), but there are some mandatory questions in order to progress through the survey. Once you have submitted the survey, we will be unable to remove your responses from survey data. You may choose to end the survey before it is complete, and the data will not be saved.

Risks and Benefits: We do not anticipate any risks from taking the survey, nor do we anticipate that you will derive any benefit. Data generated from surveys may be used in presentations and/or publications to support contributions to research.

Confidentiality and Data Storage: We will treat your personal information as confidential, although absolute privacy cannot be guaranteed. No information that discloses your identity will 
Page 1 of 18 
be released or published without your specific consent. Research records may be accessed by the Carleton University Research Ethics Board in order to ensure continuing ethics compliance. All data will be kept confidential, unless release is required by law (e.g. child abuse, harm to self or others). The results of this study may be published, but the data will be presented so that it will not be possible to identify you. Our data will be stored and protected by Qualtrics on Toronto-based servers but may be disclosed via a court order or data breach.All research data will be password-protected and any hard copies of data will be kept in a locked cabinet at Carleton University. De-identified data will be retained for a period of 5-7 years and then securely destroyed. Email addresses will be retained for only the purpose of contacting the winners of the draw.

REB Review and Contact Information: This project was reviewed and cleared by the Carleton University Research Ethics Board. If you have any ethical concerns with the study, please contact Dr. Bernadette Campbell, Chair by phone at 613-520-2600 ext. [4085 for CUREB B] or by email at ethics@carleton.ca. Implied consent: By completing the online survey, you are agreeing to participate in the study.

○ Yes, I consent (1)

No, I do not consent (2)

Skip To: End of Block If Research Consent Text for Survey Name and Contact Information of Researchers: Simon Eden-Walker,... = Yes, I consent

Skip To: End of Survey If Research Consent Text for Survey Name and Contact Information of Researchers: Simon Eden-Walker,... = No, I do not consent

End of Block: Consent

Start of Block: Demographics

Q7 How old are you in years?

Page 2 of 18 
Q8 What gender are you?
○ Male (1)
○ Female (2)
○ Prefer to self describe (4)
- Prefer not to say (3)

Q9 What is your highest level of education that you have completed?

○ High school (1)

$\circ \quad$ Undergraduate (2)

○ Post graduate (3)

O Other (4)

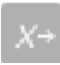

Q48 In which country are you from?

$\nabla$ Canada (31) ... Zimbabwe (581)

Page 3 of 18 
Q10 How would you rate your physical fitness? ( $1=$ low, 4 = high)
$\circ 1(1)$
$\circ 2(2)$
$\circ 3(3)$
$\circ 4(4)$

\section{End of Block: Demographics}

Start of Block: Experience

Q1 Are you currently using a wearable fitness tracker?
$\bigcirc \quad$ Yes (1)
$\circ \quad$ No (2)

Q2 Have you ever used a wearable fitness tracker?
$\bigcirc \quad$ Yes (1)
$\circ \quad$ No (2)

Skip To: Q3 If Have you ever used a wearable fitness tracker? = Yes

Skip To: End of Survey If Have you ever used a wearable fitness tracker? = No

Q3 What's the name of the wearable fitness tracker? 
Q44 For how many months did you use it?

Q4 After giving up your wearable fitness tracker, how many days did you get at least 30 minutes of moderate intensity physical activity? ( Physical activity is defined as getting your heart rate up, i.e., not merely walking)

Q5 Please list all the wearable fitness trackers you've used and for how many months you used it._._.

Q6 Before you got your wearable fitness tracker, in a typical week, how many days did you get at least 30 minutes of moderate intensity physical activity? (Physical activity is defined as getting your heart rate up, i.e., not merely walking)

\section{End of Block: Experience}

\section{Start of Block: fitness and reasons}

Q11 Have you ever used a smart garment? ( A smart garment is clothing that has embedded sensors to monitor the physical condition, and not a wrist worn device. For example, Hexoskin Smart shirt, Athos shorts, Sensoria smart socks etc.)

\section{$\bigcirc$ Yes (1)}

No (2) 
Q12 Which smart garment and what did you use it for?

Q13-Whatwas the reason you-deciđed to-wear the wearable-tracker in the-first place? Fick-all-that apply

To improve fitness (1)

To improve health (2)

to improve appearance (3)

to monitor activities (4)

to share my activity (5)

to compete with friends/family (6)

to keep up with new technology (7)

Other(Please specify) (8) 
Q14 What have you done with the data generated by the fitness tracker? Tick all that apply

Charted progress (1)

Consulted with a trainer (2)

Didn't know what to do (3)

Didn't do anything (4)

Planned a course of action (5)

Other( please specify) (6) 
Q15 What is the reason you stopped using your wearable? Tick all that apply

It broke (1)

Got lost (2)

It was difficult to understand (3)

Technical difficulties (4)

I could not interpret the data (5)

It wasn't helping with my goals (6)

I didn't like it (7)

I found it intrusive (8)

I didn't know what to do with the data (9)

I was experiencing negative psychological impacts (10)

I learnt everything I could from it (11)

Other ( please specify) (12)

Q16 Before using the wearable fitness tracker did you read the manual?

$\bigcirc \quad$ Yes (1)

No (2)

Page 8 of 18 
Q17 Before using the wearable fitness tracker did someone show you how to use it?

$\bigcirc \quad$ Yes(1)

No (2)

Q18 Before using the wearable fitness tracker did you watch a tutorial?

$\bigcirc \quad$ Yes(1)

No (2)

\section{End of Block: fitness and reasons}

Start of Block: Interpretation 
Q19 Did you have any complaints with your wearable fitness tracker? Tick all that apply

None (1)

technical issues (2)

it falls off (3)

it doesn't fit (4)

it is uncomfortable (5)

lost it (6)

low battery life (7)

general wear and tear (8)

it often does not match my outfit (9)

problems with the screen (10)

problems uploading the data to supporting software (11)

problems interpreting data (12)

problems with navigation of supporting website and technology (13)

inaccurate at recording data (14)

Other(please specify) (15)

Page 10 of 18 
Q20 How much do you agree/disagree with the following statement

\begin{tabular}{|c|c|c|c|c|c|}
\hline & $\begin{array}{l}\text { Strongly } \\
\text { agree (1) }\end{array}$ & $\begin{array}{c}\text { Somewhat } \\
\text { agree (2) }\end{array}$ & $\begin{array}{c}\text { Neither agree } \\
\text { nor disagree } \\
\text { (3) }\end{array}$ & $\begin{array}{c}\text { Somewhat } \\
\text { disagree (4) }\end{array}$ & $\begin{array}{c}\text { Strongly } \\
\text { disagree (5) }\end{array}$ \\
\hline $\begin{array}{l}\text { I have had } \\
\text { trouble } \\
\text { interpreting } \\
\text { the data } \\
\text { generated by } \\
\text { a fitness } \\
\text { tracker (1) }\end{array}$ & 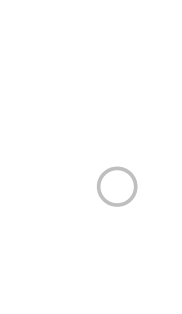 & & & & ( \\
\hline $\begin{array}{l}\text { I have had } \\
\text { trouble } \\
\text { deciding what } \\
\text { to do with the } \\
\text { data } \\
\text { generated (2) }\end{array}$ & 0 & $\cap$ & 0 & & 0 \\
\hline
\end{tabular}

Q21 If you had trouble understanding or interpreting data, what did you have trouble with? Please give concrete examples 
Q22 What did you do to solve the problem you were having?
Read the manual (1)
Watched a tutorial (2)
Asked a friend or family (3)
Consulted a fitness professional (4)
Other( Please specify) (5)

Q23 How much do you agree/disagree with the following statements

$\begin{array}{lcccc}\text { Strongly } & \text { Somewhat } & \begin{array}{c}\text { Neither agree } \\ \text { nor disagree }\end{array} & \begin{array}{c}\text { Somewhat } \\ \text { disagree (4) }\end{array} & \begin{array}{c}\text { Strongly } \\ \text { disagree (5) }\end{array} \\ \text { agree (1) } & \text { agree (2) } & (3) & & \end{array}$

I can

understand

graphs well

(1)

I can make sense of physiological data (2)

I can plan a course of action based on the results

(3) 
Q24 Please look at this data of a man's heart rate. This represents each night that the man was sleeping.

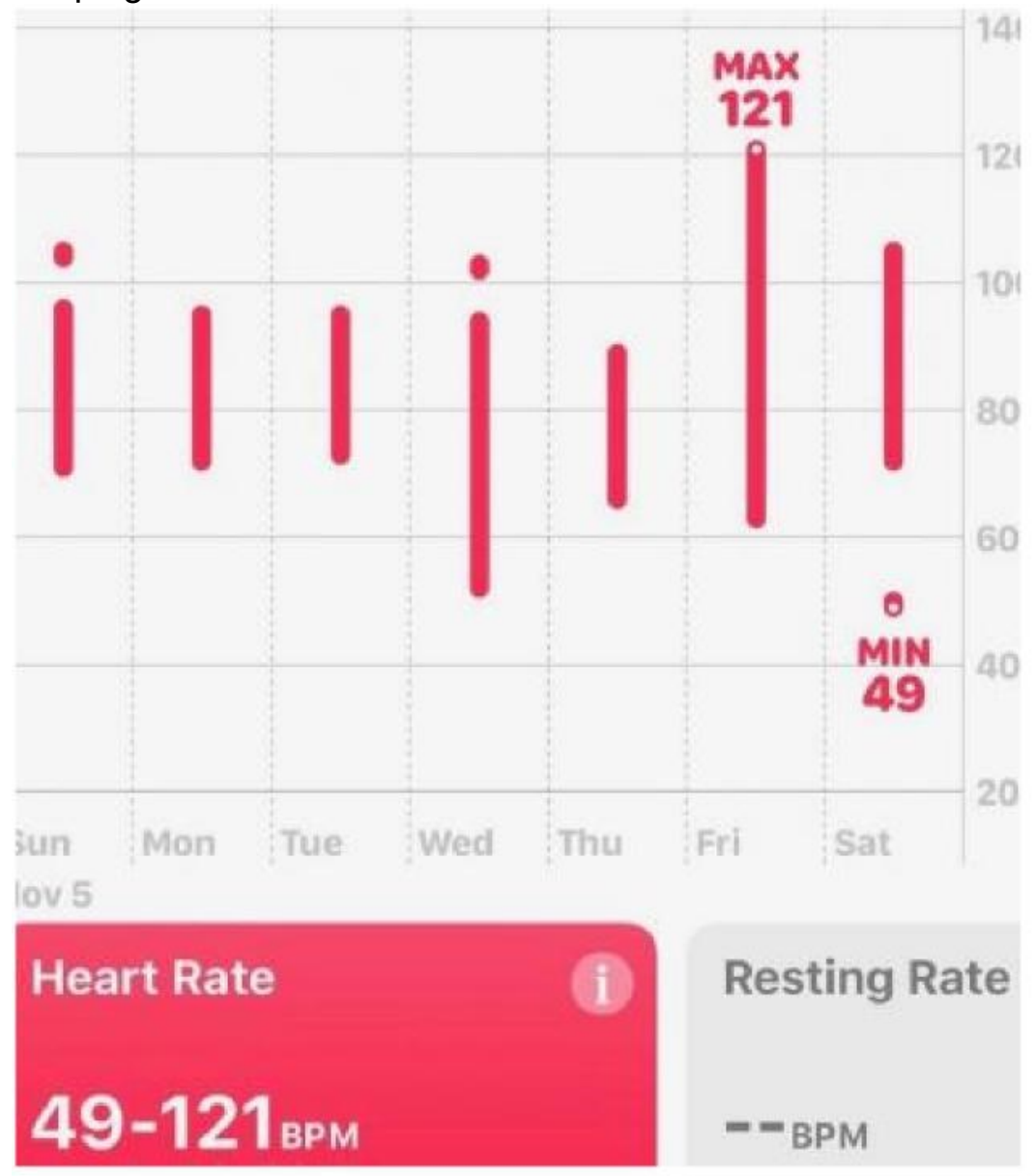

Q25 With the above data, what can you understand from the data? What might you do with this data?

Page 13 of 18 
Q26 How much do you agree/disagree with the following statements? My experience with my wearable made me feel...

\begin{tabular}{|c|c|c|c|c|c|}
\hline & $\begin{array}{l}\text { Strongly } \\
\text { agree (1) }\end{array}$ & $\begin{array}{c}\text { Somewhat } \\
\text { agree (2) }\end{array}$ & $\begin{array}{c}\text { Neither agree } \\
\text { nor disagree } \\
\text { (3) }\end{array}$ & $\begin{array}{c}\text { Somewhat } \\
\text { disagree (4) }\end{array}$ & $\begin{array}{c}\text { Strongly } \\
\text { disagree (5) }\end{array}$ \\
\hline $\begin{array}{c}\text { More } \\
\text { knowledgable } \\
\text { about my } \\
\text { body (1) }\end{array}$ & & & & & ) \\
\hline $\begin{array}{l}\text { less confident } \\
\text { about my } \\
\text { physical } \\
\text { ability (2) }\end{array}$ & & & & & \\
\hline $\begin{array}{l}\text { more aware } \\
\text { of my form } \\
\text { while I } \\
\text { perform } \\
\text { movements } \\
\text { (3) }\end{array}$ & 2 & $\cap$ & & & 0 \\
\hline $\begin{array}{c}\text { less } \\
\text { motivated to } \\
\text { improve my } \\
\text { fitness (4) }\end{array}$ & & $\cap$ & $\cap$ & & \\
\hline
\end{tabular}


Q27 How much do you agree/disagree with the following statements? I find the following measure on my wearable useful...

\begin{tabular}{|c|c|c|c|c|c|}
\hline & $\begin{array}{l}\text { Strongly } \\
\text { agree (1) }\end{array}$ & $\begin{array}{l}\text { Somewhat } \\
\text { agree (2) }\end{array}$ & $\begin{array}{c}\text { Neither agree } \\
\text { nor disagree } \\
\text { (3) }\end{array}$ & $\begin{array}{c}\text { Somewhat } \\
\text { disagree (9) }\end{array}$ & $\begin{array}{c}\text { Strongly } \\
\text { disagree (10) }\end{array}$ \\
\hline $\begin{array}{c}\text { Active } \\
\text { minutes (1) }\end{array}$ & & & & & \\
\hline Steps (2) & & & & & \\
\hline Stairs (3) & & & & & \\
\hline Sleep (4) & & & & & \\
\hline Heart rate (5) & O & & & ( & 0 \\
\hline $\begin{array}{c}\text { Energy } \\
\text { burned (6) }\end{array}$ & & & & & \\
\hline $\begin{array}{l}\text { Energy } \\
\text { consumed } \\
\text { (food) (7) }\end{array}$ & & & & & \\
\hline
\end{tabular}

Page 15 of 18 
Q28 How much do you agree/disagree with the following statements? I find the following measure on my wearable accurate...

\begin{tabular}{c|ccccc} 
& $\begin{array}{c}\text { Strongly } \\
\text { agree (1) }\end{array}$ & $\begin{array}{c}\text { Somewhat } \\
\text { agree (2) }\end{array}$ & $\begin{array}{c}\text { Neither agree } \\
\text { nor disagree } \\
\text { (3) }\end{array}$ & $\begin{array}{c}\text { Somewhat } \\
\text { disagree (4) }\end{array}$ & $\begin{array}{c}\text { Strongly } \\
\text { disagree (5) }\end{array}$ \\
$\begin{array}{c}\text { Active } \\
\text { minutes (1) }\end{array}$ & & & \\
Steps (2) & & & \\
Stairs (3) & & & \\
Sleep (4) & & & \\
Heart rate (5) & & & \\
Energy \\
burner (6)
\end{tabular}

Page 16 of 18 
Q29 How much do you agree/disagree with the following statements? Since using my wearable I now...

\begin{tabular}{l|ccccc} 
& $\begin{array}{c}\text { Strongly } \\
\text { agree (1) }\end{array}$ & $\begin{array}{c}\text { Somewhat } \\
\text { agree (2) }\end{array}$ & $\begin{array}{c}\text { Neither agree } \\
\text { nor disagree } \\
(3)\end{array}$ & $\begin{array}{c}\text { Somewhat } \\
\text { disagree (4) }\end{array}$ & $\begin{array}{c}\text { Strongly } \\
\text { disagree (5) }\end{array}$ \\
$\begin{array}{c}\text { Eat Healthier } \\
\text { (1) }\end{array}$ & & \\
$\begin{array}{l}\text { Incorporate } \\
\text { more activity } \\
\text { in my day (2) }\end{array}$ \\
sleep less (3)
\end{tabular}

\section{End of Block: Interpretation \#2}

\section{Start of Block: Summary}

Q30 What do you feel is missing from wearable fitness trackers? What would you like to see that would increase your likelihood of maintaining use?

Q31 Anything else to add about wearable fitness trackers?

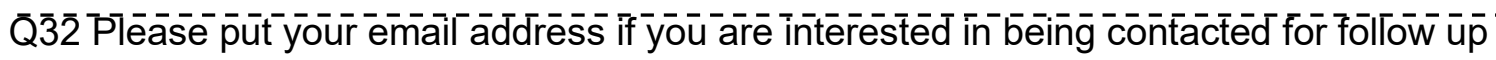
questions? 
Q33 Please put your email address to be entered into the draw

End of Block: Summary 
